
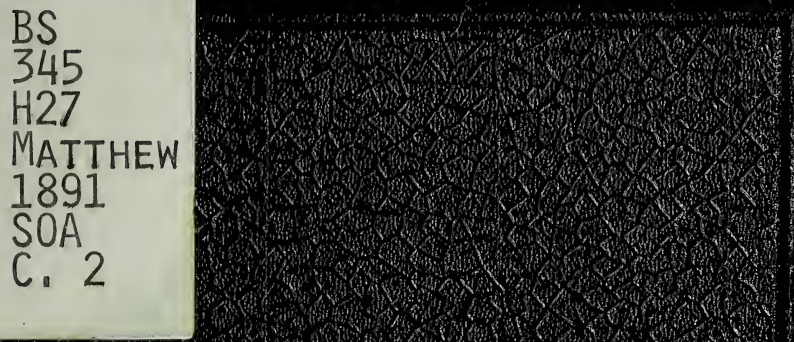

MATTHEW 1891 SOA C. 2

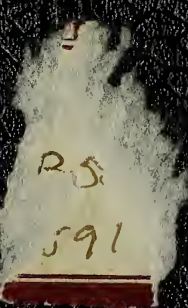
5.

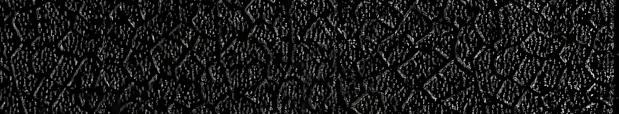
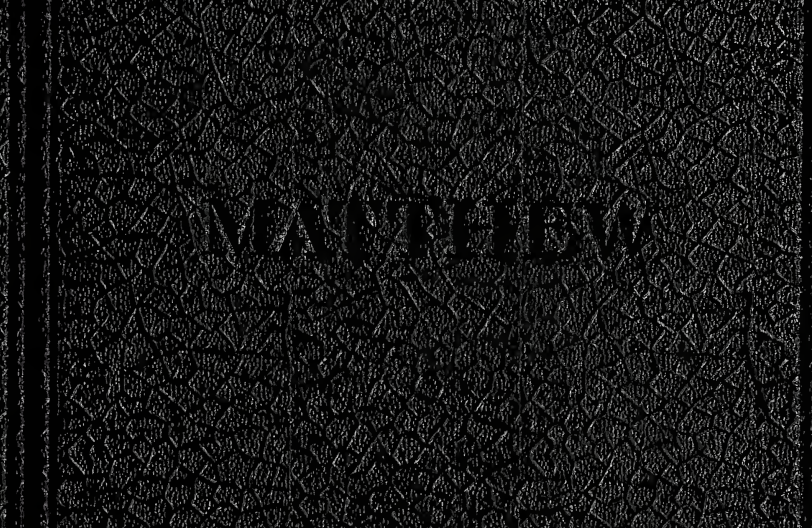

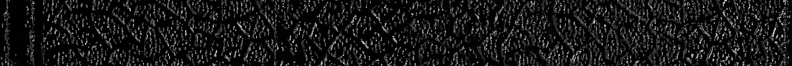

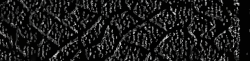

ob

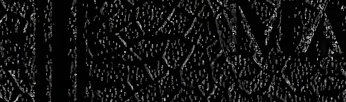

in. 

tang. 
345

\section{SAINT MATTHEW}

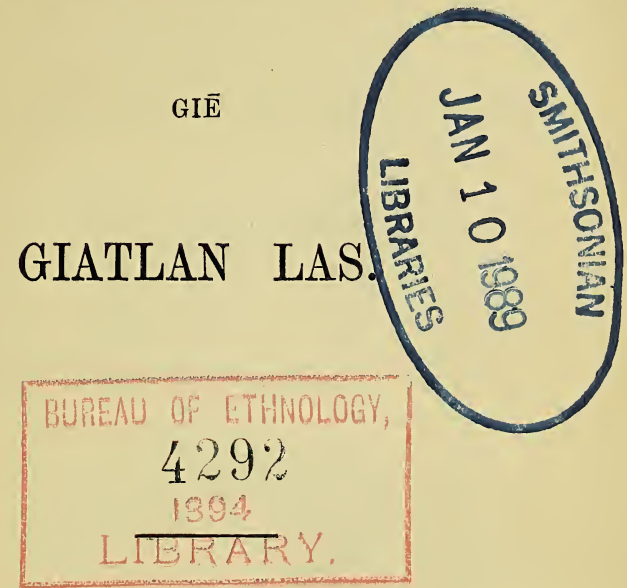

ST. MATTHEW, HAIDA.

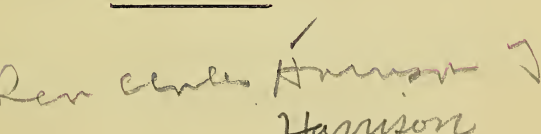

\section{LONDON :}

BRITISH AND FOREIGN BIBLE SOCIETY.

1891. 


\section{KEY TO THE SOUNDS OF THE LETTERS.}

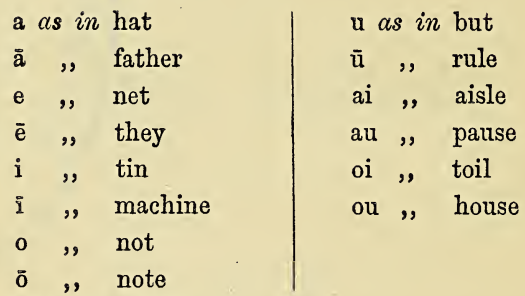

$\mathrm{g}$ begins a syllable

$\mathrm{k}$ ) correspond to the deep guttural $\chi$ in the Greek kh language

Ith is like the Welsh 11

$z$ when initial is equal to $\mathrm{ds}$

$\mathrm{z}$ when final is equal to ts.

THE GOSPEL ACCORDING TO ST. MATTHEW TRANSLATED INTO THE HAIDA

BY THE

REV. CHARLES HARRISON. 


\section{SAINT MATTHEW GI $\bar{E}$}

\section{GIATLAN LAS.}

Chaptergē Swaunshung.

TESUS CHRIST gwudistakānḡē koginēu iching: David kitu il idjan, waigen Abraham kit ishin.

2. Abraham Isaac kaiang; waigen Isaac Jacob kaiang; waigen Jacob Judah kaiang, waigen il tuanalung ishin;

3. Waigen Judah Tamar stāhā Perez kaiang, waigen Zerah ishin: waigen Perez Hezron kaiang, waigen Hezron Ram kaiang:

4. Waigen Ram Amminadab kaiang: waigen Amminadab Nahshon kaiang; waigen Nahshon Salmon kaiang;

5. Waigen Salmon Rahab stāhā Boaz kaiang: waigen Boaz Ruth stāhā Obed kaiang;

6. Waigen Obed Jesse kaiang; waigen Jesse King David kaiang; 
7. Waigen David Uriah chā stāhā Solomon kaiang ;

8. Waigen Solomon Rehoboam kaiang; waigen Rehoboam Abijah kaiang; waigen Abijah Asa kaiang; waigen Asa Jehoshaphat kaiang; waigen Jehoshaphat Joram kaiang;

9. Waigen Joram Uzziah kaiang; waigen Uzziah Jotham kaiang; waigen Jotham Ahaz kaiang; waigen Ahaz Hezekiah kaiang;

10. Waigen Hezekiah Manasseh kaiang: waigen Manasseh Amon kaiang; waigen Amon Josiah kaiang ;

11. Waigen Josiah Jechoniah kaiang, waigen il tuanalung ishin; waigen ashgē timegē gud Babylon tligē $\overline{\mathrm{a}}$ ltha ltha istaodzouāni.

12. Waigen Babylon tligē à ltha ltha istaiang silì, Jechoniah Shealtiel kaiang; waigen Shealtiel Zerubbabel kaiang;

13. Waigen Zerubbabel Abiud kaiang; waigen Abiud Eliakim kaiang; waigen Eliakim Azor kaiang;

14. Waigen Azor Sadoc kaiang; waigen Sadoc Achim kaiang; waigen Achim Eliud kaiang;

15. Waigen Eliud Eleazer kaiang; waigen Eleazer Matthan kaiang; waigen Matthan Jacob kaiang;

16. Waigen Jacob Joseph kaiang Mary tlāl $\bar{a}$, waigen lā stāhā Jesus tlakaiang, waigen Christ hinu il kēyang. 
17. Gwudistakānḡè wautliwan Abraham stāhā David $\bar{a}$ gwudistakāngēe klāalth wok stanshangang: waigen David stāhā Babylon tlige $\bar{a}$ ltha ltha istatālangtlo gwudistakāngē klāalth wok stanshangang; waigen Babylon tligē $\bar{a}$ ltha ltha istaiang stāhā Jesus Christ $\bar{a}$ gwudistakānḡe klāalth wok stanshangang.

18. Itan Jesus Christ tlakaiangtlo, Mary il ou Joseph ināsangang, waigen gwu il inēlthawē kwunast Hānts Las alth il telthkiāyēlan.

19. Waigen Joseph il tlāl kwutungè skwunaiang, waigen ltha hangku il tlaēdãgē kum il gwulaangang, il dāngkwolthtiē tlou il gwulāgang.

20. Waigen houān $\bar{a}$ kin isis addu il kwulthilgundang, kwoking, Shālānā giē Angelgē la an kātlang il kungaiāni, waigen hinū il shouan, Joseph, David kitu dung iching, altsīilth kum Mary chā unga an istiē ga lth lthwaugāng, Hānts Las alth il telthkiēlths althlā.

21. Waigen il kit kaiashang, waigen Jesus hin lā dung kēyādāshang, il touilung kin dāunga istas stāhā il kagindāsēsi althlā.

22. Tliku Shālānā nung Prophet ga shouan kingān adshi wautliwan èlthkigang, waigen hinū il shouan,

23. Kwoking, nung chitlthlingā nung hāhutsu telthkiashang waigen lā il kaiashang, waigen Immanuel hin lā ltha kēyādāshang; waigen Immanuel Shānungetlagidas itil alth stungs hinū èdung. 
24. Itan Joseph il kattaiang stāhā il kātlouang, waigen tliku Shālānā giē Angelgē lā ga shouan kingānu il waugang, waigen chā unga kinung an il istaiang.

25. Kum lā alth il tīdaangang il kit kaiasēs kwunast; waigen Jesus hin lā il kēyādaiang.

\section{Chaptergē Stung.}

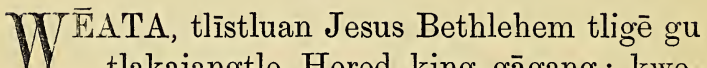
tlakaiangtlo, Herod king gāgang: kwoking lth hāada kutungā hougust stāhā Jerusalem tligē gu istlāgang, waigen hin il shūouang,

2. Kitlano lā tlakaigun Jew hāadē an nung king gas $\bar{a}$ ? kaiēlthta hougust langa talung kinguni althlā, waigen singelthkang lā à gūshūē annu talung istlāgun.

3. Waigen tlīstluan Herod nung king gas kwudangantlo, il kwutungē tlakwīdistlaiang, waigen Jerusalem hāadē wautliwan lā dungalthan.

4. Ga laplēt ìtlagidas gē wautliwan isken, lth hāada an takālunglēilung wautliwan ishin gwuda il istaiang, waigen tlitzan Christ tlakaiasēs ta ltha alth il kiānangang.

5. Waigen hin lā ltha shūtaiang, Bethlehem tligē $\bar{a}$ Judea tlige gu lā tlakaigun, altsīilth nung Prophetgas hin kālangāni :

6. Waigen dahou Bethlehem, Judah tligē 


\section{ST. MATTHEW 2.}

gu dung īching: waigen Judah Princesgē hangast kum dung edānḡung: dung stāhā nung îtlagida kātlāsēsi althlā, waigen kiagin Israel hāadē an il îtlagidāshang.

7. Itan Ith hāada kutungas an Herod aiyinkwolthtaiang, waigen askaskit kīslūstlo kaiēlthta skatsalē lā alth il kiānung yūanouang.

8. Waigen Bethlehem tligē $\bar{a}$ lā il kil istiēdouang, waigen hinū il shouan, gundiēdwala, waigen nung hāhutsūs da lth yenkien kindalwang, waigen tlīstluan lā dalung kiastlo, houshen dì ga lth shūdwang, waigen tlaou ishin $\bar{a}$ kaiitshang lā $\overline{\mathrm{a}}$ singelthkang lth gūshūēanā.

9. Tlistluan nung king gas shūs il kwudungwastlo il gundiēdouang, waigen kwoking, kaiēlthta hougust il kingouang lā kwunast il skatsūdalouang, waigen giouk nung hāhutsu isis gē shā il skatsalthgīgang.

10. Waigen tlisstluan kaiēlthta il kingouangtlo yenkien kwutungē lāyūan alth il tlikagūlouang.

11. Nē ik il istsaouang, nung hāhutsūs ou unga kwulth il kingouang Mary $\bar{a}$; waigen kwulung katsingalth il tlououang, waigen la $\bar{a}$ singelthkang il gūshūouang: itan kin kwoyā unga il kikustloouang, waigen saouhadan lā ga il istaouang, gold isken, skwunalou ishin, waigen kinlthkai skwunalou ishin.

12. Il kungouangtlo, Shānungetlagidas hin il shūdaouang, kum houshen Herod gwi lth 
stīlthāngwang; altsīilth kūwē kalat gud tliga unga gwi silthkang il stillthouang.

13. Tlìstluan il istiēdouangtlo, kwoking, Shālānā giē Angelgē Joseph an kātlang il kungaiang, waigen hinū il shouan, kātlūltha, waigen nung hāhutsūs lth ista, il ou han ishin, waigen houitang Egypt tligē à kaiit: gū lth ising dung ga lth shougè kū, Herod nung hāhutsūs takāngungkasēs althlā lā il tīiyēanā.

14. Il kātlouang ken nung hāhutsūs il istaiang, il ou han ishin, waigen halgwau Egypt tligè $\bar{a}$ il istiēdouang: Herod kwotalē ku gu il idjāni.

15. Wēata, tliku Shālānā nung Prophetgas ga shouan kingānu edāni, waigen hinū il shouan, Egypt tligē stāhā kit unga an lth aiyingun.

16. Itan, Herod lth hāada kutungas il kinkonangang ai il katlthkiastlo, yenkien il kātliyilthdaiang, waigen itlansida hudila wautliwan Bethlehem tligē gu is il tlitataiang, waigen ilnigē wautliwan gīougust ishin: tada stung da hēlōsi isken wauhangast glāgāsi ishin giadlu lth hāada kutungā alth il kiānung yūanan: gè nūd ltha ga kaiawaiang gè $\bar{a}$.

17. Tliku Jeremiah nung Prophetgas shouan itan kingānu edāni, waigen hinū il shouan :

18. Kilu Ramah tligè gu kwudungāgung: kagininayūan isken, sahaige ishin: ltha kwutungē lthtunagwutyūan ishin; Rachel kitilung hagunan sahaigyūangung, waigen kum tliku il 
kwutungē wausaaskit tlingē kāng gaanḡung, kum hāagē langa kāng gaansi althlā.

19. Herod kwotalang tlo, kwoking, Egypt tligē gu à Shālānā giē Angelgē Joseph an kātlang kungaiang, waigen hinū il shouan:

20. Kātlūltha, nung hāhutsūs lth ista, il ou han ishin, waigen Israel tligē $\bar{a}$ lth istiēdo, nung hāhutsus tīiēd nung kwudunḡun kwotalths althlā.

21. Waigen il kātlouang, waigen nung hāhutsūs il istaiang ken il ou han ishin, waigen Israel tligē gu il istlāouang.

22. Herod kwotalang silīd Archelaus Judea tligē gu aung unga siliā il nayēlang il kwudangan tlo, altsīilth $\bar{a}$ kägē ga il lthwaugaiang: altsiilthu tliku Shānungetlagidas lā ga shūung il kungaiang kingānu il idjan.

23. Waigen Galilee tligē gwi il stēlang, waigen ilnigē gu il kātlāsken gu il nayēlāni: waigen ilnige Nazareth hin kēyägun.

24. Tliku ga Prophetgas gè shouan kingānu edāni, waigen hin ltha shouan Nazarene hin il kēyāsang.

Chaptergē Lth'unilth.

WAIGEN ashgē shantlanē gud John the Baptist kātlāgang, waigen Judea tligē dāungas gu tlāgūk il gūshouang. 
2. Waigen hinū il shouan, Kwutungē unga lth stilthto, shāgē kingdomgē āanān isis althlā.

3. Altsiilth anisu Isaiah nung Prophetgas shūtaiang, waigen hin $\bar{u}$ il shouan, Nung kil swaunshung tligē dāunga gu hin sahailthlang, Shālānā giē kūwē tlaēlthkīu, waigen kūwē tumzūsi langa tlayāgulthu.

4. Wēata, John kin giandas camels hou idjan, waigen skidal tlidskou alth il tlïdzguwaugang, waigen tou langa locusts idjan, waigen attlthwun tou ishin.

5. Itan Jerusalem hāadē isken, Judea hāadē ishin, lth hāada wautliwan Jordan addu ilnigē wautliwan isis stāhā lā $\bar{a}$ iswāgang.

6. Waigen Jordan hānlthē shengs $\bar{a}$ hānlthē ltha gwi il istaiang ltha dāungas hansta unga ltha shügangang.

7. Tlisstluan Pharisee hāadē kwan isken, Sadducee hāadē kwan ishin hānlthē an langa istlātalsi il kāngang tlo, hin ltha il shūtaiang, O gwudistakāngè sik dalung isis, kātliyildtals stāhā dalung gundiēdē à kistho dalung shūtaiang ?

8. Hāna lāguns kingān kin lā lth istou dalung kwutungē tlastelgēanā.

9. Abraham ìtil aungu ìching kum hin agung lth shūdāngu: yenkien dalung ga lth shūgung, Shānungetlagidas ashgē kwauē stāhā kitilung Abraham an tlakātluē an tagwiāgung. 10. Waigen wēata kinlthkai skūshangwē 
gu kūtiljou īching, altsīilth kinlthkai wautliwan ai kum hāna lā inastlānstlo ltha skikundalgungung, waigen zanoa si ltha istagungung.

11. Hānlthē alth dalung lth baptizdang alth kwutungē unga dalung stīlthtiēanā : waigen dī tlā nung kātläs tlou dī telgu tagwiāshang: staskoga langa haiidē annu kum dī lānḡung. Hānts Las alth dalung il baptizdāshang, waigen zanoa alth ishin.

12. Il stlai ou yhitouwē langa īching, waigen wheatnē stlin kouwē unga yenkien il tlaskwunāshang: wheatnē ai gwuda wheat unga il istāshang, knul tlou zanoa hēninga swaunung alth il ougulthtāsang.

13. Itan Jesus Galilee tligē stāhā Jordan tligẽ gu kātlāgang John an ā, hānlthē lā ga il istiēanā.

14. John langa kwudāungaiang, waigen hinū il shouan, dung stāhā hānlthē istiē da dī kwudunḡung, waigen dī an dung gu kātlā us ?

15. Waigen Jesus hangtlan il shūtaiang, agwan lth waikingān wēata eda, kin lā wautliwan talung tlaoutliē îtil an lāsi althlā. Waigen itan kingān lā il istaiang.

16. Waigen Jesus, tlisstluan hänlthē il istaiang tlo, houitang hānlthē stāhā sīk il kātlaiang: waigen kwoking, shā tligē lā an helthtlālang, waigen Shānungetlagidas Hānts kaltsida yhītlatalguns kingān eds lā inku kouwang.

17. Waigen kwoking, kil swaunshung shā 
tligē stāhā hin shouan, anis dī kit kwoyāyūans ĩching, lā an dì kwutungē lāgung.

\section{Chaptergē Stanshung.}

TTAN Hānts Jesus tligē dāungas ai halkā1 gang hetgwaulana il eddē kil kingēdēanā.

2. Tlīstluan sin klālē stanshung isken hal klālē stanshung ishin il kīsalang tlo, silìd il kwōtagālang.

3. Waigen ltha eddē nung kil kingungs hin il shūtaiang, Shānungetlagidas Kit dung istōalth adshi kwauē shibili gaiēlthā hin lth shūda.

4. Waigen hin hangtlan il shouan, ou kālungāgun, kum nung ìtlinga shibili alth swaunan hēningāngsang: kil wautliwan Shānungetlagidas helthli stāhā isis alth swaunan il hēningāsang.

5. Itan hetgwaulana lana lā $\bar{a}$ il istaiang, waigen churchnē lāyūans tlimits inku agwi lā il koudaiang.

6. Waigen hin lā il shūtaiang, Shānungetlagidas Kit dung istōalth, lth agung kātalth: kālungāgāni althlā, angelgas gē tuman dung unga il kingalthasang, waigen stlē unga alth shā an dung ltha hätlthidzuasang, waigen kum tliku timegē ed gud dung stai kwau i hatawāngsang.

7. Jesus hin il shūtaiang ishin ou kālungā- 
gun, Shālānā İtlagida unga kum eddē lth kil kingāng.

8. Houshen, hetgwaulana lthdou jinga yūan gwi lā il istaiang, waigen hētk tligēe gu kingdomgē wautliwan isis lā il kingdaiang, waigen kin anyākwudungā gu isis ishin.

9. Waigen hetgwaulana hin il shūtaiang, dung tikwushtloasken, waigen dī $\bar{a}$ singelthkang dung gūshūsken, $\bar{a}$ kin is wautliwan dung ga lth istāshang.

10. Itan Jesus hin il shūtaiang, hinda Satan : ou kālungāsi althlā, Shālānā dung Ītlagīdou iching, là à singelthkang lth gūshu, waigen tlan lā an swaunan lth ‘ttāangwilu.

11. Itan hetgwaulana lā stāhā kaiitang, waigen kwoking, ga angelgas gē istlāgang, waigen il kwutungè wau ltha saaskidang.

12. John kētsit nai $\bar{a}$ isis tlīstluan il kwudangantlo, Galilee tligē gwi silthkang il stēlang.

13. Nazareth tligē stāhā il kaiitang, waigen Capernaum tligē gu il nayēlāni, tungē gustga ouãdaiani. Zebulon tlīgē isken, Naphtali tligē ishin aiyūwē giougu Capernaum tligē īching,

14. Tliku Isaiah nung Prophetgas shouan kingān edāni, waigen hinū il shouan.

15. Zebulon tligē isken, Naphtali tligē ishin, tungē an dūungāgung, Jordan hānlthē shengs waugust iching, waigen Galilee tlīgē gu $\bar{a}$ lth hāada isis idjāni.

16. Lth hāada halga $\bar{a}$ tluadaiang hatga yūan 
kāngang, waigen kwotal tligē $\bar{a}$ ga tluadaiang ishin, waigen kwotal hānts à ga idjan ishin da hatgā èlang.

17. Ashgē timegē stāhā Jesus tlāgūkgūshouìdāni, waigen hinū il shouan, kwutungē unga lth stīlthto shāgē kingdomgē āanān isis althlā.

18. Waigen Jesus Galilee tligē skwaus jinit kāgangtlo, kwaialung stung il kāngang: Simon Peter hin kēyāgang, waigen Andrew il tuan ishin ; chān ga âatē unga il istaouang, āatālēilung il isouāni althlā.

19. Hin lā il shūtaouang, dī tlā lth istalo, waigen àat stāhā skātlink dalung istaguns kingan kin dāunga stāhā lth hāada dalung kagindāshang. Yenkien lth hāada dāunga washt kil kagunē an dalung lth tlaoutlāshang.

20. Waigen houitang āate unga stāhā lā tlā il istalouang, waigen aung unga il inaouang.

21. Stāhā il kaiitang ken kwaialung adda stung il kāngang, James Zebedee kit idjan, waigen John il tuan jshin: aungē unga alth kontluwē gwau il isouang, waigen āatē unga il tlinglāouang tlo lā an il aiyingouang.

22. Houitang kontluwē il takistlaouang, waigen aungē unga ishin il tatlistlaouang, waigen lä tlā il istalouang.

23. Jesus Galilee tligē askwan ai il kaouangang, waigen Churchnē hudila ai lthanga isis $\bar{a}$ kin ltha il skadadagangang. Kingdomgē giatlingē las alth tlägūk il güshūgangang, waigen 
ltha helthilthkias isken sti gwudila ed wautliwan ishin il tlanūngistlagangang.

24. Waigen giatlingē Syria tligē askwan gu langa kokgustlowaiang, waigen lth hãada sti wautliwan lā $\bar{a}$ ltha istaiang: gwudila helthilthka ed wautliwan ishin, ltha houāgun ishin, hetgwaulana alth ltha staouas ishin, ltha konungala ishin, ltha stigliiida ishin lāa ltha kelthilungangang, waigen ltha wautliwan il tlanūngistlaḡangang.

25. Galilee tligēe stāhā isken, Decapolis tligē stāhā ishin, Jerusalem tligē stāhā ishin, Judea tligē stāhā ishin, waigen Jordan hānlth sheng waugust stāhā ishin lth hāada skūla yūan lā tlā istiēdang.

\section{Chaptergē Klēlth.}

THA skūla yūan il kāngang tlo, lthdou gwi U sīk il kātlaiang, waigen tlīstluan il kouwaiang tlo lagaga hatijangē lā an istlāgang.

2. Waigen helthli unga il kisistlaiang, waigen hin ltha il skadadaiang.

3. Ltha hānts kuniskidēgasu lāgung, shāgẽ kingdomgè lthāgiou isis althlā.

4. Ltha kagininasu lāgung, ltha kwutungē wausaakitangsēsi althlā.

5. Hētk ltha kwutungè edsu lägung, adshi tligē ltha istasēsi althlā. 
6. Kin lā ta ltha kwōtsken isken ta ltha kattuwaiu ishin lāgung, ltha skisūsēsi althlā.

7. Kin kalthshint ltha kwutungsu lāgung, Shānungetlagidas ltha kalthshint kwutungsi althlā.

8. Ltha kwutungē skwunasu lāgung, Shānungetlagidas ltha kingasēsi althlā.

9. Tlouwa gidsgutlēilung isken kintlinlanlēilung ishin lāgung, Shānungetlagidas kitilung hin ltha kēyāsēsi althlā.

10. Kin lā hagunan ltha chākwudungsu lāgung, shāgē kingdomgē lthāgiou isis althlā.

11. Tlisstluan lth hãada dalung alth kilthnangstlo: tlīstluan kin singētzas dalung ltha hāndungdastlo: waigen kin dāunga gwudila ed wautliwan alth di hagunan dalung alth ltha kilthkadungstlo dalungū lāgung.

12. Kwutungē unga lth lādōga, waigen kwunan tlika lth gūlouga, dalung giē giasougē shā yūansi althlā: dalung kwunasta ga prophetgas gē kin singētzas ltha hāndungda gangāni althlā.

13. Tung yillā hētk tligè gu dalung īching, waigen tung yillā houkiyè wast hēlōstlo, gūshu althlu tungēlthasang: ashgē timegē glu kum kinhan an lānḡung: kiak ltha dānggēan tlou lāgung, lth hāada stē unga alth inku tadteldungēan.

14. Hatgā hētk tligē gu dalung īching : lana kītsuwau inku atlindasu kum tliku saalga tlingē kāng gaanḡung. 
15. Lth hāada kāsotouho hokulthtastlo kum kwīdou skakōna hetgwi ltha istaḡunganḡung. Kāsotouho kuasi inku ltha istaḡunḡung, waigen ltha wautliwan nāgud isis da hatgāgunḡung.

16. Waikingān agwan lth dalung hatgas lth hāada wautliwan hangku hatgādou lthāangwila lā dalung istas ltha kāngēean, waigen dalung Aung shā tligē gu isis an ltha yākwudungasang.

17. Ga prophetgas gē kil isken, lawgē ishin lth tlahustiean lth kātlātalthing lth kum kwudungāngo: ga prophetgas gē kil isken, lawgēe ishin lth tlahustiēan kum lth kātlāanḡun, kingān lth waugēanu lth kātlātalgun.

18. Altsīilth yenkien dalung ga lth shūgung, shā tligē isken hētk tligē ishin hēlōwē kū, kum tliku kin lth'althskodis ska swaunshung isken, kin lth'alth hutis hu swaunshung ishin lawgē stāhā is tlingē kāng gaanḡung kin wautliwan kingān edgē kū.

19. Altsiilth kīstho adshi kingwogungē swaun wauhangastihutsüsi tlahustang, waigen waikingān lth hāada il skadadastlo, shāgē kingdomgē gu wauhangastihutsūs hin il kēyāshang: waigen kīstho kingwoguns kingān waugung, waigen ltha il skadadastlo, nung yūansi hinū il kêyāshang:

20. Altsiilth dalung ga lth shūgung, takālunglēilung isken, Pharisee hāadē ishin kwutungē skwunas telgu kum dalung kwutungē 
skwunānsken, kum tliku shā tligē kingdomgē gu dalung istzā tlingē kāng gaanḡung.

21. Tlaglu agwi tliku ltha shouan dalung kwudangang. Hin ltha shouan: kum nung hāada lth tiāng; waigen kīstho nung ìtlinga tiastlo ginkilislang ga agung il lthanstlāsang.

22. Tlaou hin dalung shūdang, kīstho kwai unga an kātliyildungstlo, ginkilislang ga agung il lthanstlāsang; waigen kīstho Rācā kwai unga hin shütasken, council ga agung il lthanstlāsang: waigen kīstho dung kōnungung hin shūsken hetgwaugē zanoa ai agung il lthanstlāsang.

23. Shālānā giē tableg'è $\bar{a}$ saouhadan kin unga dung giālastlo, waigen gaigu dung kwai dung an kätliyildungas ai dung kēitstlo,

24. Shālānā giē tablegē hangku saouhadan kin unga dung istas lth ina, kūwē gud lth unga kaiit, kwai unga an kwutungē lāgelthtlāgang, waigen itan althkwi lth kā, waigen lth saouhadan kin unga dung istas ista.

25. Houãn kūwē gud nung alth gwutelga dung kings alth dung kägundang, houitang lā alth kwutunge unga swaunshung ëlthta: kum waikingan edānstlo nung telga dung kings ginkilislanglē ga dung istāshang, waigen nung ta ginkilislungs kētsitlē ga dung istāshang, waigen këtsitnai ā dung ltha istāshang.

26. Yenkien dung lth shüdang, cent ōstliē alth dung giasougē kū, kum tliku stāhā kiak dung is tlingē käng gaanḡung. 
27. Tlaglu agwi tliku ltha shouan dalung kwudangang, waigen hin ltha shouan, kum lth laaigungāngu, waigen kum lth chaaigungāngu.

28. Tlaou hin dalung shūdang, kisstho nung chada kinḡung, lā alth tīdiē da il kwudungsken, ltha alth ltha tīdaguns kingānu il kwutungē à èlthkigung.

29. Waigen soolgust dung hangi dung tlidiItadasken, lthāalgwi washt lth ista, waigen stagan lth dāng: dung āni swaun gougē wautelgu dung an lāgung, waigen kum dung tlu tliskwan hetgwaugẽ ai isāngshang.

30. Soolgust dung stlē dung tlidiltadasken, washt lth kētsitla, waigen stagan lth dāng; dung āni swaun gougè dung an lāsi althlā, waigen kum dung tlu tliskwan hetgwaugē ai isāngshang.

31. Houshen, tliku tha shouan dalung kwudangang, waigen hin ltha shouan, kisstho chã unga dānḡung, gwud stāhā ltha itzgè kālungē là ga il istaēu lāgung.

32. Tlaou dalung shūdang, kīstho chã unga dānḡung, kum il lagāanskenan, lagā an lā il tlaoutlang: waigen kīstho nung ltha dāngs inēlgung lā ishin hingānu lā alth tīgādāshang.

33. Tlagu agwi tliku ltha shouan dalung kwudangang, waigen hin ltha shouan : kum agung Ith kilth kadungadānḡa, waigen tliku Shālānā ga dung shūs kingān lth wauga:

34. Waigen tlaou dalung shūdang, kum kli- 
ngān sūtsu giālanu-wāngu : kum shāgē lanuwāngu, Shānungetlagidas giē aulthkaaungwē isis althlā.

35. Kum hētk tligē lanuwāngu, il stai kuasi langa isis althlā: kum Jerusalem tligē lanuwāngu, nung King ga yūans ilnigē isis althlā.

36. Kum kats unga lanuwāngu, kum tliku katsa saas swaunshung addā isken lth'alth ishin dung tlaoutla tlingē kāng gaansi althlā.

37. Hin lth shūu Āng, Āng: Kāhano, Kāhano : ashgē gūshouwē telgu kin edis kin dāunga an nung ìtlagidas stāhā îching.

38. Tliku ltha shouan dalung kwudangang, waigen hin ltha shouan: nung hangi $\bar{a}$ nung hangi kāgunḡung, waigen zing ki swaunshung $\bar{a}$ nung zing kāgunḡung.

39. Tlaou dalung shüdang, kum th nung dāungas hangtlan istaangu: waigen kīstho soolgust dung kānsita skodastlo hinawē ishin lth lā gwi èlthta.

40. Nung ìtlinga lawgē dung an istastlo, waigen kodets dānga il istasken, agwan lth kodets chakūnas ishin dānga il dādi.

41. Kisstho tliga kwīdiē swaunshung gud dung kil kaiitstlo kwīdiē stung gud lā alth kā.

42. Kin da dung alth nung kiānungs lā ga Ith ista, waigen kistho dung alth kin lthakākitung kum lā stāhā hangouāng.

43. Tlaglu agwi tliku ltha shouan dalung 
kwudangang, waigen hin ltha shouan, dung kwulth nung naas lth kwoyāda: waigen dung telga nung kings telga lth king.

44. Tlaou dalung shüdang, dalung telga ltha kings lth kwoyādou, waigen kin singètza dalung ltha hāndungdas singelthgūshū :

45. Dalung Aung shā isis kitilung dalung iselgēanā: lth hāada dāunga inku isken, lth hāada lā inku ishin, kkhuyigēan juiē unga il kākidaltlātlidagunḡung, waigen ltha lā isken, ltha dāunga ishin gwi guīēenu delē unga il gwououdagunḡung.

46. Dalung ltha kwoyādas swaunan dalung kwoyādasken, kasin giasou eddu dalung dāashang? Kum gu giasougununglēilung kingān edāng us ?

47. Touilung hangā swaunan dalung kwaukalthtastlo, kasin lth hāada kalat telgu dalung istang? Kum gu gwaigangē kalat kingān edāng us? Kum gu gwaigangē kalat touilung hangā kwaukalthtagungān us ?

48. Dalung Aung shā isis kwutungē glaias kingān lth kwutungē unga glaiado.

Chaptergē Lthūunilth.

TUMAN lth agung kingo, waigen kum lth 1 hāada hangku saouhadan kin unga istaangu ltha kānḡeanā : kum waikingān edān- 
stlo, dalung Auug shā isis stāhā kum giasougēe dalung daāngshang.

2. Altsīilth tlistluan saouhadan kin unga dung istastlo, tliku ltha kwutungēstungs churchnē hudila $\bar{a}$ isken, kūkitias $\bar{a}$ ishin ëdungs kingān lth kum kwunast agung kin hēgundang lth hāada ltha an yākwudungēanā. Yenkien dalung lth shūdang, giasougē unga ltha istang.

3. Waigen tlistluan saouhadan kin unga dung istastlo, kum stlangust stlē unga anūnshitānda, tliku soolgust stlē unga alth kin dung istasa.

4. Saouhadan kin dānga isis kwulgung gāgēanā : waigen dung Aung wai kingkwolthtasi giasougē washt dung an astlāshang.

5. Waigen tlisstluan singelthkang dalung gūshūstlo, kum ltha kwutungēstungs kingān kwutungē unga edāngōga: churchnē hudila à isken, kū gudi kiatawas kātli $\bar{a}$ ishin singelthkang gūshū tlazūgiangē ltha kwoyādang lth hāada ltha kāngēanā. Yenkien dalung lth shūdang, giasougē unga ltha istang.

6. Waigen tlīstluan singelthkang dung gūshūstlo, nē hutsu ai lth unga katsi, waigen kūwē wau unga dung daaskitsista, dung Aung agung saalgādas $\bar{a}$ lth singelthkang gūshu, waigen dung Aung wai kingkwolthtasi giasougē washt dung an astlāshang.

7. Tlistluan singelthkang dalung gūshūstlo, kum lth hetgwaulana touilung kingān gūshū 
kwan lth giandāngōḡa: ltha gūshū kwans althlu ltha kil lthanga il kwudungasang ltha kwudungsi althlā.

8. Altsiilth kum ltha kingān edāngu : dalung Aung kin ga dalung isstatlas anūnshits althlā Iā alth dalung kiānungsēs kwunastā.

9. Altsiilth adshi kingān singelthkang lth gūshū: Ittil Aung shā dung isis: agwan lth kēyi unga kwoyãda: agwan lth kingdom althgwi unga ista.

10. Hētk tligē an dung kwuduns kingān lth shāgē kingān edē :

11. Shantlan wautliwan singwud tou itil ga lth ista :

12. Itil dāungas kalthshint lth kwutung: itil an ga dāungas gē kalthshint talung kwutunḡuns kingān.

13. Kum ga dāungas gē shū îtil istaldāng, waigen nung dāungas stāhā ìtil kaginda.

14. Lth hāada kin dāunga istas kalthshint dalung kwutungsken, dalung Aung shā isis dalung kalthshint ishin kwutungsang.

15. Waigen lth hāada kin dāunga istas kum kalthshint dalung kwutungānsken, dalung Aung shā isis kum dalung kalthshint ishin kwutungāngsang.

16. Altsiiilth tlīstluan dalung kīsalstlo, kum kwutungēstunglēilung hangsahaiḡāḡuns kingān edāngu : hangi unga ltha kālunḡuns althlā, ltha kīsals lth hāada kānḡēan. Yenkien 
dalung ga lth shūgung, giasougē unga ltha dāēlgun.

17. Waigen tlīstluan dung kīsalstlo kats unga lth touda, waigen hangi unga lth tlin;

18. Waigen dung kissals lth hāada kum kingāngēana. Dung Aung agung saalgādas dung kāngèeanā. Dung il kingasang, waigen giasougē washt dung an il daastlāshang.

19. Kum hētk tligē gwau kin kwoyās kinung an gwudingwi lth istatlāngo, giouk stlakum isken, whaudūnā ishin kin tasgwau, waigen giouk kwolthtalëilung kin skokwutuljasken ltha kwolthtagunsgwau.

20. Shā tligē gwau kin kwoyās kinung an gwudingwi lth istatlou giouk kum stlakum isken, whaudūnā ishin kin tānsgwau, waigen giouk kwolthtalëilung kum kin skokwutuljānsken kum kwolthtagunānsgwau.

21. Tlïtzan kin kwoyās dānga isisken dung kwutungē ishin gu isisang.

22. Ltha tlu annu lth hangi kāsotouāgung: dung hangi lāsken, dung tlu tliskwan hatgā alth stāougāshang.

23. Waigen dung hangi dāungasken, dung tlu tliskwan halga alth stāougāshang. Altsiilth dung hatgā isis halgastlo, kīslu halgagē yūanasin.

24. Kum tliku nung itlinga ètlagida stung an lthāangwiliē klingè kāng gaanḡung: nung 
swaun telga il kingsken, nung kalat il kwoyādāsang: nung swaun alth il stungsken, nung kalat ga il gwouāsang. Kum tliku Shānungetlagidas an dalung lthāangwiliē klingē kāng gaanḡung, waigen dālā an ishin.

25. Altsīilth hin dalung lth shūdang, kum hēninga unga addu kwulthilthāngu : kin talung tāasēs isken, kin talung nīlthasēs ishin: tlu unga kin giandasēs ishin. Kum gu tou telgu hēninga edāng us? waigen kum gu kin giandatlingē telgu tlu edāngus?

26. Kwoking, sièt ettit ichings kum kin tlidzaḡungānḡung: kum kin tlī̄ungānḡung, waigen tou nē ai kum kin tatlingē gwuda $\bar{u}$ istaḡungānḡung, waigen dalung Aung shā isisu ltha tanudagungung. Kum gu ltha telgu dalung lāang us?

27. Dalung swaun kwulthilthyūansken, stē kīsku hinawē gu il zuwē tlajingēlth us ?

28. Kashintlou kin giandatlingē addu dalung kwulthilthgungung: kwulthkadis kātli $\bar{a}$ stlakistā tliku inastlatlidzūs addu lth kwulthiltho: kum lthāangwilgungānḡung, waigen kum hādang kin tliskādsulanḡungānḡung:

29. Waigen hin dalung ga lth shūgung, Solomon anyākwudungāgang tlo, kum ashgē swaun kingān kin il giandatlidzuānḡangang.

30. Altsiilth Shānungetlagidas kwulthkadis kātli kun isis kin giandadastlo, aiata kougung, waigen adātlth zanowe $\bar{a}$ iching. Kum gu 
wautelgu kin dalung il giandadāngashā us? O klingān dalung yetasgē :

31. Kum hin lth shūāngu, gūshu talung tāasin, gūshu talung nīlthasin: gūshu talung giandāsin, kum lth hin shūāngu, waigen kum addu lth kwulthilthāngu.

32. A kin isis wautliwan da gwaigangē wautliwan kingsi althlā. $\overline{\mathbf{A}}$ kin isis wautliwan ga dalung istatlas annu daluing Aung shā isis anūnshïtung.

33. Kingdom ga lth langa king tlāgangu, waigen kin lā langa isis wautliwan ishin, waigen $\bar{a}$ kin isis wautliwan dalung an kwaiundiāshang.

34. Kum adātlth-tligē addu kwulthilthāngu: adātlth-tligē kwodanan adang kwulthilthasang. Sin saasgu kin dāunga alth unga skistliāgungung.

\section{Chaptergē Chigwau.}

$\mathrm{K}^{\mathrm{UM} \text { lth ta ginkilislungāngu, waigen dalung }}$

2. Altsiilth tliku ginkilislung ed alth dalung ta ginkilislungstlo dalung ishin alth ltha ginkilislungshang: waigen tliku kwīdou ed alth dalung kwīdastlo, dalung ishin alth ltha kwidāshang.

3. Waigen kashintlou dung kwai hangi $\bar{a}$ kinḡiiskuns dung kinḡung, waigen dung hangi $\bar{a}$ kin yūan isis alth kum dung kwuskitāngung? 
4. Dung hangi stāhā lthāalgwi kin dĩ istada hin gu kwai unga dung shūta us ? waigen kwoking kin yūan dung hangi $\bar{a}$ īching.

5. Dung kwutungē stunḡung, hangi unga stāhā lthāalgwi lth kin yūan ista tlāgang, waigen itan kwai unga hangi stāhā lthāalgwi kin dung istiēan yenkien dung an kāngūlāsang.

6. Kin lā isis kum hā ga istaangu, isi ishin kum pearlsgē kwosho kwunast unga katdāngu : stē unga alth wē $\overline{1}$ tananungasēsi althlā, waigen dalung gwi hangousken dalung $\bar{i}$ ishin hananungasang.

7. Kin da lth kiānungu, waigen dalung daēlthasang: kin da lth kingu, waigen dalung kiāshang: skostaḡouultha, waigen wast dalung an astlāshang:

8. Ltha wautliwan han kin da kiānungsi $\bar{u}$ istagungung: kin da nung kingsu wū kiāgungung, waigen nung skostagasi an wast astlāshang.

9. Kasin nung itlinga ed dalung shu isis il kit shibili da lā alth kiānungsken, kwau gu lā ga il ista us ?

10. Waigen skātlink da lā alth il kiānungsken, sik gu lā ga il ista us?

11. Dalung dāungaskenan, tliku saouhadan kin las ginggangan kitilung ga istiē an dalung ūnshitstlo: kisitlu wautelgu dalung Aung shā isis lā alth ltha kiānungs ga kin lā istāshang?

12. Altsiilth kin wautliwan lth hāada dalung 
an istiē da dalung kwudungstlo, waikingān dalung ishin ltha an lth isto: ou lawgē iching, waigen ga prophetgas gē kālungē ishin.

13. Kwulthkadis kūwē àlthli tumzu ai lth istalo: hetgwaulana giē kwulthkadazi kūwē ālthlasi althlā: hetgwaulana giē kūwē ishịn àlthlāgung, waigen ga kwan ai istalgungung, gēu hetgwaugē $\bar{a}$ ltha halistalgung.

14. Kwulthkadazi kūwē tumzūsi althlā, kūwē ishin kityāang, waigen ltha gūgē kīigunḡung, gēu hēninga $\bar{a}$ ltha halistalgung.

15. Ga prophetgas gē kilthkadungasu lamato kinā giandas dalung an istlāstlo, stāhā lth ga gwudagungo, tha kātli ou hōots saatsa isis althlā.

16. Lthāgiē hānē althlu ltha an dalung ūnshitalthasang. Lth hāada gu wine hānē kin lthkai k̂î stāhā gwuda istagung us ? gu hōtdungal stāhā ishin figsgè gwuda ltha istagung us?

17. Altsiilth kin lthkai las wautliwan hāna lā inastlagunḡung, waikingān kin lthkai dāungas gud hān dāunga inastlagunḡung.

18. Kin lthkai las gud kum tliku hān dāunga inastla klingē kāng gaanḡung: waigen kin lthkai dāungas gud kum tliku hān lā inastla klingē kāng gaanḡung.

19. Kin lthkai wautliwan gud kum hān lā inastlānsken ltha skikundalgungung, waigen zano si ltha istagungung. 
20. Altsīilth lthāgiē hānē althlu ltha an dalung ünshitalthasang.

21. Kum ltha wautliwan Shālānā, Shālānā, hin dī shūtas shāgē kingdomgē gu istlāngshang : tliku dī Aung shā isis kwuduns kingān nung was swaunan shāgē kingdomgē gu katsāshang.

22. Shantlan ostlastlo, ltha kwan hin dĩ shūtāshang, Shālānā, Shālānā, kum gu dung kēyi alth tlāgūk talung gūshūāngudja? dung kēyi alth kum gu kin an kaldunga talung tlaoutlāngudja? waigen dung këyi alth kum gu ga hetgwaulanagas gē kiak talung dāngāngudja?

23. Waigen hin ltha lth shūtāshang, kum dalung an dì ūnshitānḡung, dì stāhā lth issu kin dāunga dalung istas althlā.

24. Altsiilth kīstho ashgē gūshouwē dī na kwudungsken, waigen kingān il wausken, nung ìtlinga kutungā tīsh inku nē tlaoutlaiang kingān lā lth edāsang.

25. Waigen dela gūouang, hānlth kāgang, tatjouwē attawaiang, waigen wadshi nē inku attaouang, waigen kum khōhunzāngani, tīsh inku nē idjāni althlā.

26. Ltha wautliwan ashgē gūshouwē dī na kwudungsken, waigen kum kingān nung wāngsken, nung kōnungala tās inku nē tlaoutlaiang kingān lā lth edāsang.

27. Waigen dela gūouang, hānlth kāgang, tatjouwē attawaiang, waigen wadshi nē inku 
attaouang, altsiilth nē knhōhunzaiang, yenkien $\bar{u}$ knhōhunza yūanāni.

28. Jesus ashgē gūshouwē tlanēlthtaianglu, ltha skūlas kin il skadadaiang an ltha kaldunḡanḡang.

29. Kin wautliwan an nung ūnshitungs kingān kin ltha il skadadaiang althīa, waigen kum ta kālunglēilung kingān il edāngang.

\section{Chaptergē Stanshungā.}

TLİSTLUAN lthdouwē stāhā il kātlātālānitlo, 1 ltha skūl yūan lā tlā istiēdang.

2. Waigen kwoking, nung hēlōda lā an kātlāgang, waigen hinu singelthkang il gūshouang: Shālānā, dung kwudungstlo, kwunan dì dung tlask wunagelthasang.

3. Stlē unga il jistlaiang, waigen lã il gidsgildasken hinu il shouan, kingän lth waushang, skwunageltha: waigen houitang hēlōda langa skwunagālang.

4. Waigen Jesus hin il shūtaiang, kum nung ïtlinga swaunshung ga lth shūdāng: kūwē gud lth unga kaiit, waigen nung laplētga lth agung kingda, waigen tliku Moses takingwogangang kingān saouhadan kin lā ga lth ista.

5. Tlīstluan Capernaum tligē gu il kātlāgang tlo, Soldiers lagwau klēlth an nung itlagidāgang là an kātlāgang, waigen hinū là alth il kiānangang: 
6. Shālānā, dī kitzadalung swaun annā tīdang, stigliida alth il stigung waigen il whauaḡunḡung.

7. Waigen Jesus hin il shütaiang, lā lth tlatagwiēlāshang.

8. Waigen Soldiers lagwau klēlth an nung itlagidas hin hangtlan shouan, Shālānā, kiagin nē shāshi hetgwi dung katsiēannu kum dī lāngung. Kil unga alth swaunan Ith shū, waigen dī kitzada nūngistlāsang.

9. Nung itlagida hangast nung ittlinga ed dī isis althlā, waigen kiagin Soldiersgē ishin dì hangast ëdung: anis hin lth shūdang, kaiitla, waigen il kaiitaḡungung: nung kalat hin lth shūdang, halūt, waigen althkwi il kāḡunḡung: waigen kitzada unga hin lth shüdang, adshi lth ista, waigen kingān il wauḡunḡung.

10. Tlīstluan Jesus kwudangāni tlo il kwulthlthālang, lā tīā ltha istals hin il shūtaiang: yenkien dalung ga lth shūgung, Israel tligē gu anung yetayūans kum hin lth kīīnḡun.

11. Waigen dalung lth shüdang, ltha sküla hougūst stāhā istlāshang, chāgūst ishin : waigen Abraham isken, Isaac ishin, Jacob ishin kwulthlu ltha tluadäshang shägē kingdomgē gwau.

12. Waigen kingdomgë kitilung kiak halga ā dānḡashang, giouk sahaigasēsi gwau, waigen zing unga kokopitasēs ishin.

13. Jesus hin Soldiers lagwau klēlth an nung itlagidas shutaiang, kūwē gud lth unga kaiit, waigen tliku dung yetas kingān dung an 
edasang. Yenkien ashgē askaskitē glu il kitzada nūngistlaiang.

14. Tlīstluan Jesus Peter giē nē ik katsaiang tlo, il jūnan stikina alth stigang il kāngang.

15. Waigen il stlē il gidsgildaiang, waigen stikīna gē lā stāhā hēlouang: waigen il kātlouang ken tou ltha ga il istaiang.

16. Waịen singyāstlo, lth hāada kwan hetgwaulana alth stāouwas lā $\bar{a}$ ltha kēlthilangang, waigen kil unga alth hānts dāungas kiak il dāngang, waigen ltha stis wautliwan il tlanūngistlaiang.

17. Tliku nung Prophetgas Isaiah shouan kingānu edāni, waigen hinū il shouan : îtil stisu lā kwodanan istaiang, waigen itil helthilthkiasu il wunaḡunḡung.

18. Wēata, tlīstluan Jesus ltha skūla yūan addūlthkang il kāngāni tlo, ingwīk ltha il istasālang.

19. Waigen takalunglē swaun kātlāgang ken hin lā il shūtaiang, Nungītlagidas, tlītzan dung kās kingān dung tlā lth kāshang.

20. Waigen Jesus hin il shūtaiang, nakadziū nē daang, waigen siēt ettit isis lthtelgē daang, waigen nung itlinga kit kum tlitzan il kats kēyūda klinḡe il daānḡung.

21. Waigen lagagahatijanḡe kalat hin il shūtaiang, Shālānā kwai lth aung unga dī tlēēwau tlāganda.

22. Waigen Jesus hin il shütaiang, dī tlā lth 
$k \bar{a}$, agwan ltha kwotalthgiē ltha kwotalthgas unga tlēēwauda.

23. Waigen tlīstluan kontluwē gwi i il kātlīgāni tlo, lagaga hatijanḡē ishin lā tlā istlīgang.

24. Waigen kwoking, tungē $\bar{a}$ aiyūdstl' yūanan, waigen aiyuwē kontluwē telgu gūstlagangang: waiken il kattaiang.

25. Waigen lagagahatijanḡe lā kwulth istzaiang, waigen lā ltha tlaskinaiang, waigen hin ltha shouan: kagindaltha, Shālānā ìtil güdalgung.

26. Waigen hin ltha il shütaiang, kashintlou dalung lthwaugaḡunḡung? O klingān dalung yetang! Itan il kātlouang ken, tatjouwē isken tungè ishin il stitaiang, waigen wadla glaiad yūanan.

27. Waigen lth hāada kaldungāgang, waigen hin ltha shouan: kasin nung ìtlinga ed $\bar{u} \bar{a}$ iching. Yenkien tliku il shūs kingān tatjouwē isken tungē ishin iching.

28. Waigen tlīstluan Gadarene tligē gu il tlu kātlātajāni tlo, lth hāada stung hetgwaulana alth stāouwas lā an istlāgang: giouk tlēēwas stāhā lā an il istlaouang. Yenkien il kātliyil dung gīuḡangang, altsīilth kum tliku nung itlinga wadshi kūwē gud kà klingē kāng gaangang.

29. Waigen kwoking, kwunan il hin sahaigaouang: kasino dung talung edāshang, Jesus? Shānungetlagidas kit dahou īching: timegē 
kwunast hetgwaugē ik itil dung dāngēan gu ìtil an dung kātlā us ?

30. Waigen ltha stāhā wadshgwau agwi kwosho kwan lthtanouang.

31. Altsiilth ga hetgwaulanagas gē hin lā alth kiānung tlīdzouang: kiak ìtil dung dāngsken, kwai lth kwoshougē kātliā ìtil kil istiēd.

32. Waigen hin ltha il shūtaiang, istiēdulthā. Waigen tlistluan ltha issāgang tlo, kwoshougē kātli ik ltha istzaiang, altsīilth kwoshougē wautliwan stelahans stāhä tungē ik knhūdjangaiang, waigen hānlthē à akkītūkōodzouani.

33. Waigen tuman ga kāngang gē ishin knhūstaiang, waigen ilnigē $\bar{a}$ il istiēdouang : kin wautliwan alth il giatlindaouang, tliku hetgwaulana alth ltha stāouwaiang alth il giatlindaouang.

34. Waigen kwoking, lana asku hāada kiak issāḡang Jesus an ltha istlāḡēanā: waigen tlīstluan lā ltha kāngāni tlo, skwausgiou stāhā lthanga il kaiitē da lā alth ltha kiānangang.

\section{Chaptergē Klãalthswansinḡu.}

WAIGEN kontluwē gwi il kătliggāni, waigen ingwìk à il tlu kātijang, waigen ilnigē gu unga il askidāni.

2. Waigen kwoking, nung itlinga stiglīìda 
alth sti lā ā ltha istaiang, waigen tīdādunē inku unga il tĩdaiang: Jesus ltha yetas kāngāni tlo, nung stiglīidas hin il shūtaiang, Lthkin, kwutungē unga lth kladskādi, dung dāungas gakakunḡung.

3. Waigen kwoking, takālunglèilung itli hin gwu shūtaḡangang: anung itllinga isis gūshou dāunga shūdang.

4. Waigen Jesus tliku ltha kwulthilths anūnshitalthsken, hinū il shouan, kashintlou kwutungè unga alth kin dāungas an dalung kwudungung?

5. Kinaso yāngulang hin shouḡēḡwau, dung dāungas gakakunḡung: kātlūultha waigen lth kaiit hin shouḡēḡwau?

6. Waigen nung itlinga kit hētk tligē gu kin dāungas gakunḡēan tagwias an dalung ūnshitēana, (altsiilth itan nung stiglīìda alth sti hin il shūtaiang) kātlūultha, waigen tīdādunē unga lth ista, waigen nē gwi unga lth kaiit.

7. Waigen il kätlouang, waigen nē gwi unga il stēlang.

8. Waigen tlīstluan ltha skūlas kāngāni tlo, Itha kaldungāgang, waigen Shānungetlagidas an ltha yākwudangang, $\bar{a}$ kin tagwiā isis lth hāada ga il istaiāni althlā.

9. Tlīstluan Jesus stāhā kaiitāni tlo, nung itlinga il kāngang, Matthew hinū il kēyaiang: giouk ltha giasougunungs gu il kouwaiang: 
waigen hin lā il shūtaiang, dī tlā lth kā. Waigen il kātlouang ken lā tlā il kaiitang.

10. Waigen tlīstluan Jesus anis giè nē $\bar{a}$ il lthatanouan kouwaiang tlo, giasougunungā lēilung kwan isken, ga dāungas gè ishin istlāgang, waigen Jesus isken, lagagahatijanḡe ishin alth ltha tluadaiang.

11. Tlīstluan Pharisee hāadē kāngang tlo, lagagahatijanḡe hin ltha shūtaiang, kashintlou dalung ìtlagīda giasougunungā lēilung isken, ga dāungas gē ishin alth lthtanūḡung ?

12. Waigen tlīstluan Jesus kwudāngāni tlo, hin ltha il shütaiang, ga althlings gē kum doctor gustatlāğunganḡung : ga stis gē swaunan doctor gustatlaḡungung.

13. Altsiilth lth istièdo, waigen tliku lth shūs lth skado, kalthshint dī kwutungsang, waigen tagiāsa lth kum: kum ltha lā an aiyingē an lth kātlāanḡun: ga dāungas gē kwutungē unga stîlthtiēanu lth kātlātalgun.

14. Itan, John gagahatijanḡe $\mathrm{la}_{\mathrm{a}}$ an istlāgang, waigen hin ltha shouan: kashintlou talung isken, Pharisee hāadē ishin kỉsal kwanguung, dung gagahatijanḡe tlou kum kīsalānḡung.

15. Jesus hangtlan hin ltha shūtaiang, nung chādunēlths houān tha alth stungstlo, nung laiinēlths touilung gu nē kātli à sahaigaḡung us ? Shantlanē althkwi isisang, waigen nung chādunēlths ltha stāhā ltha istāshang, itan ltha kisalasang. 
16. Kum nung itlinga gioung houtla kin giandatlingē knigà $\bar{a}$ gwushgìtlingānḡung: kin giandatlingē kīgā stāhā gioung houtlas ì hananungasēsi althlā, waigen kin giandatlingē $\bar{i}$ hananungs wu kin dāungēdsang.

17. Isi ishin, kum lth hāada winegē houtla kalk kīgā ì istaḡunganḡung, kalkē hustasēsi althlā, waigen winegē kwaukunzāshang, kalkē ishin gūashang. Winege houtla kalk houtla ai ltha istaḡunḡung, waigen stungan kaḡungung.

18. Houān ashgē ltha ga il shūdagundang, kwoking, nung ìtlagida swaunshung kätlāgang, waigen lā $\bar{a}$ singelthkang il gūshouang: hinū il shouan, dī gwudjana wēata yenkien kwotalgung, alth kwīk lth $k \bar{a}$, waigen stlē unga lā inku ista, waigen il hēnanstlāsang.

19. Jesus kātlouang ken lā tlā il kaiitang, waigen lagagahatijanḡe ishin kingān idjan.

20. Waigen kwoking, nung chada tada klāalth wok stung kaginistaaiang lā tlā kātllägang, waigen kin il giandas kiēkwun il gidsgildaiang.

21. Agung hin il shūtaiang, kin il giandas swaunan lth gidsgildastlo dī kaguntlingagung hinū il kwudangang.

22. Jesus lā gwi hangouang, waigen lā il kingstlo, hinū il shouan, dī gwudjangs, kwutungē unga th wausaaskita, dung yetas althlu dung kaḡungung: waigen ashgē askaskitē gud anung chada is kagānang. 
23. Tlisstluan Jesus anung îtlagidas giē nē ik katsaiang tlo, ltha hūkingans il kāngang, waigen lth hāada takoukwudas ishin.

24. Hin ltha il shūtaiang, kwai lth edo, anung hāchadas kum kwotalānḡung: laou katdang: waigen ltha wautliwan la alth ltha kilthnangang.

25. Tlistluan th hāada kiak il istaiang tlo $\bar{i}$ il katsaiang: il stlē lā il douang, waigen anung hāchadas kātlouang.

26. Adshi tligē askwan gud ashgē giatlingē kinā kokgustlowaiang.

27. Stāhā il kaiitāni tlo ltha hangkagas stung lā tlā istalang, waigen hinū il shūouang, itil kalthshint lth kwutung, David Kitu dung iching.

28. Tlīstluan nē ik il katsaiang tlo, ltha hangkagas stung lā an istlāgang, waigen Jesus hin il shūtaouang, adshi lth tlaoutliē an di tagwias gu dalung yetē? Waigen hinū lā il shūtaouang, āng Shālānā.

29. Wadlu il hangi il gidsgildaouang ken hinū il shouan, tliku dalung yetas kingānu dalung an edasang.

30. Waigen il hangi helthilthkaouang, waigen Jesus il kīngwoḡungouang kum nung ìtlinga anūnshitāngwang.

31. Waigen stāhā il istiēdouang tlo, adshi tligè askwan gud giatlingē langa kinā kokgustlowaiang. 
32. Waigen itan il issougundang, nung itlinga kil gūdsias hetgwaulana alth stāougas lā $\bar{a}$ ltha istaiang

33. Tlīstluan hetgwaulana kiak il dāngstlo, anung kil gūdsias tuman kilthgūlaiang, waigen ltha skūlas kaldungägang, waigen hin ltha shouan, tlaglu Israel tligē gwau kin wēata talung kingsa kingān kum kin edāngāni

34. Pharisee hāadē hin shouan, ga hetgwaulanagas gẹe an nung princegas kalthgud ga hetgwaulanagas gē kiak il dānḡung.

35. Waigen Jesus ilnigē wautliwan ai isken, lana wautliwan ai ishin kaouangang: churchne hudila ai lthanga isis $\bar{a}$ kin ltha il skadadagangang, waigen kingdomgē giatlingē las alth tlāgūk il gūshūgangang, waigen ltha helthilthkiā wautliwan isken, lth hāada sti wautliwan lth hāada shūwït isis ishin il tlanūngistlaḡangang.

36. Tlīstluan ltha skūlas il kāngāni tlo il kwutungē sahailthlaiang, ltha hāaḡāgang althlā, waigen lamatoē kētsitlē kum ltha dā̄nḡuns kingān tligwanan ltha istalḡunḡangāni althlā.

37. Altsīilth lagagahatijanḡē hin il shūtaiang, yenkien takwula kwanḡung, tatlïidlēilung tlou gūhutsūḡung

38. Tākwulas hansta singelthkang Shālānā $\bar{a}$ gūshū tatliidlēilung tākwula à unga il kil istiēdēanā. 


\section{Chaptergē Klāalth.}

[AGAGAHATIJANḠGE klāalth wok stung 1 āgang an il aiyangan tlo, hānts kum skwunaans telgu tagwiē lā ga il istaouang, kiak ltha il dāngoueanā : waigen gwudila helthilthkiā ed wautliwan isken, gwudila sti ed wautliwan ishin il tlanūngistlouēanā.

2. Waigen ga apostlegas gē klāalth wok stung kēyi ā ìching: Simon kwuniāgang, Peter ishin hinū il kēyāgang, waigen Andrew il tuan ishin. Zebedee kit James idjan, waigen John il tuan ishin:

3. Philip isken, Bartholomew ishin, Thomas ishin, waigen Matthew nung giasougunungs, James ishin Alphaeus kit il idjan ken Lebbaeus ishin, Thaddaeus hinū il kēyāgang:

4. Simon Canaan hāadāgang, waigen Judas Iscariot ishin : anis lā alth giadāgang.

5. Ashgē klāalth wok stung Jeșus kil istiēdang, waigen ltha il kingwogangang: tliga kalat hāada giē kūwē gud isken, Samaria hāada giē ilnigē gu ishin kum istalāngwang.

6. Israel hāada lamatoē gūguns kingān eds $\bar{a}$ lth istalo.

7. Waigen houān dalung istalgundang hin tlāgūk lth gūshū, shāgē kingdomgē dūungāgung.

8. Ga stis gē tlanūngistlōga: ltha kwotalth- 
kias ishin lth kātlūdōga: ga hēlōdas gē tlaskwunagelthōga: waigen ga hetgwaulanagas gē kiak lth dāngōga; saouhadan kin dalung istas kingān lth saouhadan ltha ga kin istowang.

9. Gold isken, dālā ishin, nukanadz ishin kum lth gwaule ai unga istaangu.

10. Dalung istiēdstlūlth, kodets sis stung isken, staskoga ishin, taska ishin kum lth wundiāngo, nung lthāangwilastlo tou il istiē lāsi althlā.

11. Waigen tlītzan lana yūan isken, lana hutsu ishin gu dalung istlāstlo, gu nung lagē da alth kiānungo, waigen lā kwulth lth isōga, stāhā dalung istiēdē kū.

12. Waigen tlisstluan nē ai dalung istzastlo hangā lth kwaugulthtōga.

13. Waigen nē lāsitlo agwan wau inku dalung kwutungē glaias lth istōga: waigen kum lāngstlo dalung kwutungē glaias agwan unga gwigang lth stīlthtōga.

14. Waigen kisstho kum dalung istānstlo, waigen kīstho kum dalung kil kwudungānstlo, tlīstluan wadshi nē stāhā dalung isistlo: waigen ilnigē stāhā ishin; stē unga stāhā lth kwiē gīidowang.

15. Yenkien dalung ga lth shūgung, altsgē ilnigē telgu Sodom tligē isken, Gomorrah tligē ishin lāsang ginkilislungē shantlanstlo.

16. Kwoking, hōots shūi lamato ichings kingānu dalung lth kil istiēdung: altsiilth sik 
kingān lth agung kutungādōga, waigen kaltsida kingān lth agung kungkwutungdōga.

17. Waigen lth hāada stāhā ltha ga gwudagungōga, councilge $\bar{a}$ dalung ltha istağunasēs althlā, waigen churchnē hudila lthanga isis $\bar{a}$ dalung ltha skidungungashang.

18. Ang, waigen dī hagunan governorgas gē isken, ga king gas gē ishin $\bar{a}$ dalung ltha istagungasang, waigen ltha an isken, tliga kalat haādē an ishin dalung witness gāgungasang.

19. Waigen tlīstluan kētsit nai à dalung ltha istastlo tliku dalung gūshūasēs addu kum lth kwulthilthāngowang: wadlu askaskit èlthsitlu tliku dalung gūshūsēs dalung ga lth istasēsi althlā.

20. Kum dalung gūshūānsi althlā, dalung Aung hāntsu dalung kātli $\bar{a}$ isis gūshūasang.

21. Nung kwaiu tuan unga kwotal $\bar{a}$ istāshang, waigen nung aung ishin kit unga kwotal $\bar{a}$ istāshang, ltha kitilung ishin yāalung an kātliyildāsang, waigen kwotal $\bar{a}$ ltha ltha istāshang.

22. Waigen dī kēyi hagunan lth hāada wautliwan dalung telgakingasang, waigen nung kwutungē kladska gīisitlo laou kagunasang.

23. Tlīstluan adshi ilnigē gu kin singètza dalung ltha hāndungdastlo, houitang ga kalat $\bar{a}$ istiēdwang; yenkien dalung lth shüdang, nung ìtlinga kit houshen kātlāsēs kū Israel ilnigē wautliwan ai kum dalung istalāngshang. 
24. Nung ganung tlitasisu kum îtlagīda unga telgu edungānḡung, waigen nung kitzada ishin kum ìtlagīda unga telgu edungānḡung.

25. Nung ganung tlitasisu isken, nung kitzada ishin îtlagīda unga kingān edgē lāḡunḡung: nē lē Beelzebub hin ltha kēyādastlo, ltha wautliwan lagiē nē $\bar{a}$ isis wautelgu Beelzebub hin ltha kēyādāshang.

26. Altsiilth kum ltha ga lth lthwaugāngu: kin wautliwan lthtelgasu kānḡēlthasēs althlā, waigen kin wautliwan saalgas an ltha ūnshitalthasang.

27. Tliku halga $\bar{a}$ dalung ga ltha shūs lth hatgā $\bar{a}$ shūdo: tliku kū unga alth kin dalung kwuduns lth nās inku ltha gūk shūdo.

28. Kum ltha tlu ltha tlitasgē ga lth lthwaugāngu kum ltha hātlandē ltha tlitatlingāns althlā: wautelgu ltha hātlandē isken, ltha tlu ishin nung tlitas ga dalung lthwaugiē tlou lāgung: yenkien hetgwaugē $\bar{a}$ ltha hātlandē nung tlitas ga lth lthwaugo.

29. Kum gu kwutsugu stung cent swaunshung $\bar{a}$ ltha istagungan us ? waigen dalung Aung ādang kum tligē ingwi swaunshung gluiāngshang.

30. Katsa wautliwan dalung kats ai kous kwaiundiāgung.

31. Altsiilth kum lth lthwaugāngu, kwutsugu kwan telgu dalung kwoyāgung.

32. Altsīilth kisstho lth hāada wautliwan 
hangku dī hansta shūasang, tlaou ishin dī Aung shā isis hangku lā hansta shūasang.

33. Waigen kisstho lth hāada wautliwan hangku dī da kadāstlo, tlaou ishin dì Aung shā isis hangku lā da kadāsang.

34. Hētk tligē gu kwutungē glaia hanshūtiēan lth kātlātalthing lth kum kwudungāngu: kwutungē glaia hanshūtiēan kum lth kātlātālthānguun: tlan sitz swaunan hētk tligè gu hanshūtiēan lth kātlātalgun.

35. Nung itlinga kwutunga kalat aung unga an istiēan lth kātlātalgun, waigen nung gwudjan ou unga an ishin, waigen nung kit chā jūnan unga an ishin kwutunga kalat istiēan lth kātlātalgun.

36. Nung ìtlinga telga ltha kings lagiē nēzai īching.

37. Aung unga isken ou unga ishin dī telgu nung kwoyādasken kum dī an lānḡung: waigen kit unga isken gwudjan unga ishin dì telgu nung kwoyādasken kum dì an lānḡung.

38. Waigen skaumā unga kum nung istānsken, waigen kum dī tlā il kāngsken, kum dì an lānḡung.

39. Hēninga unga nung kiasu wau gūdāshang, waigen dì hagunan hēninga unga nung gūdasu wau kiāshang.

40. Dalung nung istasken dī ishin il istang: waïgen dī nung istasken dī nung kil kaiitsu ishin il istang. 
41. Nung prophetgas kēyi alth nung prophetgas nung istasken, nung prophetgas giē giasougē il istāshang: nung las kēyi alth nung las nung istasken, nung las giē giasougē ishin il istashang.

42. Nung ganung tlitasisu kēyi alth kīstho skatlangwē ska swaunshung alth hānlth tadas $\bar{a}$ lth hihudila swaun ga skatlasken, yenkien dalung ga lth shūgung, kum tliku giasougē unga il gūda klingē kāng gaanḡung.

Chaptergē Klāalth wok Swaunshung.

TLİSTLUAN Jesus lagagahatijanḡē klāalth 1 wok stung il kingwogung ēlthtaiang tlo, stāhā il kaiitang: lthagiou ilnigē gu kin ltha il skadadiēanā waigen tlāgūk il gūshūēanā.

2. Wadlu John kētsit nē ā idjan: tlīstluan Christ lthāangwiliē il kwudāngāni tlo, lagagahatijanḡè stung il kil istiēdang, waigen hin lā il shūtaiang :

3. Nung kätlātalthtals dahou gu is? nung kalat gu talung kiatsū us ?

4. Waigen Jesus hin hangtlan il shūtaouang, istiēdūltha, waigen ou kin dalung kwuduns isken, kin dalung kingsa ishin John ga lth shūdo:

5. Ltha hangkagasu houshen kin kingēdung: ltha kwollo kodasu istalgungēdung: ga 
hēlōdas gē skwunagelgung, ltha kūunas ishin kin kwudungeddung: ltha kwotalthkia katlougudunḡung, waigen ltha kuniskidēgas $\underline{k} \bar{u}$ gu giatlan las alth ltha gūshūgungung.

6. Waigen laou wausaaskitashang kum dī an nung kwutungē dāungānstlo.

7. Il istiēdouang silīd Jesus ltha skūlas ga tliku John edang alth giatlindiēdang, waigen hinū il shouan, gūshū dalung kānḡeanu tliga dāunga $\bar{a}$ dalung istiēdang? Kun chits tatjou alth hūyhildungs gwau?

8. Gūshū dalung kānḡèan tlou ā dalung idjan? Nung ìtlinga kin lthtanā giandas gwau? Kwoking kin lthtanā ltha giandasu ga king gas gē nai $\bar{a}$ ìching.

9. Gūshū dalung kāngēean tlou à dalung idjan? Nung prophetgas gwau? Yenkien dalung lth shüdang, nung prophetgas telgu nung eds dalung kingāgang.

10. Laou $\bar{a}$ ìching nung kālungasa: kwoking, dung hangku giatlinlē unga lth kil kaiitang, waigen dung kwunast dungiē kūwē il èlthkidāshang.

11. Yenkien dalung ga lth shügung, ltha chāada kaiawas shu kum John the Baptist telgu nung edānḡung: wauhangast nungihutsūs shāgē kingdomgē gu isis tlou lā telgu èdung.

12. John the Baptist giē shantlanē stāhā wēat an kūelthkang lth hāada kwutungē klad- 
ska shāgē kingdomgē ltha skokutanḡung, waigen ga skokutanḡē kladska gwi $\bar{u}$ kāēlgung.

13. John kū prophets wautliwan isken lawgē an ishin kin isungkasas shütaiang.

14. Waigen istiē da dalung kwudungstlo Elijah ou ïching, waigen houshen il kātlātalungkashang.

15. Kin kwudungūng knu nung daas lth agwan il kwudungda.

16. Gūshū kingānu adshi gwudista kanḡēe lth edāshang? giouk kin alth ltha waddas $\bar{a}$ Ith hihudila tluadaguns kingānu Itha ëdung, waigen gwudga ltha kiāganḡunḡung.

17. Waigen hin ltha shūḡunḡung, dalung an talung hūkinganḡung waigen kum dalung yhētlthānḡung : dalung ä talung sahaigung, waigen kum dalung kagininaānḡung.

18. John kātlāgang tlo kum il lthtanuāngang, waigen kum il anīlthängang, waigen il hetgwaulana gang ltha shouan.

19. Nung ittlinga kit kātlāgang tlo, il lthtanuḡung, waigen il anīlgung : waigen kwoking, hin ltha shūguung, kwotagalē isken winegē nēillē ishin il iching. Giasougununga lëilung isken ga dāungas gē toui il is hin ltha shūḡung. Kin kutungas kitilung tlakutungelgurig.

20. Itan ashgē ilnigē gu lthāangwila an kaldunga kwan il tlaoutlaiang, waigen il güshūsaats̄̄īilang kum kwutungē unga ltha stîlthtaangāni althlä. 
21. Chorazin tligēe, dung an kin ga lthwōgigāsang: Bethsaida tligē, dung an kin ga lthwōgīgāsang; dalung gu lthāangwila an kaldunga lth tlaoutlagun kingān Sodom tligē gu isken, Gomorrah tlige gu ishin lth waugastlo, tlaglu agwi whaustagwālth isken haiit ishin alth ltha kwutungē stîlths gaiaunḡung.

22. Altsiilth hin dalung ga lth shūgung, ginkilislangē shantlanstlo, Sodom tligē isken Gomorrah tligē ishin dalung telgu lāsang.

23. Waigen dahou Capernaum tligē, shā tligē an agung dung yūandung: yenkien hetgwaugē $\bar{a}$ dung edālthasang: dung gu lthāangwila an kaldunga lth tlaoutlagun kingān Sodom tligē isken Gomorrah tligē gu ishin lth waugastlo, ashgē shantlanē kū isgaiaungung.

24. Yenkien dalung ga lth shūgung, ginkilislangè shantlanstlo, Sodom tligē dung telgu lāsang.

25. Wadlu Jesus hin hangtlan shouan, tungā lth killāḡung $O$ Aungā: shā tligē isken hētk tligē ishin an dung Shālānā gāgung: $\bar{a}$ kin isis ga kutungas gē isken tagan ga kwutajūs gē ishin stāhā dung saalḡangāni althlā, waigen lth hihudila dung kingdagangang.

26. Ang Aungā, dung hangku $\bar{a}$ kin isis lāyūanāni althlā.

27. Dì Aung kin wautliwan dì ga istagun, waigen kum nung ìtlinga il kit anūnshitānḡung tlan il Aungē swaunan: altsīilth kum nung 
îtlinga ì Aung anūnshitānḡung tlan il kit swaunan, waigen il kit Aung unga nung isiṣ kingdastlo il Aung an il ūnshitalthasang

28. Dalung lthāangwilas isken, dalung gà kukinas ishin di $\overline{\mathbf{a}}$ lth isso, waigen anshanzouta dalung ga lth istāshang.

29. Kiagin hellthkulthkitlanuwē inku lth gang isto, waigen dì lth skado, dì kungkwutungas althlā, waigen dī kwutungē ishin hēt ēdung, waigen hātlandē unga an anshanzouta dalung kiāshang.

30. Kiagin hellthkulthkitlanuwē yāngulas althlā, waigen kin lth wunḡungs ishin kiang.

\section{Chaptergē Klāalth wok Stung.}

A SHGE timegē gud sundigāgang tlo, Jesus A corn kwulthkadazi kalthgwīd kāgang, waigen lagagahatijanḡe kwotagālang, altsīilth corngē kal ltha dunḡīìdang ltha tāan.

2. Tlīstluan Pharisee hāadē kāngang tlo hin lā ltha shūtaiang, kwoking sundigastlo dung gagahatijanḡē tliku kingwoguns shūs kingān kum wauānḡung

3. Hin ltha il shūtaiang, tliku David waugang kum gu dalung readadāngudjang tlīstluan il kwotagālang tlo waigen lā alth ltha idjan gē ishin :

4. Yenkien Shānungetlagidas giē nē ai il 
katsaiang, Shālānā giè shibiligē il tāgang, waigen kum il tāgēan lawḡāngang, waigen lā alth ltha idjan gē ishin. Tlan laplētgas gē an swaunan idjāni.

5. Kum gu lawgē $\bar{a}$ ishin an dalung readadāngudjang? Sundigastlo laplētgas gē churchnē yūans à sundiga tlaoulthdāunḡunsā, waigen ltha kwudou lāgung.

6. Tlaou hin dalung shūdang, churchnē yūans telgu nung swaunshung eds àdlun iching.

7. Kalthshint lth kwutungsang, waigen tagiāsā lth kum. Tliku adshi edgē an dalung unnshitalstlo lth hāada kum kin dāunga istāns kum dalung ginkilislungs gaiahānḡung.

8. Nung itlinga kit altsiilth sundiga ishin an Shālānā gāgung.

9. Tlīstluan il kaiitan tlo churchnē hudila ai lthanga il katsaiang.

10. Waigen kwoking nung stlē yilgalā $\bar{a}$ idjāni, waigen hin lā alth ltha kiānangang, sundiga ai lth hāada tlanūngistliē gu lā us ? lā an ltha gakilskulthliēanā.

11. Waigen hin ltha il shütaiang, nung itlinga dalung shu isis lamato swaunshung il daastlo, sundigastlo kin hēla à il gluīsastlo kum gu stāhā lā il dungtlisstāngashā us ?

12. Altsiilth lamato swaunshung telgu nung îtlinga kwoyāgung: altsiilth sundiga ai kin lā istiē $\bar{u}$ lāgung.

13. Itan hin nung ìtlingas il shūtaiang, stlē 
unga lth jistli, waigen stlē unga il jistlaiang, waigen hinawē gē kingānu langa lagālāni.

14. Waigen Pharisee hāadē issāgang, waigen tliku lā ltha tiatlidzuasēs eddēid ltha kaoukgāgang.

15. Tlīstluan Jesus anūnshitālang tlo stāhā il kaiitang, waigen ltha skūla yūan lā tlā istiēdang, waigen ltha wautliwan il tlatagwiēlgangang,

16. Waigen kum hanstagang ltha il shūalthāngang.

17. Tliku Isaiah nung Prophetgas shouan kingānu edāni, waigen hinū il shouan :

18. Kwoking dì kitzada isis lā lth kīang : lā lth kwoyādung: waigen lā alth dī kwutungē lāgung, altsīilth hānts unga lā inku lth istāshang, waigen ginkilislang tliga kalat hāadē il kingdāshang.

19. Kum il gūshū saatsḡaāngasang, waigen kum il sahailthāngsang, waigen kūkit $\bar{a}$ kum nung itlinga swaunshung il kil kwudungāngsang.

20. Kun chits whaundals kum il tlawhauāngshang, waigen kinēsta aiyoudastlas kum il tlakīlthāngsang: lth häada wautliwan il ginkilislungs silīd lā gwikāēlthasang.

21. Il kēyui tliga kalat hāadē yetāshang.

22. Wadlu hetgwaulana alth nung stãougas lā $\bar{a}$ ltha istaiang, il hangkagāgang ken il kil gouang, waigen lā il tlanūngistlaiang, altsīilth 
nung hangkagas kil gūs gūshouang, waigen kin il kāngang.

23. Waigen lth hāada wautliwan kaldungāgang ken hin ltha shouan, kum gu David kit $\bar{a}$ isāng us ?

24. Tlīstluan Pharisee hāadē kwudangāni tlo, hin ltha shouan: anung itlinga Beelzebub alth stunḡung, waigen Beelzebub ga hetgwaulanagas gē an Prince gāgung, altsīilth lā alth ga hetgwaulanagas gē kiak il dānḡung.

25. Tliku ltha kwudungs an il ūnshitālang tlo hin ltha il shütaiang, kingdomgē wautliwan gū istasken hēlō odzūashang: waigen ilnigē wautliwan isken nāa an ishin gu istasken kum tlazūḡiangāngshang.

26. Waigen hetgwaulana hetgwaulana an kiak dāngstlo, kasino itan kingdomgē langa giangtlidzūashang?

27. Beelzebud alth ga hetgwaulanagas gē kiak lth dāngstlo, kīst althlu dalung kitilung ga hetgwaulana gas gē kiak dānḡunḡung? altsīilth dalunḡiē ginkilislung lēilung ltha isisang.

28. Shānungetlagidas hānts alth ga hetgwaulanagas gē kiak lth dāngstlo, yenkien Shānungetlagidas giē kingdomgē dalung an edatlā tlingāgung.

29. Kasino nung itlinga tagwias giē nē ai nung katsa tlidzoutlingāgung, kin ai langa il skininungēanā? nung tagwias il kētsgust tlāgangstlo itan kin ai langa il skininungasang. 
30. Kum dī alth nung isāngs dī hanlthā il eddung: waigen kum dì alth gwuda kin nung istānsu tligwanan hagwudjanḡung.

31. Altsiilth dalung ga lth shūgung, kin dāunga gwudila ed wautliwan isken, gūshou dāunga gwudila ed wautliwan ishin lth hāada an dalung istas gakakungasang: waigen Hānts Las $\bar{a}$ ginggangan gūshouwē lth hāada shūtas kum gakakungāngsang.

32. Waigen kīstho nung ìtlinga kit $\bar{a}$ ginggangan gūshou ed shūtasken lā gakakungasang: waigen kīstho Hānts Las $\bar{a}$ ginggangan gūshou ed shūtas "kum gakakungāngsang, adshi tligē gwau isken, tligē isungkasas gu an ishin kum lā gakakungāngsang.

33. Kinlthkai tlalāgelth, waigen hānē langa lāsang: kinlthkai tladāunged, waigen hānē langa dāungasang: kinlthkai hānē althlu an ìtil ūnshītung.

34. O sik "gwudistakāngèe, dalung dāungang: kasino dalung dāungas gūshou lā shūta tlidzūgung? ltha kwutungē $\overline{\mathrm{a}}$ kin isis stāhā ltha hēlthli gūshūsi althlā.

35. Nung itlinga las il kwutungē $\bar{a}$ kin lā isis stāhā lthāalgwi kin las il istaḡunḡung, waigen nung ìtlinga dāunga il kwutungē $\bar{a}$ kin dāunga isis stāhā "lthāalgwi kin dāunga il istaḡungung.

36. Altsiilth dalung ga. lth shūgung, lth hāada kil skunsalunga wautliwan shūtas gin- 
kilislangē shantlanē ai lthāalgwi unga ltha istāshang.

37. Dung kil hagunan dung kagunasang, waigen dung kil hagunan dung gūashang.

38. Itan takālung lēilung ìtli isken, Pharisee hāadē îtli ishin, hangtlan hin lā ltha shūtaiang, Nungītlagidas, kin skadagā dung stāhā isis kāngē da îtil kwudunḡung.

39. Waigen hin hangtlan ltha il shütaiang, ga dāungasgē isken, waigen chaaiga gwudistakānḡe ishin kin skadagā da kinḡunḡung, waigen kum kin skadagā ltha ga istiāngshang, tlan Jonah swaunan giē kin skadagā ltha ga istiāshang.

40. Jonah sin lth'unilth isken hal lth'unilth ishin kwun del ā idjan kingān nung itlinga kit tligē kātli à isisang sin lth'unilth gud, waigen hal lth'unilth ishin.

41. Nineveh hāadē ginkilislangē shantlanē ai adshi gwudistakāngē alth tlazügiangshang, waigen unga ltha ginkilislungshang: Jonah tlāgūkgūshouang tlo ltha kwutungē unga stīlthtaiāni althlā, waigen Jonah telgu nung eds ādlun īching.

42. Housik hāadē an nung Queengas ginkilislangē shantlanē ai adshi gwudistakānḡēe alth giangshang, waigen unga il ginkilislungshang: tliga unga stāhā Solomon kutungas kwudıngēanu il kātlāgāni althlā, waigen kwoking Solomon telgu nung eds ādlun iching. 
43. Tlīstluan hānts k̉um skwunaans nung itlinga stāhā kāgulthstlo, tlītzan kum hānlth kāng gaangs kalthgwīd il kaounḡunḡung anshanzouta da il kingēan, waigen kumu il kīānḡung.

44. Altsīilth hinū il shūḡung, nē gwi unga lth stīlthasang giē stāhā lth kāgwulgunā: waigen nē ik il katsastlo kal is il kīīgun, waigen lthkioudal skwunagalāsi an ishin.

45. Itan il kaiitang, waigen lā telgu hānts adda dāungas chigwau isis kinung an il istang; wai ltha istzasken waigen $\bar{a}$ ltha naangelgung. Kwunā il dāungaiang telgu otgwau il dāungēdung. Waikingān adshi gwudistakānḡē dāungasi an edasang.

46. Houān lth hāada ā il gūshūḡundang, kwoking il ou isken kwaialung ishin kiā tlazūgiangang lā $\bar{a}$ gūshūē da il kwudungouān althlā.

47. Itan nung swaunshung hin il shütaiang, kwoking dung ou isken dung kwaialung ishin kiā tlazügianḡung, waigen dung $\bar{a}$ güshūē da il kwudungwang.

48. Waigen hangtlan lā ga nung shūs hin il shūtaiang, kīstho dī ou īching'? Kitildou dī kwaialung iching?

49. Lagagahatijanḡē gwi stlē unga il jistlaiang ken hinū il shouan, kwoking dī ou isken dī kwaialung ishin $\bar{a}$ ìching.

50. Altsiilth kistho dī Aung shā isis kwu- 
tungē kingān wausken, dī kwai isken, dī chas ishin, dĩ ou ishin il ĩching.

\section{Chaptergē Klāalth wok Lth'unilth.}

A SHGE shantlanē gud Jesus nē stāhā kaiiA tang, waigen skwausjinku il kouwaiang.

2. Waigen ltha skūla yūan kwudungalthan lā an istlāgang, altsiilth kontlu gwi il kātlīsken gwau il kouwaiang, waigen ltha skūlas wautliwan skwausjinku tlazūgiangang.

3. Waigen kin kwan kigang $\bar{a}$ isis ltha ga alth il giatlindaiang, waigen hinū il shouan, kwoking tatlidzalē kiak kāgwulgung tatlidzaēanā;

4. Waigen tlīstluan il tatlidzaiang tlo, mātla tītch kūwē kātli khhūgaiāni, waigen ettit ungadaltlāgang, waigen $\bar{u}$ tāḡangāni.

5. Tliga kwau ingwi mātla tītch knhūgaiang giouk kum kwiē kwanāngan gwau, waigen houītang kwustajāni kum kwiē gungāngani althla :

6. Waigen tlīstluan juiē kātlātlaiāni tlo sahādungkilthistlaiang, waigen kum skūshangu wau angāni althlā kōdanstlaiani.

7. İtli ishin hōtdungal shuīt kૂhūgaaiani, waigen hōtdungalē inastlasken hōknhoujistlaiang.

8. Waigen ga kalat kwiē lā ai khhūgaaiang, waigen hānē waugud koustlaiang, tītch gud 
lagwau k]ēlth gangang : tītch gud ishin lagwau lth'unilth gangang, waigen titch gud ishin klālè lth'unilth gangang.

9. Kin kwudungūng k $k \bar{u}$ nung daas agwan lth il kwudungda.

10. Lagagahatijanḡē lā an istlāgang, waigen hin lā ltha shūtaiang, kashintlou kïgangē alth ltha ga dung giatlindung?

11. Waigen hangtlan hin ltha il shūtaiang, shāgē kingdomgē kin saalgas dalung ga istias althlā an dalung ūnshitēanā : ltha ga tlou kum istiānḡung.

12. Altsiìlth kīstho kin daas lā ga istiāshang, waigen wautelgu il daēlthasang: waigen kīstho kum kin daāngung, yenkien kin il daas lā stāhā istiāshang.

13. Altsiilth kigangē alth ltha ga lth giatlindang, kin ltha kings kum ltha kingāngsi althlā, kin ltha kwudungs kum ltha kwudungānḡung, waigen isi ishin kum an ltha ūnshitānḡung.

14. Waigen tliku Isaiah shouan kingān ltha èdung: waigen hinū il shouan, kin dalung kwudungstlo kum an dalung ūnshitalthāngsang: kin dalung kingstlo kum ai dalung kwudāāngashang.

15. A lth hāada isis kwutungē kwanelgung, waigen kin ltha kwudungēanu ltha knu katsang: waigen hangi unga ishin ltha oiyūlthtadang. Kin hangi unga alth ltha kings isken, kin knu 
unga alth ltha kwudungs ishin: kin kwutungē unga alth an ltha unshits ishin : di gwi kwutungē unga ltha stïlthtiē ishin, waigen ltha lth tlanūngistliē ishin ga ltha lthwaugaḡunḡung.

16. Dalung hangi tlou lāgung kin kingsi althlā : dalung $k \underline{u}$ ishin lāgung kin kwudungsi althlā.

17. Altsīilth yenkien dalung ga lth shūḡung, prophets kwan isken, ga las gē kwan ishin $\bar{a}$ kin isis dalung kingsu kānḡē da kwudangang, waigen kum ltha kingāngāni : kin dalung kwudungsu kwudungē da ltha kwudangang, waigen kum ltha kwudungāngāni.

18. Altsiilth tatlidzalē alth kïgangē lth kwudungo.

19. Tlīstluan kingdomgē kil nung kwudungstlo, waigen kum an il ūnshitānsken, itan nung dāungas kātlāḡunḡung, waigen il kwutungē $\bar{a}$ kin tlidziāgan lā stāhā il dungistlang. Kūwē kalthgwīd mātla knhūgaaiang kingānu anis ēdung.

20. Tliga kwau ai mātla nung istias kil nung kwudungu il iching, waigen houitang alth il kwutungē lāgung, waigen kum skūshang il kātli althgang il istāns althlu kum tlāā il giangānḡung.

21. Tlīstluan kin singētzā il hāndungstlo kil il yetas althlā houītang il tlidalthtāsang.

22. Hōtdungal shuît nung mātla istias kil kwudungu il īching, waigen adshi tligē gu kin 
isis isken, dālā ginggangan eds ishin kil il kwudungsu hōknhouyistlang, waigen kum hānē lā gud inastlāngung.

23. Kwiē lā ai nung mātla istias kil nung kwudungu il īching, waigen an il ūnshitung, hānē ishin lā gud inastlang, tītch waugud lagwau klēlthang, tītch waugud lagwau lth'unilthang, waigen tītch waugud klālē lth'unilthang.

24. Kigang kalat is ltha ga il istaiang, waigen hinū il shouan, shāgē kingdomgē nung itlinga kwulthkadis kātliā mātla lā unga tlidzāguns kingānu ēdung.

25. Waigen houān itlansidas kāstalth, lā telga nung kings kātlāgang ken wheatgē shuit in ishin il tlidzaiang, waigen stāhā il kaiitang.

26. Waigen tlīstluan yhil inastlaiang tlo, hānē ishin inastlaiang, waigen itan īnē ishin kānḡēlang.

27. Waigen anung nēlēgas kitzadalung istlāgang, waigen hin lā ltha shūtaiang, Nungìtlagidas, kum gu mātla lā kwulthkadazi $\bar{a}$ unga dung tlidzāngudja? Kïtchistahā īn ishin iching?

28. Waigen hin ltha il shūtaiang, dĩ telga nung kingsu adshi istaiang. Waigen il kitzadalung hin il shūtaiang, dahou gu in washt itil istada us?

29. Waigen hinū il shouan kāhano: īn washt dalung dungstasken, wheatgē ishin wau alth 
washt dalung dungstāshang. Agwan an lth $\mathrm{k} w u d u n g a l t h a n$ inastlada tlīidē $\mathrm{k} \overline{\mathrm{u}}$ :

30. Waigen tatlīid nūt gēthstlo, tatlīîllēilung hin lth shūtāshang, inka tlāgangultha, waigen tlaizito sissōan: waigen lth wheatgē kiagin nē ai gwuda isto.

31. Kigang kalat ltha ga il istaiang, waigen hinū il shouan, shāgē kingdomgē mustard mātlē sūtsu kingānu èdung, nung itlinga istaiang ken kwulthkadazi $\bar{a}$ unga il tlidzaiang.

32. Mātla wautliwan hangast gē èdung, waigen tlistluan inastlastlo, yhil wautliwan telgu èdung, waigen kinlthkai isilgung, altsiilth siēt ettit isis ungadaltlāgang, waigen lthāds inku tlaouang.

33. Kigang kalat alth tha ga il giatlindaiang: shāgē kingdomgē shibili tlikulthdouwē kingānu èdung. Tlikulthdouwē nung chada istaiang ken shibili kwīdouwē lth'unilth shuìt il istaiang tlikulthdouwē tlaodzuwē kū.

34. $\bar{A}$ kin isis wautliwan kīgangē $\bar{a}$ isis Jesus ltha skūla ga alth giatlindaiang, waigen kīgangē àdang kum ltha ga il giatlindāngang.

35. Tliku nung prophetgas shouan kingānu edāni, waigen hinū il shouan: kīgang alth helthli unga lth kisistlāsang : hētk tligè tlaoutliēlan stāhā kin saalgāgānu lthāalǵwi lth istāshang.

36. Wadlu ltha skūlas il kil istiēdang, waigen nē ik il katsaiang: lagagahatijanḡe là an istlā- 


\section{ST. MATTHEW 13.}

gang, waigen hin ltha shouan: kwulthkadis $\bar{a}$ in isis alth kigangē an lth itil unshitalthta.

37. Waigen hangtlan hin ltha il shūtaiang, mātla lā nung tlidzas nung itlinga kitu iching.

38. Kwulthkadisu tligè askwan iching, waigen mātla lā kingdomgē kitilungu ìching: in tlou nung daungas kitilungu iching.

39. Kin telga nung kings in tlidzasu hetgwaulạna īching: waigen hētk tligē tlanelgēu tlī̄dāgung, waigen tatlīillēilung an angelgas gē iching.

40. Altsiilth in gwuda istiāgang ken ltha tlaizadāni, waigen zanoē $\bar{a}$ hōgālani: kingān adshi tligē ishin tlanelgē edasang.

41. Nung itlinga kit angels unga kil istiēdashang, waigen kingdomgē stāhā langa kin dāunga wautliwan isken, ga dāungas gē ishin gwuda ltha istāshang:

42. Waigen zanoa kladska kātli à ltha ltha istāshang giouk sahaigāsēsi gwau, waigen zing unga kōkopitasēsī gu ishin.

43. Itan ga las gē juiē kākītīchings kingānu hatgāshang. Kin kwudungūng k kū nung daas lth agwan il kwudungda.

44. Houshen, ga lasgē juiē kākītīchings kingānu Aung unga giē kingdomgē gu edasang. Shāgē kingdomgē kwulthkadazi ā kin kwoyās saalgāguns kingānu ēdung, waigen tlīstluan nung itlinga kiastlo il saalēdunḡung. Il kwutungē las alth kin il daas wautliwan alth il 
giadouḡunḡung, waigen wadshi kwulthkadazi il dakgungung.

45. Houshen, nung wadda lēga pearlsgè lā yūan gakinḡuns kingānu shāgē kingdomgē eddung.

46. Tlīstluan ska swaunshung il kīaiang tlo il kaiitang: waigen kin il daas wautliwan alth il giadawaiang il dakgēanā.

47. Houshen, shāgē kingdomgē āat chān ga ltha istaiang kingānu ēdung, waigen skātlink gwudila ed wautliwan ltha chitlaiang.

48. Tlīstluan āatē stāgānītlu ltha dungchaougālang, waigen ltha tlousken lāsi tlu gwē ltha kingstagangang: dāungasi tlou ltha dāngwaiang.

49. Kingānu hētk tligē tlanelgē edasang. Ga angelgas gē shā stāhā istlāshang, waigen ga las gè shu stāhā ga dāungas gē ltha kingstāshang.

50. Waigen zanoē kladska ai ltha ltha istāshang giouk sahaigasēsi gwau, waigen zing unga kōkopitasēsi gu ishin.

51. Jesus hin ltha shūtaiang, $\overline{\mathrm{a}}$ kin isis wautliwan an gu dalung ūnshit? Hin ltha shūtaiang Āng Shālānā.

52. Itan hin ltha il shūtaiang, takalung lēilung wautliwan shāgē kingdomgè skadas nung ìtlinga nung nēlē gāguns kingānu èdung. Kin kwoyā il daas stāhā kin houtla isken kin kīgā ishin istaḡunḡung. 
53. Tlisstluan ashgē kīgangē Jesus tlanēlthtaiang tlo stāhā il kaiitang.

54. Waigen tlīstluan tlïga unga gwi il stēlang tlo, churchnē hutsūs à lthanga kin ltha il skadadaiang, altsiilth ltha kaldungāgang, waigen hin ltha shouan, kitchistahā anung itlinga isis adshi kutungas isken lthäangwila kladska ishin istaiang?

55. Kum gu nung carpentergas kit il isāng us? Kum gu il ou Mary hin kēyāng us? waigen James isken Joseph ishin Simon ishin Judas ishin kum gu il kwaialung isāng us?

56. Waigen kum gu il chasalung wautliwan ishin itil alth isāng us? Kïtchistahā anung itlinga isis $\bar{a}$ kin isis wautliwan istaiang?

57. Waigen la an ltha kwutungēstigang. Jesus hin ltha shütaiang: ilnigē gu unga isken nē à unga ishin nung prophetgas isītlu kum lā ltha kwoyādaḡungānḡung.

58. Waigen gaigu kum Ithāangwila kladska kwan il istaangang kum kwunan ltha yetāngani althlā.

Chaptergē Kläalth wok Stanshung.

A SHGE timegē gud Herod nung King gas Jesus giatlingē il kwudangang :

2. Waigen kitzadalung hin il shūtaiang, John the Baptistū à iching, kwotal il kātlouang 
altsīilth kin an kaldunga lā hagunan kānḡèlgung.

3. Herod awolth John istaiang althlā, il yhē lā il kētsgustlaiang ken Herodias il kwai Philip chā isis hagunan kētsit nē à lā il istaiang.

4. John hin lā ga shouan althlā kum lā dung inalē lānḡung.

5. Tlisstluan il tỉiē da il kwudangang tlo ltha skūlas ga il lthwaugaiang, nung prophetgas il is hin ltha kwudangāni althlā.

6. Tlisstluan Herod tlakaiang shantlanē idjan tlo, Herodias gwudjan ltha hangku yhelang, waigen alth Herod kwutungē lāgang:

7. Altsiilth gūshou kladska yūan alth hinū il shouan: kin ga il kiānungs kingān lā ga il istasangang.

8. Waigen gwudjana unga hin il ou shūhālang, John the Baptist kats lth kēlthka $\bar{a}$ isis ādlun dī ga ista: waigen hinū il shouan John the Baptist kats lth adshi kēlthka inku dī ga ista.

9. Itan anung king gas kwutungēstigang: il gūshouwē kladskāgang hagunan : ltha wautliwan lā alth lthtanouang hagunan hin il shouan, agwan lth lā ga isto:

10. Waigen kitzadalung il kil istiēdang, waigen kētsit nē $\bar{a}$ John kats washt ltha skikitlaiang.

11. Il kats kēlthka $\bar{a}$ isis anung hāchadas ga ltha istaiang, waigen ou unga $\bar{a}$ il istaiang. 
12. Waigen lagagahatijanḡē istlāgang, il tlu ltha istaiang ken ltha tlëëwaiang. Waigen Jesus ga ltha shūtāgāni.

13. Tlistluan Jesus kwudangang tlo, wadshi stāhā tliga dāunga $\bar{a}$ il tlu kaiitang; waigen tlīstluan Itha skūlas kwudangang tlo, ilnigē stāhā lā tlāid stē unga alth ltha istiēdang.

14. Waigen Jesus kāgwālang; waigen tlīstluan ltha skūla yūans il kāngang tlo ltha kalthshint il kwutangang ken ltha stis ltha il tlanūngistlaḡangang.

15. Singyāsken lagagahatijanḡēe lā an istlāgang, waigen hin ltha shouan : tliga dāungou $\bar{a}$ iching, waigen timegē tlanelgung, altsïilth wēata ltha skülas lth kil istiēda: lana ā ltha istiēdsiken tou ltha dāhouiēanā.

16. Waigen Jesus hin ltha shutaiang, kum ] tha istiēdē lānḡung, kin tātlingē lth ltha ga isto.

17. Waigen hin lā ltha shūtaiang, shibili alungē kwu klēlth swaunan ādlun ìtli à īching, waigen skātlink stung ìshin.

18. Waigen hin $\bar{u}$ il shouan althgwi dì ga lth isto.

19. Waigen ltha skūlasu kunē inku il kil tlaouāni; shibili alungē kwu klēlth isken skātlink stung ishin il istaiang ken shā tligē il kiatsgildaiang. Sing il killāgīisken hē il ginanangang, wadlu shibili alungē lagagahatijanḡē ga il istaiang, waigen lagagahatijanḡe ltha skūlas ga istaiang. 
20. Waigen ltha wautliwan lthtanouang, waigen skīsouang: waigen basketgē $\bar{a}$ klāalth wok à stung shibili kwōkungwē alth stāouas ltha istaiang.

21. Waigen ìtlansidas lagwau klālē klālē stung wok ishin lagwau klālē klēlth lthtanouang, ilā lth chāada ishin idjan, waigen lth hāhudila ishin.

22. Waigen houitang Jesus lagagahatijanḡè kontluwē gwi istlīhālang, waigen lā kwunast ingwik ltha tlu kātijēanā houān ltha skūlas il kil istiēdundang.

23. Tlīstluan ltha skūlas il kil istiēdgīgan tlo lthdou gwi il katlaiang singelthkang il gūshūēanā: waigen tlīstluan singyā yentlo lā swaunan gu idjāni.

24. Wadlu kontluwē sīgē yākwusi ā yēlāni, waigen tatjouwē katsūḡudāngāni alth kontluwē ga stliskāsilunḡangāni.

25. Askaskit stanshung ltha skānaiang tlo Jesus aiyuwē ingud ltha à kāgang.

26. Tlīstluan lagagahatijanḡe aiyūs ingud il kās kāngang tlo, ltha kwutungē tlakwīdistlaiang; waigen nung hānts $\bar{a}$ hin ltha shouan. Ltha lthwaus sahaigaiang.

27. Houitang Jesus hin ltha shütaiang, kwutungē unga lth lādo tlaou $\bar{a}$ ìching; kum lth lthwaugāngu.

28. Peter hangtlan hin il shūtaiang, Shālānā, dahou is tloalth tūngē ingud āgang dì kādi. 
29. Waigen hinū il shouan, halūt. Tlīstluan Peter kontluwē gwau stāhā kāgaiang tlo tungē ingud il kāgang Jesus ā il kaiitēanā.

30. Tlīstluan tatjouwē attawas il kāngang tlo laou lthwaugaiang : il tlidiēdgaiang tlo hinū il sahailthlaiang : Shālānā dī lth kaginda.

31. Waigen houitang Jesus stlē unga jistlaiang ken lā il gidsgildaiang, waigen hin lā il shūtaiang, O klingān dung yetang, kashintlou dung lthwaugalthudjang?

32. Tlīstluan kontluwē gwi il istlīouang tlo tatjouwē hēlouang.

33. Waigen kontluwē gwau ga isi gē lā an istlasken lā $\bar{a}$ singelthkang ltha gūshouang, waigen hin ltha shouan: yenkien Shānungetlagidas kitu dung īching.

34. Inagūst ltha tlu kātlātajan tlo, Genneserat tlige gu ltha askidang.

35. Waigen wadshi tligē bāadē lā an ūnshitālang tlo lana addu isi wautliwan ai ltha kingādaiang, waigen ltha stis wautliwan lā $\bar{a}$ ltha kēlthilangang.

36. Waigen kōdets kiēkwun swaunan langa ltha gidsgildaḡungē da lā alth ltha kiānangang, waigen ltha wautliwan langa gidsgildaiani kingān nūngistloodzouang. 


\section{Chaptergē Klāalth wok Klēlth.}

W ADLU Pharisee hāadē isken, takālung lēilung ishin Jerusalem tligē gu isis Jesus an istlāgang.

2. Waigen hin ltha shouan, kashintlou dung gagahatijanḡē lthkiāsi kingwoguns tlahustaḡunḡung? Tlīstluan shibili ltha tāsītlo kum stlē unga ltha tlināns althlā.

3. Waigen hangang hin ltha il shütaiang, kashintlou kīgangē unga alth Shānungetlagidas kingwoguns dalung tlahustaḡunḡung?

4. Altsīilth Shānungetlagidas hin takingwogangang: aung unga lth kwoyāda ou unga ishin, waigen shūshi kingān lth wau: waigen kisstho aung unga isken, ou unga ishin $\bar{a}$ gūshou dāungasken, agwan kwotal alth il kwotalthta.

5. Hin dalung shūḡung: kīstho aung unga isken, ou unga isken $\bar{a}$ hin shütasken, kin alth dalung ta lth tlāts Shānungetlagidas ga lth istāshang: kingān il waustlo, kum aung unga isken ou unga ishin il kwoyādānḡung.

6. Altsīilth kīgangē unga alth Shānungetlagidas kingwoguns ginggangan dalung tlaēdung.

7. Yenkien Isaiah tliku dalung edasēs shūtaiang dalung kwutungē stungs : altsīilth hinu il shouan :

8. A lth hāadas helthli unga alth $\mathrm{d} \overline{\mathrm{i}}$ an 
- āanāgung, waigen ltha kwutungē lthanga di stāhā jingāgung.

9. Tliku lth hāada kingwoguns skadadas ltha skadas althlā, altsiilth ginggangan singelthkang dī $\bar{a}$ ltha gūshügung.

10. Waigen ltha skūlas an il aiyangang ken hin ltha il shütaiang: kwudungūlthā waigen lth anūnshito.

11. Nung helthli ik kin katsasu kum nung ìtlinga tlaskēlēlthānḡung: nung helthli stāhā kin isu nung ìtlinga tlaskēlēlgung.

12. Wadlu lagagahatijanḡè istlāgang, waigen hin lā ltha shūtaiang: Pharisee hāadē ashgē gūshouwē kwudunḡun silīd ltha kwutungēstis an gu dung ūnshit us?

13. Waigen hangtlan hinū il shouan, kinlthkai wautliwan kum dī Aung shā isis tlidzānsu gwunistlāsang.

14. Agwan an ltha lth eda: ltha hangkagā halistal lēilung ltha īching. Nung hangkagā nung hangkagā an halkāsken, hānlth silī il hou wilgu waushang.

15. Waigen Peter hangtlan hin il shūtaiang, adshi kīgangē alth itil ga lth kigang.

16. Waigen hinū Jesus shouan, dalung ishin gu houān dakētisōdja?

17. Kin wautliwan helthli ik istzasu kitch ik istalgung, waigen ltha kāgwulgunḡung: kum gu an dalung ūnshitāng us ?

18. Kin wautliwan ltha helthli stāhā isu 
ltha kwutungē stāhā īching, waigen ou kin isis nung îtlinga tlaskēlēlgunḡung.

19. Kwulthal dāunga isken; lth hāada ltha tlitas ishin: ltha chäada alth ltha tians ishin: kwolthta ishin: ltha alth ltha kilthkadungs ishin: gūshou saatsga ishin : ou kin isis wautliwan kwutungē stāhā īching.

20. Waigen $\bar{a}$ kin isis nung itlinga tlaskēlēlgungung, waigen stlantlan ādang nung lthtanūstlo kum nung itlinga tlaskēelēthānḡung.

21. Stāhā il kaiitang, waigen Tyre tligē isken Sodom tligē ishin gu il kātlāgang.

22. Waigen kwoking nung Canaan chitga adshi aiyūskiou stāhā kātlāgang ken hin lā ā il sahailthlaiang: di kalthshint lth kwutung $\mathrm{O}$ Shālānā, David kitu: dī gwudjana hetgwaulana alth kwutungē kinkaladāgung.

23. Waigen kum kil swaunshung alth hangtlan lā il shūtaangang. Lagagahatijanḡè istlāgang, waigen hin lā ltha shūtaiang, lā lth kil kaiit îtil glā il sahailthlas althlā.

24. Waigen hin $\bar{u}$ hangtlan il shouan: Israel tligē lamatoē gūguns kingān edis ou dì il kil kaiidāḡungwau.

25. Il kātlăsken hinū lā $\bar{a}$ singelthkang il gūshū tlidzouang: Shālānā dī ta lth tlāt.

26. Waigen hin hangtlan lā il shūtaiang, lth hāhudila giē shibiligē hà ga nung istiē $\bar{u}$ kum lānḡung.

27. Waigen hinū il shouan: āng Shālānā: 
yenkien hai ishin kwōkungwē nung itlagidas giē tablegē stāhā khhouwesu tāgung.

28. Itan Jesus hin hangtlan il shütaiang, $O$ nung chadas, dung yeta yūanḡung: tliku dung kwudungs kingan agwan lth dung an eda. Waigen ashgē askaskitē gud il gwudjana nūngistlaiang

29. Waigen Jesus stāhā kaiitang ken Galilee tungē an il kātlātalstlo lthdou gwi il kātlaiang ken gu il kouwaiang.

30. Waigen ltha skūla yūan lā an istlāgang: ltha kwollo kōdas isken : ltha hangkagas ishin: ltha kil gūs ishin: ltha tlikiā ishin: waigen ltha stis gwudila ed kwan ishin ltha alth idjan. Jesus stai hetgu ltha ltha istaiang, waigen ltha wautliwan il tlatagwiēlāni.

31. Altsīilth ltha kil gūdsias gūshūs isken: ltha kwollo ködas istalguns ishin: ltha hangkagas kin kingsa ishin: ltha tlikias nūngistlas ishin ltha kāngang tlo, ltha skūlas kaldungāgangang, waigen Israel hāadē an nung Itlagidas an ltha yākwudangang.

32. Waigen Jesus lagagahatijanḡē agang an il aiyangang ken hinū il shouan: ltha skūlas kalthshint dī kwutunḡung, wēata sin lth'unilth gud dì alth ltha isis althlā, waigen kum kin tātlingē ltha daānḡung. Ltha kīsalgundang kum ltha lth kil ïstiēdângshang kūwē gud ltha hāaḡādalsēs althlā.

33. Waigen lagagahatijanḡē hin il shūtaiang, 
tliga dāunga gu kītchistahā shibili hūga kwan talung istāshang $\bar{a}$ ltha skūl yūans skisouēanā. 34. Jesus hin ltha shūtaiang shibili hūga ki kislu dalung daang? waigen hin ltha shouan ki chigwau, waigen skātlink hudila klingān ishin iching.

35. Waigen ltha skūlas tligē inku il kil tlaouang.

36. Waigen shibili hūga ki chigwau isken, skātlingē ishin il istaiang: sing il killāgāni, waigen hē il ginanangang ken lagagahatijanḡe ga il istaiang, lagagahatijangēe ishin ltha skūlas ga istaiang.

37. Ltha wautliwan lthtanouang waigen skisouāni : waigen kwōkungwē gwuda ltha istaiang ken basketgē $\bar{a}$ chigwau staouwaiang.

38. Itlansidas lagwau klālē klālē stung isken, lth chāadāsi ishin, lth hāhudila ishin lthtanouang.

39. Waigen ltha skūlas il kil istiēdang ken kontluwē gwi il kātlïgang, waigen Magadan skwausgiou gu il tlu kātlāgang.

Chaptergē Klāalth wok Lthūunilth.

WAIGEN Pharisee hāadē Sadducee hāadē alth istlāgang, waigen ltha kiānang alth il eddē ltha kil kāngang kaountsida shā stāhā tha il kingdiēanā. 
2. Waigen hangtlan ltha il shūtaiang, singyāstlo sin lāshang dalung shūgunng yeni s'hetsi althlā.

3. Waigen, singai gastlo, aiat zīgulthasang yeni s'het isken waigen yeni lth'alth ishin isis althlā. Yeni hangi an dalung ūnshītung, waigen ashgè timegē kaountsida an gu kum dalung ūnshitāng us ?

4. Gwudistakānḡè dāungas isken waigen chaaigas ishin kin kaountsida gakinḡung, waigen kin kaountsida kum ga istiāngshang, tlan Jonah giē swaunan kin kaountsida iching. Waigen ltha stāhā il kaiitang ken tliga jinga $\bar{a}$ il kaiitang.

5. Tlīstluan lagagahatijanḡè inagūst istlāgang tlo, shibili istiē da ltha kïskitang.

6. Waigen Jesus hin ltha shūtaiang, tuman lth agung kingo, waigen Pharisee hāadē isken Sadducee hāadē ishin giē tlikulthdouwē stāhā lth ga gwudagungo.

7. Waigen gwud alth ltha kwulthilthgangang, waigen hin ltha shouan: kum shibili talung istaanḡun, altsīilth ìtil an il kwutungē stiḡung.

8. Waigen tlīstluan Jesus anūnshitalthstlo hin ltha il shūtaiang, kashintlou gwud alth dalung kwulthilthgungung kum shibili dalung istaangāni althlā. O klingān dalung yetang.

9. Shibili hūga kwu klēlth ìtlansidas lagwau klālē klālē stung wok lagwau klālē klēlth glu èdung kum gu an dalung ūnshitāng us ? waigen 
basketgē à kĩslu $\overline{\mathrm{a}}$ kwōkungwē isis dalung istān kum gu ē dalung kēitāng us ?

10. Kum gu shibili hūga kwu chigwau ittlansidas lagwau klālē klālē stung glu edāngudja? waigen basketgē $\bar{a}$ kīslu $\bar{a}$ kwōkungwē dalung istān ishin kum gu è dalung kēitāng us ?

11. Kashintlou kum an dalung ūnshitānḡung (kumu shibili edde $\bar{a}$ dalung $\bar{a}$ lth kaoukgaanğun) Pharisee hāadē isken Sadducee hāadē giē tlikulthdouwē stāhā ga dalung gwudagungēanā.

12. Itan shibili tlikulthdouwē stāhā ltha ga gwudaḡungē kum il shūtaans an ltha ūnshitālang: Pharisee hāadē isken Sadducee hàadē ishin kin ltha skadadasu il shütaiang.

13. Tlīstluan Ceaserea Philippi aiyuwē giouk gu Jesus kātlāgang tlo lagagahatijanḡè alth hin il kiānangang, kasin nung hāada edu dī is hin ltha shūḡung, dīū nung ìtlinga kitu īching.

14. Waigen hin ltha shouan, John the Baptist dahou is hin ltha tītch shūgung : Elijah dahou is hin ltha tītch shūgung: waigen ltha kalat Jeremiah dahou is hin shūgung: waigen ga prophetgas gē swaun dahou is hin gu hutsu shūḡung.

15. Waigen hin ltha il shūtaiang, kīstho dī is hin dalung shūḡung?

16. Waigen Simon Peter hin hangtlan lā il shūtaiang, Shānungetlagidas hēninga kit Christ dahou ìching. 
17. Waigen Jesus hin hangtlan lā il shūtaiang, Simon Bar Jonah yenkienu dung shūḡung, waigen dung kagunasang: kēā isken ai ishin kum dung ga shūtaanḡun: dī Aung shā isis lthāalgwi dung ga shūdaḡun.

18. Waigen houshen hin dung ga lth shūgung, Peter dahou īching, waigen tīsh kingānu dung èdung; altsiilth dung inku churchnē unga lth tlaoutlāshang, waigen hetgwangē kūwē kum wau gwikāēlthāngshang.

19. Shāgē kingdomgē kīkustlouwē dung ga lth istāshang: waigen hētk tligē gu kin dung kētsgustlasken shā tligē gu ishin kētsguwaushang: waigen hētk tligè gu kin hēsta dung tlāadsken shā tligē gu ishin hēsta ltha adēlthsang.

20. Itan lagagahatijanḡe il stitaiang, waigen Jesus Christ il isis kum nung itlinga ga il shūtātlāngang.

21. Ashgēe timegē stāhā Jesus tliku Jerusalem tligē $\bar{a}$ il kāasēs lagagahatijanḡe il skadadiēdang, waigen lth kīassi isken laplēt ga îtlagidas gē ishin, takālung lēilung ishin il tīlthwandasēs isken lā ltha tiasēs ishin, waigen shantlan lth'unilthstlo houshen il kātlūsēs ishin.

22. Itan, Peter il gidsgildasken lā il stitaiang, waigen hinū il shouan, agwan stigan lth jingāda Shālānā : adshi kum dung ì edāngshang.

23. Waigen lā gwi il kīaiang ken, Peter hin il shūtaiang, Satan, dī tlā lth kā, kin lth gin 
tlidalthtaguns kingānu dī an dung èdung: lth itlansidas kinā ou dung gwudanunḡung, waigen Shānungetlagidas kinā ou kum dung gwudanungānḡung.

24. Wadlu lagagahatijanḡe hin il shūtaiang, nung îtlinga dì tlā kaiitē da kwudungs tlo agwan lth agung il chākwudandādi: skaumā sīk unga il istada dī tlā il kāgēanā.

25. Altsīilth hēninga unga nung kagindasu gūdāshang, waigen dī hagunan hēninga unga nung gūdasu wau kīāshang.

26. Nung ìtlinga tligē askwan gwikāelthsiken waigen hātlandē unga il gūdastlo, gūshū lā gwikāēlthasang? Gūshū nung ìtlinga hätlandē unga saoutk istāshang?

27. Altsiilth nung itlinga kit Aung unga giē kin anyākwudungas isken ga angelgasgē dungalthan ishin langa il kātlāshang, waigen lth hāada wautliwan tliku lthāangwiltlidzus kingān ga il giasouasang.

28. Yenkien dalung ga lth shūgung, ādlun ltha tlazūgians titch kum kwotalthkāngshang nung itlinga kit kingdomgē ai unga il kātlāgē ltha kānḡe kū.

Chaptergē Klāalth wok Chigwau.

WAIGEN shantlan lthūunilth silīd Jesus
Peter istaiang, James ishin, John il tuan ishin, waigen lthdou jing ingwi lā il istaouang. 
2. Waigen ltha hangku adda il edang: juiē kingān il hangi hatgāgang, waigen kin il giandas hatgāguns kingānu addaiang.

3. Waigen kwuking, Moses isken, Elijah ishin lā ga il gūshuwas il kingouang.

4. Wadlu Peter hangtlan hin Jesus il shūtaiang, Shālānāa ādlun an talung itzgēu lāgung: dung gwulāstlo, agwan gioungnē ti lth'unilth lth tlaoutläshang: ti swaun dung̈iou isisang, ti swaun Moses giou isisang, waigen ti swaun Elijah giou isisang.

5. Houan il gūshūgundang, yen addā shā stāhā ltha addu idjang, waigen kwoking, kil yen stāhā hin shouan, anis dī kit kwōyāsi îching, il kil lth kwudungo.

6. Waigen tlīstluan lagagahatijanḡe $\mathrm{kwudā-}$ ngāni tlo ltha hānlthkikukidangang, waigen yenkien ltha lthwaugaiang.

7. Waigen Jesus kātlāgang ken ltha il gidsgildaiang, waigen hinu il shouan; katlüulthā, waigen kum lth lthwaugāngu.

8. Waigen tlisstluan sīk ltha kītlaiang tlo tlan Jesus swaunan kum nung itlinga kalat ltha kingāngang.

9. Waigen houan lthdouwē stāhā ltha istaalgundang, Jesus ltha stitaiang, waigen hinu il shouan, itan kin an kaldunga dalung kingsa kum nung îtlinga ga lth shūdāngo nung ìtlinga kit kwotal stāhā kātluwē kū.

10. Waigen lagagahatijanḡe hin lā alth kiā- 
nangang, kashintlou takālung lēilung Elijah kātlātlāgangshang shūḡung?

11. Waigen Jesus hin ltha shūtaiang, Elijah yenkien kātlātlāgangshang, waigen kin wautliwan il êlthkidāshang.

12. Waigen hin dalung ga lth shūgung, itanu Elijah kātlāgang, waigen kum lā an ltha ūnshitāngang, altsiilth tliku ltha kwudungs kingān lā $\bar{a}$ ltha istaiang. Waikingān nung itlinga kit ishin ltha tilthwangshang.

13. Wadlu John the Baptist il shūtaiang an lagagahatijanḡè ūnshitālang.

14. Waigen tlīstluan ltha skūlas an ltha istlāgāni tlo, nung ìtlinga lā an kātlāgang, waigen $\mathrm{k}$ wollo kats ing alth il kaoustlo hinū il shouan :

15. Shālānā dĩ kit kalthshint lth kwutung il kōnunḡalas althlā, waigen il stiyūanḡung: timegē kwan gud zanoa si il assaḡunḡung, waigen chān ga ishin il atgaḡunḡung.

16. Itan dung gagahatijanḡe $\bar{a}$ lã lth istagun, waigen kum tliku lā ltha tlagũēth tlingē kāng gaanḡun.

17. Waigen Jesus hin hangtlan shouan, $\mathrm{O}$ gwudista kāngē gouan dalung yetaanḡung, waigen dalung käskādsulanḡung; kīslu dalung ga lth tlitisisang, kīsittlu dalung kwulth lth isisang?

18. Waigen Jesus hetgwaulana stitaiang, waigen lā stāhā il kaiitang, waigen gē askaskitē stāhā anung hāhutsūs lāgalāni. 
19. Wadlu lagagahatijanḡē giouk Jesus swaunan idjan gaigu istlāgang, waigen hin lā ltha shūtaiang, kashintlou kum kiak lā talung dangāngudja?

20. Waigen ltha il shūtaiang, kum dalung yetāns althlā.

21. Altsiìlth yenkien dalung ga lth shūḡung, mustard mātlē swaunshung kingān dalung yetastlo, adshi lthdouwē hin dalung shūtāshang, wädshgwau tligē $\bar{a}$ lth is, waigen kingānū isisang, waigen kum kin swaunshung dalung an singētzāngsang. Altsīilth singelthkang gūshū isken kīsal ishin ädang kum hetgwaulana kiak isānḡung.

22. Waigen houan Galilee tligē gu ltha ichingdang, Jesus hin ltha ga shouan; nung itlinga kit lth hāada stlē ik alth ltha giadāshang;

23. Waigen lā ltha tiāsang, waigen shantlan lth'unilthstlo houshen il kātlūdiāshang. Waigen kwunan ltha kwutunge stigangang.

24. Waigen tlīstluan Capernaum tligē gu ltha istlāgāni tlo, ga giasougunungs gē Peter an istlāgang, waigen hin ltha shouan, kum gu dalung ìtlagīia dālā hinawē alth giasouāngus? Waigen Āng hinū il shouan.

25. Waigen nē ik il katsaiang tlo Jesus lā $\bar{a}$ kilthgwultlāgangang, waigen hinu il shouan, Simon, kasino dung kwudunḡung: kītildas sto tligē an ga king gas gē giasou istang? Kiti- 
lung stāhā gwau? tliga kalat hāadē stāhā gwau?

26. Waigen hin lā il shūtaiang, tliga kalat hāadē stāhā. Jesus hin il shūtaiang, lāgung, altsīilth kitilung ākānāgung.

27. Ltha kwutungē talung estigē kum lān$\bar{g} u n g$, altsiilth tunge $\bar{a}$ lth kaiit, waigen lth chān ga touul ista : skātlink sīk dung istatlāgangs lth ista, waigen tlistluan il helthli dung kisistlastlo dālā kēskwau dung kiāshang : washt lth istang, waigen di saoutk wēata ltha ga lth istang, waigen dāha ishin.

Chaptergē Klāalth wok Stanshungā.

A SHGĒ askaskitē gud lagagahatijanḡē Jesus $A$ an istlāgang, waigen hin ltha shouan, shā tligē gwau kisstho ìtlagida sitlthlīgung.

2. Waigen nungihutsūs an àgang il aiyangang, waigen ltha yākwusiā lā il istaiang,

3. Waigen hinū il shouan, kum kwutungē unga dalung stîlthtānstlo, waigen kum hīhudila kingān dalung èlthānstlo, kum tliku shāgē kingdomgē gu dalung istlā tlingē kāng gaanḡung.

4. Altsīilth kīstho anung hīhutsūs kingān kwutungē unga edasken laou shāgē kingdomgē gu itlagida sitlthlissang.

5. Waigen kistho $\bar{a}$ lth hīhudila swaun dì kēyi à istasken, dī ishin il istāshang. 
6. Waigen kīstho $\bar{a}$ lth hīhudila dì yetas swaun kwutungē kil stistlo, kwau kikōna il hēel addu ltha istiēū lā an lāgung, waigen tligèlthdīinga $\bar{a}$ il chātlādē $\bar{u}$ lāgung.

7. Kin lth gin tlidaltas hagunan adshi tligē dāungang! Yenkien kin lth gin tlidaltas althgwi itzgē $\overline{\mathrm{u}}$ lāḡung, waigen kin lth gin tlidaltas althgwi nung itlinga istas laou dāungang.

8. Dung stlē isken dung stai ishin dung tladiltadasken, washt lth ketsitla, waigen stigan lth dāng : hēningā $\bar{a}$ stlē unga chis swaun isken stai unga chis swaun ishin alth dung kāgēū dung an lāgung, waigen dung stlè chis stung isken dung stai chis stung ishin kum zanoa hēninga swaunung ai isāngasang.

9. Dung hangi dung tladiltadasken, lthaalgwi lth ista, waigen stigan lth dāng; hangi unga ska swaunshung alth hēninga $\bar{a}$ dung kāgē $\bar{u}$ dung an lāḡung, waigen dung hangi ska stung kum hetgwaugē zanoa ai isāngasang.

10. Tuman lth kingo, waigen $\bar{a}$ lth hīhudila swaun ga kum lth gwouwāngu : yenkien dalung ga lth shūgung,

11. Ltha hants dī Aung shā isis hangi king giīgung. Altsīilth nung ìtlinga kit ga gūs gē kagindiē an kātlāgang

12. Kasino dalung kwudunḡung: nung itlinga lamatoē lagwau klēlth daastlo, waigen nung swaunshung tligwan an kaiitstlo, kum gu klālē klāalthswansinḡu wok klāalthswansinḡu il 
tastlaang us? waigen kum gu lthdouwē $\bar{a}$ il kaiitāng us nung gouan da il kānḡēanā ?

13. Waigen lāil kiastlo, yenkien dalung ga lth shūḡung, lamatoē klālē klāalthswansinḡu wok klāalthswansinḡu kum tligwan an istalğungàngang telgu lā alth il kwutungē lātlingāgung.

14. Waikingān dalung Aung shā isis kum ā lth hīhudila swaunshung gougè ga istatlānḡung.

15. Waigen dung kwai dung an kin dāunga istasken, la $\bar{a}$ swaunan Ith kāa, waigen kin il hadlous lth lā ga shūda: dung kil il kwudungstlo dung kwai dung gwikāēlthasang.

16. Waigen kum dung kil il kwudungānstlo, ltha swaunshung, ltha stung katdung lth ista, waigen ltha stung ltha lth'ūnilth dung kil wautliwan kwudungsang dung kil wautliwan kladskaḡean.

17. Waigen ltha kil kwudungē à il tastlastlo, church hāadē ga lth shüdo, waigen church hāadē kil kwudungē à il tastlastlo agwan dung an il hetgwaulana hāadāda, waigen nung giasougunungs ishin.

18. Yenkien dalung ga lth shūgunng, kin wautliwan hētk tligē gwau dalung kētsitāshang shā tligē gwau kētsgūwaushang: waigen hētk tligē gwau kin wautliwan hēsta dalung tlāadsang, shā tligē gwau hēsta adadāsang.

19. Houshen yenkien dalung ga lth shūḡung, hētk tligē gwau dalung shu stāhā ltha stung 
kin ga kīānungē an kwutungē swaunshungstlo, dī Aung shā isis ltha an istāshang.

20. Tlistluan ltha stung, ltha lth'ūnilth dì kēyi $\bar{a}$ kwudungalth gwuda isistlo tlaou ishin ltha yākwusi à isisang.

21. Wadlu Peter kātlāgang, waigen hinū il shouan: Shālānā, dī kwai dī kwutungē kil sti kīslūstlo waigen da agung lth kiskitāshang, timegē chigwau gwau?

22. Jesus hin il shūtaiang, timegē chigwau kum hin dung ga lth shūānḡung; timegē klālē chigwau ellthsittlu lth ga agung kīskita.

23. Altsiilth shāgē kingdomgē nung king gas kingānu edāni, waigen kitzadalung dālā kwaiundiē ga il kwudangang.

24. Waigen tlīstluan il kwaiundiēdāni tlo, nung swaunshung dālā lagwau klālē klēlth lthakākidang là à ltha istaiang.

25. Waigen kum kin alth il giasoutlingē kāng gaans althlā, il îtlagīda lā alth giadahālang, il chā ishin, il kitilung ishin, waigen kin il daas wautliwan ishin, waigen alth ginggang il giasougēanā.

26. Waigen anung kitzadas kwollo kats ingalth il kaoung ken singelthkang hin la $\bar{a}$ il gūshouang: Shālānā kwai lth dī an agung kwutgulthsuwādi waigen dung ga lth saouodzüashang.

27. Waigen itan anung kitazadas an nung îtlagidas lā kilth kalthshint gwālang ken kin 
tlan lā il ēlthtaiang, waigen il lthakākidang wautliwan ga agung il kin kiskitang.

28. Anung kitzadas itan kiak kāgwālang, waigen lā alth ga kitzadāgang swaun il kāngang tlo lā il gidsgildasken il kāgunzu langa il gidsgildaiang; waigen hin $\bar{u}$ il shouan, dung lthakākidung lth dì ga saou. Althanisu centgē klālē klālth langa lthakākidang.

29. Altsīilth lā alth nung kitzadāgang kwollo unga kats ingalth il kaoung ken singelthkang hin lā $\bar{a}$ il gūshouang, kwai lth dì an agung kwutgulthsuwādi, waigen dung ga lth saouodzuashang.

30. Kum ga il istatlāngāni, waigen kētsitnē à lā il istaiang lthakākidē il saougēe ku.

31. Altsīilth tlīstluan lā alth ga kitzadāgang tliku il waus langa ltha kāngang tlo yenkien ltha kwutungē stigang. Etlagida unga à ltha istālang, waigen tliku il waus wautliwan hansta langa ltha shouan.

32. Itan il itlagīda silīd lā an aiyangang; waigen hin lā il shütaiang, kitzada dāungou dung ìching: dung lthakākidang wautliwan da agung lth kin kîskituni dī alth da dung kiānunḡuni althlā.

33. Kashintlou dung kilth kalthshint lth kwutunḡun kingān kum dung alth nung kitzadāgang kilth kalthshint dung kwutungāngüdja?

34. Waigen il itlagĩda kātliyildaiang tlo 
kētsitlēilung ga lā il istaiang il lthakākidang wautliwan la ga il saougē ku.

35. Dalung kwaialung kin dāunga dalung an istas kum kwutungē unga stāhā ga agung dalung kīskitānstlo: kingān dalung Aung shā isis dalung an istāshang.

\section{Chaptergē Klāalth wok Klāalthswansinḡu.}

WAIGEN ashgē gūshouwē Jesus shūda ēlthkīgang tlo, Galilee tligē stāhā il kaiitāni ken Judea tligē gưìl kātlāgang Jordan hantlā ;

2. Waigen ltha skūla yūans lā tlā istiēdang, waigen gaigu ltha il tlatagwiēlang.

3. Pharisee hāadē lā an istlāgang, waigen il eddē ltha kil kāngang: hin lā ltha shūtaiang; kin dāunga wautliwan hagunan nung itlinga chā unga dānḡē gu lā us ?

4. Waigen hin hangtlan ltha il shütaiang, kum gu dalung readadāngudjang? awolth nung itlinga isken nung chada ishin il tlaoutlāgangang $\bar{a}$.

5. Waigen hinu il shouan, $\bar{a}$ kin isis hagunan nung itlinga aung unga isken ou unga ishin tastläshang, waigen chā unga alth il stung gīishang: waigen ltha stung kēè swaunshung isilthasang.

6. Altsiilth kum houshen il stungwaangshang: kēà swaunshung il isīlthawang: kītildou 
Shānungetlagidas gwudga tlāaskīdang, agwan kum nung ìtlinga gwudistāhā il istawāngda.

7. Wadlu lā ltha shūtaiang, kashintlou Moses gwudistāhā ltha itzgè kālungē gwudga ltha il istalthudjang? waigen gwud ltha dāngwēanā.

8. Hin ltha il shūtaiang, dalung kwutungē katsas althlā chā unga dānḡē alth Moses dalung kingwogangang: tlaglu agwi kum hin edāngāni.

9. Waigen tlaou dalung ga shūgung: kīstho chā unga dānḡung, kum il lagāansken an, waigen nung kalat il inēlthstlo hinganu lā alth il tīgādāsang. Kīstho nung ltha dāngs inēlgung lā ishin hinganu lā alth tīgādāshang.

10. Lagagahatijanḡe hin il shütaiang, nung ìtlinga kum tliku chā unga dāng tlingē kāng gaansken, lā alth gu il inalēu kum lānḡung.

11. Waigen ltha il shütaiang, lth hāada wautliwan kum tliku adshi gūshouwē ista tlingē kāng gaanḡung: titch ga istiāsi swaunanu istāshang.

12. Altsīilth ltha tītch chāadasu ltha oualung kaiyugungung: waigen ltha itlansidou ltha tītch tlachāadāgung: waigen shāgē kingdomgē hagunan ltha tītch chäadasu tītch hin ltha chāadādang. Istiē an nung tagwias lth agwan il istada.

13. Wadlu ltha hīhudila lā an ltha kēlthilangang ltha inku stlē unga il istiēanā, waigen singelthkang il gūshūgēanā: waigen lagagahatijanḡe ltha $\bar{a}$ stakīdang. 
14. Waigen Jesus hin shouan, agwan lth hīhudila dī ā istaldo, waigen kum ltha $\bar{a}$ stakidāngu : shāgē kingdomgē gu hāagè isis althla.

15. Waigen ltha inku stlē unga il istaiang, waigen stāhā il kaiitang.

16. Waigen kwoking, nung swaunshung lā an kātlāgang ken hinu il shouan, Nung ētlagida las, gūshū lou lth istāshang hēninga swaunung ltḥ dāagēanā?

17. Waigen hin lā il shūtaiang, kashintlou lā hin dì dung kēyādung ? kum nung swaunshung lānḡung tlan Shānungetlagidas swaunanu lāğung: hēninga an kātlāgē da dung kwudungsken, kingwoguns lth tumanking.

18. Lā il shūtaiang, kishgaiu? Waigen Jesus hin shouan, kum lth hāada tiāng: kum lth chāgāng: kum lth kwolthtāng: kum ltha kil hansta kwaiēdungāng.

19. Aung unga isken ou unga ishin lth ga gwudgīd: waigen tlu unga dung kwōyādas kingān dung kwulth ltha naans lth kwōyāda.

20. Anung itan innas hin lā il shūtaiang, $\bar{a}$ kin isis wautliwan tuman lth kinğuni. Gūshgu wēatu ga dī statlang?

21. Jesus hin il shūtaiang; kwutungē swaunshung istiē da dung kwudungstlo, kin wautliwan dung dāas alth lth giadou wē, waigen ltha kuniskidēga ga lth ista, waigen shā tligē gwau kin kwōyas dung daāshang, waigen althgwi isanga dì tlā lth kā. 
22. Tlīstluan anung itan innas ashgē gūshouwē kwudangang tlo, il kwutungē stis dungalth il kaiitang, tligē kwan il daaiang althlā.

23. Waigen Jesus lagagahatijanḡe hin il shūtaiang, yenkien dalung ga lth shūḡung, shāgē kingdomgē gu nung kintlingā kātlāgē singētzang.

24. Waigen houshen hin dalung ga lth shūḡung, shāgē kingdomgè gu nung kintlingā kātlāgè telgu kintīga yūans stlin kwusi heèlā kalthgwīd kāgē yāngulang.

25. Waigen tlīstluan lagagahatijanḡe kwudangang tlo ltha kwutunge kaldungāgangang, waigen hin ltha shouan kashinlth edlon kagunāsin?

26. Waigen Jesus ltha gwi il kiaiang, waigen hin ltha il shūtaiang, à kin isis ìtlansidā an singetzang, waigen Shānungetlagidas an kin wautliwan yāngulang.

27. Wadlu Peter hangtlan shouan, waigen hin lā il shütaiang, kwoking, kin wautliwan stāhā unga talung istiēdang, waigen dung tlā talung istalgung: gūshū talung istāshang?

28. Waigen Jesus hin ltha il shütaiang, yenkien dalung ga lth shūḡung, tligē houtla gu, tlīstluan nung îtlinga kit aulthkaaungwē anyākwudungā inku unga il kouwastlo, dì tlā dalung istals dalung ishin aulthkaaungwē lā inku tluadāshang, waigen Israel gwaigangē klāalth wok stung dalung ginkilislangshang. 
29. Ltha wautliwan han nē isken, kwaialung ishin, tūanalung ishin, chasalung ishin, aungalung ishin, oualung ishin chāalung ishin, kitilung ishin, tligē ishin dī kēyi hagunan ltha tastlastlo, wausilthka lagwau klēlth telgu ltha gwi kāēlthasang, waigen hēninga swaunung ishin ltha daāshang.

30. Lth hāada kwan kwuniātlāgangs gaiu otgwau isîlthasang, waigen otgwau ga isgē kwuniē ēlthasang.

\section{Chaptergē Lagwau Swaunshung.}

\HĀGĒ kingdomgē nung îtlinga nalēgā kin( gānu ēdung, waigen singaian nung kāḡwālanā lthāangwilēilung vine lthkai kwulthkadazi $\bar{a}$ unga il istiēanā.

2. Waigen sin gud cent swaunshung ltha ga il giasouses an ltha il ūnshitalthtaiang tlo, vine lthkai kwulthkadazi ā unga ltha il kil istiēdang.

3. Askaskit klāalthswaunsingūistlo kiak il kāḡwālang, waigen giouk waddanē isis kwulthkadazi gu ltha kalat skunsalungā tlazūgiangs il kāngang.

4. Waigen ltha il shūtaiang, dalung ishin vine lthkai kwulthkadazi à lth istiēdo, waigen tliku an kin lā ed dalung ga lth istāshang. Waigen kūwē gud unga ltha istiēdang.

5. Waigen askaskit klāalth wok stung talstlo, 
waigen askaskit lth'unilthstlo houshen kiak il kāḡ wālang, waigen houshen kingān il shouan.

6. Askaskit klēlthstlo kiak il kāộ̂ālang, waigen ltha kalat skunsalungā tlazūgians il kāngang: waigen hin ltha il shūtaiang, kashintlou ādlun sin saasgud skunsalungan dalung tlazūgianğung.

7. Hin lā ltha shutaiang, kum nung itlinga lthāangwiliē îtil ga istaansi althlā.

8. Ltha il shütaiang, dalung ishin vine lthkai kwulthkadazi $\bar{a}$ lth istiēdo, waigen tliku an kin lā ed dalung istāshang.

9. Tlīstluan sinyāstlo, vine lthkai kwulthkadazi an nung itlagidas kin wautliwan tuman langa nung kings hin il shūtaiang, ga lthāangwilas gē an lth aiying, waigen lthāangwiliē ltha ga lthanga saou ista: otgwau ga lthāangwilas gē ga lth giasou tlāgang, waigen kwunā gē ga lth otgwau giasou.

10. Askaskit klēlth lastlo ga lthāangwilā tlāgang gē centgē swaunshung wu istaodzouang : ga lthāangwilā tlā tlāgangang gēu wautelgu wu istāshang kwudangang, waigen gē ishin waikingān centgē swaunshung wu istaodzouang.

11. Tlisstluan ltha istaiang tlo nēlē ltha kilthwangang,

12. Waigen hin ltha shouan, otgwau ga lthāangwilas gē askaskit swaunshung gud swaunan lthāangwilgun, waigen îtil kingān ltha ga dung giasouḡun juiē kousta yūanstlo, yenkien 
sin saasgud talung lthāangwilgun, waigen kashintlou kum wautelg ìtil ga dung giasouāngung?

13. Waigen nung swaunshung ltha shu hin il shütaiang, toui, kum dung lth tlaoulthdaungānḡung : kum gu cent swaunshung sing sin gud dì an lthāangwiliē an dung kwutungē lāngudjang?

14. Oudshi lth unga ista, waigen $k \bar{u} w \bar{e}$ gud .lth unga kaiit: tliku lth kwuduns kingān lth waushang, waigen dung ga lth giasous kingān $\bar{a}$ otgwau ltha isis ga lth giasouasang.

15. Tliku kin an unga lth kwudungs kingān lth istiè gu kum dī an lāng us? Dung hangi gu dāungā us ? dì hangi lâsi althlā.

16. Altsiilth ltha kwuniā tlāgangs gaiu otgwau isisang, waigen ltha otgwau hāadē gē ishin kwuniē èlthasang. Kingānu ga ostlas gē kwuniāsang, waigen ga kwunias gē ostlāsang. Lth hāada kwan an aiyingāgung, waigen ltha gū kingstiāgung

17. Waigen Jesus Jerusalem tligē à il kaiitālang tlo, kūwē in lagagahatijanḡè il istaiang, waigen hin ltha il shutaiang:

18. Kwoking, Jerusalem tligē à talung istiēdasang, waigen nung itlinga kit ga laplet itlagidasgē isken, takālunglèilung ishin ga alth ltha giadāshang: il kwōtalēanu lā ltha ginkilislungshang: siliā, tliga kalat hāadē ga lā ltha istāshang lā alth ltha nangasilungēanā. 
19. Lā ltha tilthwangēanā, lā ltha zitokliskidēanā, waigen shantlan lth'ūnilthstlo houshen il kātlūshang.

20. Wadlu Zebedee kitilung ou lā an kātlāgang il kitilung dungalthan: lā $\bar{a}$ singelthkang il gūshūstlo lā alth kin da il kiānangang.

21. Waigen hin lā il shūtaiang, gūsh gu dung istatlang? Lā il shūtaiang, dunḡiē kingdomgēè gwau dī kitilung stung tluadiē alth takingwoḡung : nung swaun dung soolgūst isken nung kalat dung stlangūst itzgēanā.

22. Jesus hin hangtlan shouan, kin da dalung kiānungs anu kum dalung ūnshitānḡung. Skatlang aist lth hutlaungkasēs aist hutliēan gu dalung tagwiā us ? Waigen baptismgē alth dī baptaizdias alth baptaizdigēan gu dalung tagwiā us ? Lā il shūtaouang an itil tagwiāgung.

23. Hin lā il shūtaouang, yenkien kiagin skatlangwē aist dalung hutlāshang : soolgūst dī kwulth kouwiē isken, stiangūst dī kwulth kouwiē ishin dalung ga lth istiēan kum kiagin isānḡung: kitildou an ltha dì Aung êlthkidasi $w \bar{u}$ istawaushang.

24. Tlīstluan ltha klāalth kwudāngāni tlo, kwaialung stung an ltha kātliyilthdaiang.

25. Waigen Jesus ltha an aiyangang, waigen hinū il shouan, ltha haldungsidāan ltha istaḡuns tliga kalat hāadē an ga princesgas gēu an dalung ūnshitung; waigen ltha hangast ga itlagidasgē kilth kingān ltha waugunḡung. 
26. Kum waikingān dalung shu edāngshang: kīstho dalung shu itlagidagè da kwudungstlo, agwan dalung kitzadou il isisang: waigen kīstho dalung shu kwuniāgē da kwudungstlo agwan dalung haldunga il isisang.

27. Waikingān nung ìtlinga kit kum an lthāangwilangēan kātlātalgun :

28. Il lthāangwilēan il kātlātalgun, lth hāada kwan hēninga unga alth il dakgēanā.

29. Waigen Jericho tligē stāhā itan ltha istiēdungdang ltha skūla yūan lā'ttā istālang.

30. Waigen kwoking, ltha hangkagas stung kūwē in tluadaiang kin il ginungāwēanā. Jesus kägians il kwudungwastlo hinū il sahaigaouang, Shālānā David Kit, ìtil kalthshint lth kwutung.

31. Waigen litha skūlas lā $\bar{a}$ stakidaouang tlan il gūshūūwēanā: waigen houshen hin il șahaigaouang, Shālānā David Kit, ìtil kalthshint lth kwutung.

32. Waigen Jesus giāgang ken lã an il aiyingouang: waigen hinū il shouan, gūsh dalung an lth istiè gu dalung istatlang ?

33. Lā il shūtaouang, Shālānā, ìtil hangi helthilthgiēan.

34. Altsiilth Jesus lã kalthshint il kwutungouang: il hangi il gidsgildaouang tlo houitang kin hangi unga alth il kingouang, waigen là tlā il istiēdouang. 
Chaptergē Lagwau Swaunshung wok Swaunshung.

W AIGEN tlīstluan Jerusalem tligē an ltha istlātālang tlo Bethphage tligē gu ltha idjāni Olives lthdouwē gwud ltha itzgēanā.

2. Jesus lagagahatijanḡē stung il kil istiēdang ken hin lā il shūtaouang, wadshgwau lana is a lth istiēdwang, waigen houitang kuitan k $\mathbf{x} \overline{\text { jinda }}$ knūtlitajas dalung kiāshang, il kīti ishin lā kwulth isisang. Lā hēsta lth tlātwang, waigen althgwìk dī à il istawang.

3. Waigen nung itlinga tliku han dalung shūtastlo, hin dalung ishin shūasang, Shālānā lā ga stalthawangwau, waigen houitang dì à lā il istawāsang.

4. Wadlu, tliku awolth nung prophetgas shouan kingān kin wautliwan edang: waigen hinū il shouan :

5. Sion gwudjana ga hin lth shūū, kwoking, dung an nung King gas kwutungē hēt eds dung an kātlātalgung kuitan k $\bar{u}$ jinda inku il kouwang, waigen kuitan kz̄ jinda kīti an ishin.

6. Lagagahatijanḡe istiēdang, waigen tliku Jesus il shūtaouang kingān il wauouang.

7. Kuitan kū jinda isken il kïti ishin il istaouang, waigen kin il giandawas unga lā inku il istaouang ken gē inku lā il istaouang.

8. Waigen ltha skūla yūan kin ltha giandas 
unga kūwē kalthgūd ltha dungtānaḡangang: waigen ltha kalat ishin lthkumal ltha skitawiğangang, waigen kūwē kalthgūd ltha kouwanstlağangang.

9. Ltha skūlas lā kwunast ltha istalsken lā tlā ga is gē ishin hin katzouang, David Kit isis $\bar{a}$ lth killou. Shālānā kēyi à nung kātlās lāḡung. Kwunan lā à lth killou.

10. Waigen tlīstluan Jerusalem tligē gu il kātlāgang tlo, ilnigē hāadē kaldungā odzouāni, waigen hin ltha shouan, kīstho īching?

11. Waigen ltha skūlas hin shouan, anis, Jesusu îching. Nazareth tligē Galilee tligē gu nung Prophetgāgang.

12. Waigen Jesus Shānungetlagidas giē churchnigè ai katsaiang, waigen lth hāada wautliwan kin alth ltha giadawas isken, kin ltha dāawas ishin kiak il dāngwāgang : tablegē inku dālā idjan ishin il skohastlaiang, waigen kaltsida alth ltha waddas giē aulthkaaungwē il skwolthgaduldangang.

13. Waigen hin ltha il shūtaiang ū kālungāḡung, kiagin nē singelthkang' gūshou nē hinū kēyāsang, waigen kwolthta nē an dalung tlaou'tlaiang.

14. Waigen churchnige $\bar{a}$ ltha hangkagas isken ltha kwollo kōdas ishin lā an istlāgang, waigen ltha il tlalāgālāni.

15. Tlīstluan ga laplēt îtlagidasgē isken takālunglëilung ishin kin an kaldunga il tlaoutlıs 
kāngang tlo, waigen th hāhudila churchnai à isis David Kit à lth killou hin shūs ishin ltha kwudangang tlo, ltha kwutunge kātliyilthdaiang.

16. Waigen hin lā ltha shūtaiang, $\bar{a}$ ltha shūs gu dung kwudung? Waigen Jesus hin ltha shütaiang, āng, lth hīhudila helthli stāhā isken ga tlinsgēe helthli stāhā ishin killāgē lā yūan dung istaiang kum gu dalung readadāngudjang?

17. Waigen ltha stāhā il kaiitang: ilnigē ishin stāhā il kaiitang Bethany tligē àă, waigen gaigu il haldaiang.

18. Singaiḡastlo ilnigē gwi il stēlang tlo il kwotagālang.

19. Waigen kūwē duul ā fig lthkai isis il kāngang tlo ā il kāgang, waigen yhil swaunan lā ì kous il kiaiang, altsiilth hinū il shouan, ashgē shantlanē stāhā agwan kum hāna dung inku houshen inastla swaunungānda. Waigen houitang fig lthkai sahādungkilthistlaiang.

20. Waigen lagagahatijanḡe kāngang tlo ltha kaldungāgangang, waigen hin ltha shouan, kashintlou houitang fig lthkai isis sahädungkilthistlou üdjang.

21. Waigen Jesus hangtlan ltha il shūtaiang, yenkien dalung ga lth shügung, dalung yetastlo, waigen kum à dalung gwudukikitānstlo, tliku adshi fig lthkai gē isisi kingān dalung kin istāshang: waigen adshi lthdouwē hin dalung 
shūtasken sīk lth is, waigen chān ga lth is, hin dalung shūtasi kingānu ĩchingsang.

22. Waigen kin wautliwan an singelthkang gūshou ā dalung yetasi hin da dalung kiānungsken dalung istāshang.

23. Waigen tlīstluan churchnigē ai il katsaiang tlo houān il taskadadagundang, ga laplēt itlagidas gē isken, ltha kiāsi ishin lā kwulth istzaiang: waigen hin ltha shouan, kist tagwiāgē hanstu $\bar{a}$ kin isis dung ïstang waigen kīstho adshi tagwīgē dung ga istaiang ?

24. Waigen Jesus hin hangtlan tha il shūtaiang, tlaou ishin kin swaunshung da dalung alth lth kiānungsang, waigen hangtlan dī ga dalung shūtastlo, nung tagwias hanstu $\bar{a}$ kin isis lth istas tlaou ishin dalung ga lth shütāshang.

25. John giē hānlthē kwōyāsi kïtchistā idjang? shā stāhā gwau? ltha ìtlansidas stāhā gwau? Waigen gwudalth ltha kwulthālang waigen hin ltha shouan, shā stāhā hin talung shūsken, kashintlou kum lā dalung yetāngūdjang hin îtil il shūtāshangwau?

26. Ltha ìtlansidas stāhā hin talung shūsken, ltha skūlas ga itil lthwaugung, John nung, Prophetgas ishin ltha kwudungsi althlā.

27. Waigen hangtlan hin Jesus ltha shūtaiang, kum hansta talung shoutlingānḡung. Laou ishin hin ltha il shütaiang, nung tagwias hanstu $\bar{a}$ kin isis lth istas kum dalung ga lth shūtāngshang. 
28. Waigen kasino dalung kwudungung? Nung itlinga kitilung stāngang: waigen il kit kwaias an il kātlāgang, waigen hinū il shouan; lthkin, aiata vine lthkai $\mathrm{k} w$ ulthkadazi $\bar{a}$ lth di nā lthāangwilā.

29. Waigen kum $\bar{a}$ lth kaiitāngshang hinū hangtlan il shouan: waigen siliā kwutungē unga il stīlthtaiang waigen $\bar{a}$ il kaiitang.

30. Il kit tuanas an il kātlāgang, waigen kingān il shouan. Waigen hinū hangtlan il shouan, Nung itlagidas, $\bar{a}$ lth kaiitshang, waigen kum $\bar{a}$ il kaiitāngang.

31. $\bar{A}$ ltha stung isis kinasu tliku il aung kwudungs kingān waugang? Ltha shouan nung kwaias. Jesus hin ltha il shūtaiang, yenkien dalung ga lth shūgung, giasougunungalēilung isken, ga laaigas gè ishin, Shānungetlagidas giē kingdomgē $\bar{a}$ dalung kwunasta istalashang.

32. John kūwē lās gud dalung an il kātlāḡang, waigen kum lā dalung yetāngāni: giasougunungalēilung isken, ga laaigas gē ishin il kil yetaiang: tlīstluan dalung kāngang tlo kum siliā dalung kwutungē unga stîlthtaangang il kil dalung yetiēanā.

33. Houshen lth kigang kalat kwudungu: nung nēlē gāgang vine ltbkai tlidzaiang, waigen addu il kwulthkadajang, waigen vine tlaoutlouwe ishin kātli $\bar{a}$ il tlaoutlaiang, waigen nē kladska ishin: tuman vine lthkai ltha kingsa 
il shildadaiang, waigen tliga jinga $\bar{a}$ il kaiitang.

34. Waigen tlīstluan hāna ltha lthīìdtalsītlo, tuman vine lthkai langa ltha kingsa $\bar{a}$ kitzadalung il kil istiēdang hāna langa washt tha istiēanā.

35. Waigen tuman vine lthkai ltha kingsa il kitzadalung istaiang: nung swaun ltha skodangang: nung swaun ishin ltha tīaiang, waigen nung kalat ishin kwau alth ltha kuntlouang.

36. Houshen kwunāgē telgu kitzadalung adda il kil istiēdang, waigen gē ishin waikingān ltha istaiang.

37. Otgwau agwi kit unga ltha ā il kil kaiitang, waigen hinū il shouan dī kit à ltha knōgāsang.

38. Waigen tlīstluan tuman vine lthkai ltha kingsa il kit kāngāni tlo hin gwu ltha shūtaiang, anis, lā silthnāsang: ōtlā lā talung tīadzing, waigen tligē lā talung istadzing.

39. Là ltha gidsgildaiang, waigen vine lthkai gē kwulthkadazi stāhā lã ltha dāngang, waigen lā ltha tīaiang.

40. Altsiilth vine lthkai tligē an nung itlagidas kātlāstlo, kasino vine lthkai tuman ltha kingsa il edāsang. Hin lā ltha shūtaiang,

41. A ltha dāungas gē wautliwan il tlitāshang, waigen vine lthkai kwulthkadazi tha kalat unga il shildadāshang, waigen hānē lā ga langa ltha istāshang hānē lthīīdgīstlo. 
42. Jesus hin ltha shütaiang, kum gu Shānungetlagidas giē kōgīnē $\bar{a}$ dalung readadāngūdjang? Kwaunē tlaoutlalēilung adshi kwauē dāngāni kwungut an kats ēalang. Shālānā waugăang, waigen kin an kaldungou itii hangā ìching.

43. Altsīilth dalung ga lth shūḡung, Shānungetlagidas giē kingdomgē dalung stāhā istiāshang, waigen lth hāada lā gud hāna lā inastlas ga istiāshang

44. Kistho adshi kwau inku tlidaltastlo aisī idasang: waigen kīsta ingwīu adshi kwauē kīwītelgung kwiē kingānu il zilthūstāshang.

45. Tlīstluan ga laplēt itlagidasgē isken Pharisee hāadē ishin il kīgangs langa ltha kwudangang tlo ltha adde $\bar{a}$ il shūs an ltha ūnshitālang

46. Waigen tlīstluan il gidsgildiē da ltha kwudangang tlo, ltha skūlas ga ltha lthwaugaiang, nung prophetga il ishin ltha kwudāngāni altblā.

Chaptergë Lagwau Swaunshung wok Stung.

TMAIGEN Jesus hangtlan shouan, waigen kigangē alth ltha ga il kīgangang.

2. Shägēe kingdomgē nung king ga kingānu ēdung, waigen gwü inēl lagunungē kit unga an il tlaoutlaiang. 
3. Waigen ltha wautliwan ga il shūtaiang il lagunungasēs : kin hansta lagunungasēs wautliwan êlthkīsitlo îtan kitzadalung il lagunungādaiang, waigen kum lagunung kāagē gu ltha istatlāngang.

4. Houshen kitzadalung adda il lagunungàdaiang, waigen kitzadalung hin il shūtaiang, ltha an lth aiyingun ga lth shüdo; kwoking lagunungē lth tlaēlthkiḡun, kiagin musmusgē isken, kiagin kin aia ishin lth tlitaḡun, waigen kin wautliwan ēlthkīḡun, altsîilth gwū inē lagunungē ai lth istzoo.

๖. Waigen ltha kāğangang, waigen kūwē gud unga ltha istiēdang, nung swaun mūsmūs tligē gwi unga il stēlang: nung kalat waddanē $\bar{a}$ unga il kaiitang:

6. Waigen ltha kalat il kitzadalung istaiang ken ltha ltha tilthwangyūanḡangang, waigen ltha ltha tlitaiang.

7. Waigen tlīstluan an nung king gas kwudangang tlo il kātliyilthdaiang: soldiergasgēe kwan yūan il kil istiēdang, waigen à ga lagunungas gē ga tlitaiāni gè ishin ltha tlitiēdāni, waigen ilnige ishin lthanga ltha hokulthtaiang.

8. Wadlu hin kitzadalung il shūtaiang, gwū inēl lagunungē èlthkīgoun, waigen àgīan tha aiyingsu kum lānḡung.

9. Altsiilth kūwē kwun à lth istiēdo, waigen ltha wautliwan dalung kings kingān gwū inēl lagunungē $\bar{a}$ ltha kil istiēdo. 
10. Yenkien il kitzadalung kūwē kwun ā istiēlang ken ltha wautliwan ltha kingskialk ltha ltha istaḡangang: ga lās gē isken ga dāungasgēe ishin, waigen gwudlth inēlths roomgē lth hāada alth stāougāḡang.

11. Waigen tlīstluan anung king gas ài katsaiang tlo touilung il kānḡēanā, nung swaunshung nung chādūnēlths kinā kum il giandāns il kāngang.

12. Waigen hin lā il shūtaiang: toui, kasino nung chādūnēlths kinā kum dung giandānskenan ai dung katsouūdjang? Waigen il kil gouang.

13. Itan anung King gas hin kitzadalung shūtaiang: il yhē isken il kwollo ishin langa yātselthto, wadshgwi lth il isto, waigen giouk halgas gē à lth il dāngu, wiouk sahaigāsēsi gwau, waigen zing unga kōkopitāsēsi gwau ishin.

14. Altsīilth lth hāada kwan an aiyingāḡung, waigen ltha gu kingstiāgung.

15. Wadlu Pharisee hāadē kiak issāgang tlo ltha counselgāgang tliku il kil da langa ltha dungdā̄wunasēsā eddē ā.

16. Waigen kitzadalung Herodias hāadē alth lā $\bar{a}$ ltha kil istiēdang, waigen hin ltha shouan : Nung itlagidas, yenkien dung shūs an itil ūnshītung, waigen Shānungetlagidas giē kūwē yenkien ltha dung skadadang: ltha itlansida ishin alth kum dung aiyuānḡung, ltha îtlansida tlu addu kum dung kwulthilthānḡung. 
17. Tliku dung kwudungs lth îtil ga shūdi : giasou dālā Caesar ga talung istiē gu lā us ? kum gwau?

18. Waigen ltha kwutungēe dāungas an Jesus ūnshitālang tlo hinū il shouan: kashintlou dì eddē dalung kil kinḡung?

19. Dalung kwutungēstungs, giasou dālē dī lth kingdo. Waigen centgē swaunshung lā à ltha istaiang.

20. Waigen hin ltha il shūtaiang, kīstā danījingaiu ìching, waigen kasin kālungē edu iching ?

21. Waigen Caesar giē hin lā ltha shūtaiang. Wadlu hin ltha il shūtaiang, Caesar kinā isis lth Caesar ga lth isto: Shānungetlagidas kinā isis tlou lth Shānungetlagidas ga lth isto.

22. Waigen tlisstluan ltha kwudāngāni tlo ltha kaldungāgangang, waigen lā stāhā kūwē gurl unga ltha istiēdang.

23. Ashgē shantlan̄̄ tlo Sadducee hāadē lā an istlāḡang: kum kwōtal stāhā lth hāada kātlūāngān ltha shouan.

24. Waigen hin lā alth ltha kiānangang, Nung itlagidas, nung itlinga kwōtalsken, kum il kit kaiānsken il tuan il chā alth gu inēlthasang, waigen kwai unga an kitilung il kaiawaushang hinū Moses shouangwau.

25. Itan, gwudalth ltha istalgā chigwau itil alth īching: waigen nung kwaias chādināēlgun ken il kwōtalgun. Kum il kit kaiānḡua 
althlā, altsiìlth tuan unga ga chā unga il tatlistlaḡun.

26. Waigen nung tuanasi ishin kingān īching, nung tuanas kalat ishin, waigen il chigwau an kwōtalthkaodzūgun, waigen kum kit ltha kaiānḡun.

27. Waigen otgwau agwi anung chada ishin kwōtalgun.

28. Altsīilth kwōtal stāhā ltha kātlūs singē aik $\bar{a}$ ga chigwau isisgē kinas chāū il isisang, il inā odzūgunuē althlā.

29. Jesus hin hangtlan ltha il shütaiang, dalung hadlouḡung Shānungetlagidas giē kōgīna isken il tagwias ishin kum an dalung unshitānsi althlā.

30. Kwōtal stāhā ltha kātlūstlo kum ltha gwud lth inā gungānḡung, kum gwud ltha ināsing gungānḡung, waigen Shānungetlagidas giē angelgas gē shā tligē gu isis kingān ltha èdunğungung.

31. Shānungetlagidas dalung shūtaiang tliku kwōtal stāhā ltha kātlūs edis kum gu dalung readadāngūdjang?

32. Abraham an dī İtlagidāḡung: Isaac an dī İtlagidāḡung: Jacob an dī İtlagidāḡung. Shānungetlagidas kum ltha kwōtalthkiē an İtlagidānḡung: ga heningasgē an il İtlagidāgung.

33. Waigen ltha skūlas kwudāngāni tlo, kin il skadadas an ltha kwutungē kaldungāganḡang. 
34. Waigen tlīstluan Sadducee hāadē il kilsitlthlīis Pharisee hāadē kwudangang tlo kwudā ltha idjan.

35. Waigen nung swaunshung ltha shu Lawyer gāgang. Lā alth il kiānangang il eddē il kil kāngēeanā.

36. Hinū il shouan, Nung itlagidas, kingwoguns shu kinasu wautelgu yūanğung?

37. Waigen hin lā il shūtaiang, Shālānā dung itlagīda lth kwutungē unga saaskwan alth kwōyāda: hātlandē unga wautliwan alth ishin": $\mathrm{kwulthal}$ unga wautliwan alth ishin Shānungetlagidas lth kwōyāda.

38. Anisu kwuniāgung, waigen kingwogung yūanu ìching.

39. Waigen nung swaun ishin wau hangast èdung. Agung dung kwōyādatlidzūs kingān lth dung kwulth ltha naans ishin kwōyādatlidzu.

40. Ashgē kingwogungē stung stāhā kingwogungè wautliwan isken ga prophetgas gè ishin kiāgāḡung.

41. Waigen houān Pharisee hāadē kwudungalth ichingdang, Jesus hin ltha alth kiānangang, waigen hinū il shouan :

42. Kasino Christ an dalung kwudunḡung? Kìsta kitu il ìching? Hin lā ltha shūtaiang David Kitā.

43. Hin ltha il shūtaiang : kashintlou waiken hants unga alth Shālānā hin lā il kēyādou ūdjang? 
44. Hinū il shouan, Shālānā dī an nung Shālānā gas hin shūtaiang, soolgūst dī kwulth kouwa dung telga ltha kingsa dung stai hetgu lth istiē kū.

45. David, Shālānā hin il kēyādaiangken kasino il kit il istlidzūḡung?

46. Waigen kum nung itlinga swaunshung kil swaushung alth hangtlan il shūtaangang: waigen gē shantlanē stāhā houshen lā alth kiānungē ga ltha hulskudang.

Chaptergē Lagwau Swaunshung wok Lth'ūnilth.

WADLU Jesus ltha skūlas isken, lagagahatijanḡē ishin hin il shütaiang:

2 Pharisee hāadē isken, takālunglēilung ishin Moses giē aulthkaaungwē inku tlūadaḡunḡung :

3. Kin wautliwan dalung ga ltha shütas kingān lth wauu: waigen $\bar{a}$ kin isis tuman lth kingo: waigen kin ltha istas kingān lth kum wauāngu, tliku kin ltha shūtas kingān kum ltha wauāngsi althlā.

4. Ang, kin kina wuniḡīgēe singētza an ltha lthaidsgustlaḡungsi althlā, waigen ltha îtlansidas skzu gwi ltha istaḡunḡung ken kum stlē kungē unga ska swaunshung alth ltha da ltha tlāèdungānḡung :

5. Lthāangwilas wautliwan lth hāada lthanga kānḡēanā ltha istaḡunḡung: kin kwōyā ltha 
giandas ālthli unga ltha yūandaḡunḡung, waigen kin ltha giandas gud kin tlikidans ltha yūandaḡungung.

6. Lagunungē gu shā agwi aulthkaaungu inku tlūadiēd ltha kwōyādaḡunḡung, waigen churchnē hudila $\bar{a}$ aulthkaaungu tatchgwau agwi ishin.

7. Waigen giouk ltha waddas $\bar{a}$ ishin ltha hangā ltha kwaukulthtiēd ga ltha istatlaḡunḡung, waigen lth hāadā nung itlagīdas, nung ìtlagīdas hin ltha kēyādiē da ltha kwudunḡung.

8. Dalung kum lth nung itlagīdas hin agung kēyādadāngu, nung swaunshung dalung an îtlagidāḡung Christ $\bar{a}$, waigen dalung wautliwanū gu kwaiildang.

9. Kum lth nung itlinga aung unga hin hētk tligē gu kēyādaāngu, dalung Aungu swaunshung shā isis althlā.

10. Ga "itlagidas gē kum lth hin agung kēyādadāngu, nung swaunshung dalung an ìtlagidāḡung Christ ā.

11. Dalung shu nung yūansitlthlīsu dalung kitzadou isisang.

12. Waigen kīstho shā kwutungē unga èdung, hētk gu il isisang: kīstho hētk kwutungē unga ēdung sīk gu il isisang.

13. Takālunglēilung: Pharisee hāadē ishin: ltha kwutunge stungs ishin: dalung an kin ga lthwōōīgāasang! lth hāada talth shāgē kingdomgē wau dalung skaskītungs althlā. 
14. Kum i dalung istzaanḡung, waigen ltha wautliwan $\bar{i}$ istziē da ltha kwudungsīken anu $\bar{a}$ dalung kēkīdung.

15. Takālunglēilung: Pharisee hāadē: Itha kwutungē stungs: dalung an kin ga lthwōḡịgasang! singelthkang dalung gūshüjingas kwulgudang ltha zütlingas giē nē dalung kwōskīdungsi althlā, altsīilth wautelgu kin dāunga kinung an dalung istāshang.

16. Takālunglēilung: Pharisee hāadē ishin: ltha kwutungē stungs : dalung an kin ga lthwōgīgàsang! tungē isken tligē ishin addu dalung istalgung nung swaunshung kwutungē dalung tlastelgēanā: kwutungē unga il stīlthtlāstlo dalung telgu hetgwaugē kit an lā dalung tlaoutlaḡung.

17. Ltha hangkagas halistal lëilung dalung iching, altsīilth dalung an kin ga lthwōḡīgāsang : hin dalung shūḡung, kisstho churchnē alth kin shūdaḡīḡung ginggangānu ēdung, waigen kīstho gold churchnē $\bar{a}$ isis alth kin shüdaḡīīgung tliku il shūs kum sīlthkang il stīlthtaḡungānḡung.

18. Dalung kōnungs isken waigen dalung hangkagas ishin, kinaso wautelgu kwōyāḡung, gold gwau, churchnē āk gold lās gwau?

19. Waigen kīstho Shālānā giē tablegē alth kin shūdaḡī̄ōung ginggangānu ēdung; waigen kīstho Shālānā giē tablegēe inku saouhadan kin isis alth kin shüdaḡīğung tliku il shūs kum sīlthkang il stīlthtaḡungānḡung. 
20. Dalung hangkagasu: kinaso wautelgu yūanḡung? saouhadan kin isis gwau; Shālānā giē tablegē iLku saouhadan kin isis gwau?

21. Altsīilth kīstho Shālānā giē tablegè alth kin shūdaḡî̀̄ung wau alth il shūdaḡì̄ḡunḡung, waigen kin wautliwan inku isi alth an ishin.

22. Kìstho churchnē alth kin shūdaḡīīgung, wau alth il shūdaḡīīgunḡung waigen à nung isi alth ishin.

23. Waigen kīstho shā tligē alth kin shūdağīīgung, Shānungetlagidas giē aulthkaaungwē isken inku nung kouwas ishin alth kin il shūdaḡì̄̄onḡung.

24. Takālunglēilung: Pharisee hāadē: ltha kwutungē stungs: dalung an kin ga lthwōḡìḡāsang! mintgē isken, anisegē ishin, cummingē ishin stāhā giasou dalung istas althlā: kingwoguns isken, ginkilislungs ishin, kin kalthshintokwutungs ishin, yeta ishin: $\bar{a}$ kin kinas kum dalung istaanḡung; ashgē dalung istiēu lāgung, waigen kin adda dalung istas kum lth tlanēlthtāngu.

25. Ltha hangkagas halistal lēilung dalungu īching: stlaldigwan ūnlthoutlilthadziē addu dalung eskang, camelgē, kintīga yūan is tlou dalung ūnlthoutlilthadzaḡunḡung.

26. Takālunglēilung: Pharisee hāadē: ltha kwutungē stungs: dalung an kin ga lthwōōigāasang ! skatlangwē knal swaunan dalung tlas- 
kwunaḡungasi althlā waigen kēlthka ishin: kātli tlou kin sālā isken, kin dalung kwolthtas ishin alth stāouḡāḡung.

27. Nung Pharisee hāadē hangkagasu dung iching: skatlangwē kātli à kin isis tlaskwunagelth tlāgang; waigen skatlangwē kal ishin skwunagelthasang.

28. Takālunglēilung isken: Pharisee hāadē ishin: ltha kwutungē stungs: dalung an kin ga lthwōḡīgāsang! shātlinga nē addaḡuns kingānu dalung edis althlā: kīāgustsi lāḡung waigen skwunang, kātli tlou ltha kwōtalthgias skwuts isken kin skwūna wautliwan ishin alth staouwauḡung.

29. Kingānu dalung ishin, ltha hāada hangku kal unga tlaskwunaḡunḡung; dalung kātli tlou kwutungē sahalthila isken kin dāunga ishin alth staouwauḡung.

30. Takālunglēilung: Pharisee hāadē: ltha kwutungē stungs: dalung an kin ga lthwōḡiḡāsang! ga prophetgas gē shātlingnigē dalung tlaoutlaḡungsi althlā, waigen ga lās gē ltha tlēēwas ishin dalung tlaskwunaḡunḡung.

31. Waigen hin dalung shūḡung: itil aungalung giē shantlanē nūd tâlung idjastlo kum ga prophetgas gē ai ltha alth talung dāngāngdādunḡung.

32. Altsīilth kinung an dalung witness gāḡung, waigen ga prophetgas gē ga tlitaian kitilung dalung ìching. 
33. Altsiilth aungalung giē kwīdouwē lth stāoudo.

34. Dalung sikgas gēē, sik dāunga kitilung dalung ìching : kasino hetgwaugē ginkilislungē stāhā dalung kā̄untlidzūashang?

35. Altsiilth kwoking, ga prophetgas gē isken, ga kutungas gē ishin, takālunglēilung ishin, dalung $\overline{\mathrm{a}}$ lth kil istiēdang: ltha tītch dalung tlitāshang, waigen zitoklikadangshang : ltha tītch ishin dalunḡiē churchnē hudilas à dalung tîlthwangshang: ilnigē stāhā ilnigē à kin singētza ltha dalung hāndungdāshang.

36. Ga las gē wautliwan ai hētk tligē gwi kwaiyangang dalung inku attūḡēanā, Abel nung ìtlinga lā isis ai stāhā Zacharias Barachias kit ai à idjan, waigen churchnē yūans kūwē isken Shālānā giē tablegē ishin yakwusiā nung dalung tīaiang $\overline{\mathrm{a}}$.

37. Yenkien dalung ga lth shūḡung, $\bar{a}$ kin isis wautliwan adshi hāadaḡē inku attawausang.

38. O Jerusalem, Jerusalem, ga prophetgas gē dung tlitaḡunḡung, waigen dung à ga kil istiēdas kwau alth dung kuntlouḡunḡung! timegēe kīslu skou chada kitilung hudila yhē unga hetgu istaḡuns kingān dung kitilung gwudā kwudungalth istiē da dī kwudunḡung, waigen kum ga dalung istatlānḡung.

39. Kwoking dâlungìiē nē wēata dalung an ginggangānu èdung. 
40. Yenkien dalung ga lth shūgung adshi stāhā kum dī dalung kingāngsang, Shālānā kēyi ā nung kātlāsu lāḡung hin dalung shūasēs kū.

Chaptergē Lagwau Swaunshung wok Stanshung.

W AIGEN Jesus churchnē yūans stāhā kiak kāgwālang ken lagagahatjanḡè lā an istlāgang churchnigē tlaoutliāsi lā ltha kingdiēanā.

2. Waigen Jesus hin ltha il shūtaiang, à kin isis wautliwan kum gu dalung kingāng us? Yenkien dalung ga lth shūḡung, kum àdlun kwau gwud ingwi istatliāngshang, kwauē wautliwan hunwēasēsi althlā.

3. Waigen Olives lthdouwē inku il kouwaiang tlo lagagahatjanḡe swaunan lā an istlāgang ken hin ltha shouan: tlīstlu $\bar{a}$ kin isis isisês ìtil ga lth shüda, waigen gūsh kaountsidou isisang dung kātlātalthsēstlo waigen adshi tligē hēloungkasastlo ishin.

4. Waigen Jesus hin hangtlan ltha il shütaiang, tuman lth agung kingwang waigen kum nung ìtlinga agung kinkōnungdāngwang.

5. Ltha kwan dī kēyi $\bar{a}$ istlāsēsi althlā: Christ tlaou iching, hin ltha shūasang, waigen tha kwan ltha kinkōnungashang.

6. Gūistā isken, gūistā giatlingē ishin dalung 
kwudungsang: kum lth kwutungē unga kwīdistladāngwang: yenkien $\overline{\mathrm{a}}$ kin isis isisang, waiken houān adshi tligē kum tlanēlthāngsang.

7. Gwaigang alth gwaigang gūistāshang: kingdomgē.alth kingdomgē gūistāshang: tou gūēlthasang: idskāshang: waigen tligē kwan ai tligē ildungsang.

8. Adshi wautliwan kin ga lthwōḡīgas an kwuniāḡung.

9. Itan, dalung ltha tilthwangasēs $\bar{a}$ dalung ltha istāshang, waigen dalung ltha tlitāshang ken dī kēyi hagunan dalung telga gwaigang wautliwan kingasang.

10. Waigen lth hāada kwan kwutungē stiasang, waigen gwud alth ltha kilthkadungashang ken gwu telga ltha kingasang.

11. Ga prophetgas gē kilthkadunga kwan kātlūshang, waigen ltha kwan ltha kinkōnungasang.

12. Waigen kin dāunga kwanasēsi althlā ga läs gē kwutungē tadāsang.

13. Waigen nung kwutungē kladskaḡīisitlo laou kaḡunasang.

14. Waigen adshi kingdomgē giatlingē lās alth lth hāada wautliwan gūk ltha gūshūasang gwaigangē wautliwan an witnessgaḡēanā, waigen itan kin wautliwan tlanēlthasang.

15. Daniel nung Prophetgas hin shouan: tlīstluan kin dāunga akaia churchnē à gians 
dalung kingstlo, kin nung readadasu lth agwan an il ūnshita.

16. Itan, Judaea tligē gu ltha isis agwan lthdouwē à ltha knhūstado:

17. Nās inku nung isis agwan lth kum hētk il kāalthtāng nē stāhā kin unga il istawaugēana:

18. Kwulthkadazi ā nung isis kōdetsē unga il istiēna agwan kum il stīlthānda.

19. Waigen ashgē shantlanē gud ltha telthkias jsken ga tatlindas gē ishin an kin ga lthwōḡịgāsang.

20. Sin gā ai isken sundiga ai ishin kum dalung khudjāngungē singelth gūshū.

21. Itan ltha kwutungē sahaigyūansang: hētk tligē isi tlāgangang tlo kum hin kin ga lthwōḡīgaangang, waigen ashgē timegē silīd kum houshen kingān kin ga lthwōḡịāangsang.

22. Waigen ashgē shantlanē kum il kwoandadānsken, kum tliku kēā kaguna tlingē kāng gaanḡung: ga kingstias gē hagunan ashgē shantlanē il kwoandadāsang.

23. Altsīilth nung itlinga hin dalung shūtasken, kwoking Christ ādlun ìching, waudlun ishin, kum lth yetāngwang

24. Christ kilthkadungas kwan kātlūshang: ga prophetgas gē kilthkadungas ishin: waigen kaountsida yūanda isken kin an kaldunga ishin dalung ltha kingdāshang : ga kingstias gē kinkōnungē ishin ltha istakwudungsang. 
25. Kwoking wau kwunast dalung ga lth shüdang.

26. Altsīilth tligē dāunga gu il idja hin dalung ltha shūtastlo kum à lth istalāngu: kwoking nē kātli à il îching hin ltha shūstlo kum lth yetāngu.

27. Hougust stāhā chāgwìk sēoulthtawauguns kingān nung îtlinga kit kātlāshang.

28. Tlitzan ltha kwōt isis gaigu hōt ishin gwudā isisang.

29. Ga singē gud tha kwutungē sahaigas siliā houitang juiē halgēlthasang : kungē ishin kum kwuntlāngangsang: kaiēlthta shā tligē stāhā huwīshang, waigen hin tagwia shā tligē gu isis kēidistlāsang.

30. Waigen itan, nung ìtlinga kit shā tligēe gu isis giē kin kaountsidas kāngēelthasang, waigen gwaigangē wautliwan hētk tligē gu isis sahaigāsang: waigen nung ìtlinga kit kin tagwia alth isken kin anyākwudunga alth ishin yeni kātli à kātlātalungkasas ltha kingasang.

31. Waigen ga angelgas gē hukingan huhēgunsi dungalth il kil istiēdashang, waigen tatjouwē stanshung hētk tligē gu isis stāhā ga kingstias gē langa gwudā ltha istāshang.

32. Wēata, fig lthkai kīgangē lth skado: tlīstluan il klāts lthtanastlo il yhil ishin inastlastlo, sinkīnā āanān isis an dalung ūnshītung.

33. Altsiilth tlistluan à kin isis wautliwan 
dalung kingstlo kūwē kwulth il isi an agung lth ūnshito.

34. Yenkien dalung ga lth shūḡung, $\bar{a}$ kin isis wautliwan kingān kin edgē kñ kum adshi gwudistakānḡēē hēloāngshang.

35. Shā tligē isken hētk tligēe ishin hēloashang, dī kil tlou kum hēloāngshang.

36. Waigen oudshi shantlanē isken askaskit ishin kum nung ittlinga anūnshitānḡung, shā angels isis ishin: tlan dì Aungēe swaunan anūnshïtung.

37. Tliku Noah shantlanē edangang kingān nung ittlinga kit ishin kātlātalthasang.

38. Gïtlīdē kwunast gē singē gud ltha lthtanuḡangang, waigen ltha anilgangang, isi ishin gwud ltha ināēlgangang waigen gwud ltha ināsinḡangang.

39. Noah ark gwau ì kātlīgē kū : gītlīdē kwunast kum kin an ltha ūnshitānḡangang, waigen ltha wautliwan tligwīk stāhā gīgīdāni. Waikingān nung ìtlinga kit ishin kātlāstlo edasangwau.

40. Itan, itlansidas stung kwulthkadis kātli à isisang: nung swaun washt gūashang, nung swaun tlou gu an isisang:

41. Lth chāada stung mōlo ā shibili tlaoutlāshang: nung swaun washtgūashang, nung swaun tlou gu an isisang.

42. Altsīilth shanlthahadzo, kum tlīstlu askaskitē gud dalung an nung Shālānāgas kātlāsēs an dalung ūnshitānsi althlā. 
43. Adshi an agung lth ūnshīto, nung nēlēga tlisstlu askaskit gud kwolthtale kātlāsēs an il ūnshitstlo, il shanlthahadzātlingāḡung, waigen nē langa skōkwulthziē addu ltha eskātlingāğung.

44. Altsiilth dalung ishin agung lth ēlthkigādo: askaskit gud kum kinai dalung gwūdāanğundang nung îtlinga kit kātlātalthasang.

45. Kīstho nung kitzada yeta isken waigen kutungā ishin īching? Il ītlagīda giang nēzai an il itlagidēlthtāshang timegè wautliwan gud tou ltha ga il istiēanā.

46. Il îtlagīda kātlāstlo, anung kitzad kingan waus langa il kingstlo lāshang.

47. Yenkien dalung ga lth shūğung, kin wautliwan il daas an lā il îtlagidēlthtāsang.

48. Nung kitzada dāunga tlou hin kwutungē unga $\bar{a}$ il shūstlo, dī îtlagīda kum houītang kātlaangshang:

49. Waigen lā alth ga kitzadas il skodasken : ga lamgas gē alth il lthtanūsken waigen hutlasken :

50 . Wou nung kitzadas anung itlagidas kätlāshang: sin swaunshung ai tlīstluan kum lā da il kiatsuānḡundang askaskit skasgu gud kum kinai il gwūdāānḡundang il kātlāshang :

51. Lā il tilthwangsang, waigen ga kwutungē stungs gē shu lā il istāshang giouk sahaigāsēsi gwau waigen zing unga kōkopitāsēsi gwau. 
Chaptergē Lagwau Swaunshung wok Klēlth.

WADLU, shāgē kingdomgē chitlingā klāalth kingānu edasang: kāsotouho unga ltha istaiang ken chādūnēlths an istlāgēean kiak ltha issā $\bar{g}$ ang.

2. Klēlthu kōnangang, waigen klēlthu kutungāḡāni.

3. Ga kōnungs gē kāsotouho unga istaiang ken tou kum wau an ltha istaangang:

4. Ga kutungas gē tlou kāsotouho unga istaiang, waigen tou ishin.

5. Houān nung chādūnēlths gūstalth ltha wautliwan tislaiang waigen ltha kaslaiang.

6. Waigen halyakwulēlthstlo sahaiga idjang: kwoking nung chādūnēlths kātlātalgung, kiak lth isso lā à dalung istalēanā.

7. Itan $\bar{a}$ lth chitlingas wautliwan katloukwudangang ken kāsotouho unga ltha hokulthtaodzouang :

8. Waigen ga kōnungs gē hin kutungas gē shūtaiang, tou îtil ga lth unga isto itil giē kāsotouho kīlthgas althlā.

9. Waigen ga kutungas gē hin shouan, kāhano: kum itil an isken dalung an ishin kwanāngsang, altsīilth waddalēilung $\bar{a}$ lth istiēdo waigen kinung an lth dahwou.

10. 'Tou ltha dahawas talth anung chādūnēlths kātlāgang, waigen ga ēlthkiḡas gē lā 
alth na ga istzaiang gwud lth inēlths lagunungs ai ā waigen kūwē wau askidāni.

11. Wadla, ga chitlingas kalat istlāganang, waigen hin ltha shouan, Shālānā, Shālānā ittil kūst lth daastla.

12. Waigen hin hangtlan il shouan, yenkien dalung ga lth shūḡung kum dalung an dī ūnshitānḡung.

13. Altsiilth shanlthahadzu, tīstlu shantlanē isken tlīstlu askaskit gud ishin nung itlinga kit kātlāsēs kum an dalung ūnshitānsi althlā.

14. Shāgē kingdomgē nung îtlinga tliga jinga $\bar{a}$ kaiitang kingānu èdung: kitzadalung an il aiyangang, waigen kin wautliwan tha ga unga il istaiang.

15. Waigen nung swaunshung ga dālā ki klēlth il istaiang : nung kalat ga dālā ki stung il istaiang, waigen nung kalat ga ki swaunshung il istaiang: tliku ltha tagwiātals kingān ltha ga kin il istaḡangang ken houītang il kaiitāni.

16. Houitang dālā ki klēlth nung istaiang kaiitang : itan gwudistā il tlakaiīdāni waigen dālā ki klēlth waug agung lā kāāskidang.

17. Kingān ishin dālā ki stung nung istaiang waugang, waigen lāgiē ki stung ishin waug agung kāāskidang.

18. Ki swaunshung nung istaiani kaiitang lā tlou hingan gatlēēwaiang ken îtlagida unga giē dālā il saālang.

19. Washt ed kout à ga kitzadas an nung 
itlagidas kātlāgang waigen lthanga il kwaiundaiang

20. Waigen dālā ki klēlth nung istaiang kātlāḡang, waigen ilā dālā ki klēlth kalat il hātlthlāḡang ken hinū il shouan, Shālānā dālā ki klēlth dī ga dung istaḡun, kwoking ilā ga ki klēlth houshen lth istağun.

21. Il îtlagīda hin il shūtaiang, Lāḡung, kitzadē las isken waigen yetou ishin dung iching: kin gu hutsu tuman dung kāngāni althlā, altsiilth kin kwan an dung lth itlagidēlthtāshang; dung ìtlagīda kwutungè las ik lth katsi.

22. Dālā ki stung nung istaiang kātlāḡang ken hinū il shouan, Shālānā, dālā ki stung dī ga dung istaḡun, kwoking ilā ga ki stung dī gwi kāēlgun.

23. Il ìtlagīda hin lā il shūtaiang, Lāḡung, kitzadē las isken waigen yetou dung ìching: kin gu hutsu tuman dung kāngāni althlā, altsiiilth kin kwan an dung lth itlagidēlthtāshang ; dung itlagīda kwutunge las ik lth katsi.

24. Itan dālā ki swaunshung nung istaiang kātlāḡang ken hinū il shouan, Shālānā, nung itlinga skalthza dung isis an dī ūnshitung: giouk kum dung tatlidzanḡunu dung tlīidung, waigen giouk kum kin dung dāngwānḡunu gwudā dung istang:

25. Waigen di lthwaugaḡun ken lth kaiitun, waigen dunḡiè dālā ki swaunshung tligè kātli 
$\bar{a}$ lth saalguni, kwoking dunḡiē ìching unga dung daēlgung.

26. Waigen il ìtlagīda hangtlan hin il shūtaiang: kitzada dāunga isken, skunsalunga ishin dung ìching: giouk kum lth tatiidzāngas lth tlīidungung, waigen giouk kum kin lth dāngwāngas gwuda lth istaḡung an dung ūnshītunḡung:

27. Altsīilth kashintlo kiagin dālā kum dālāiē ga dung istaang ūdjang, waigen waug agung kāskittastlo sīlthkang lth stilthstlo lth istasgaiaungung.

28. Altsiiilth dālā lā stāhā lth isto, waigen dālā ki klāalth nung daas ga lth isto.

29. Altsiilth ltha wautliwan han kin kwōyā daas ga ga istiāshang, waigen wautelgu il daēlthasang : kum kin nung daangs tlou kin il daas lā stāhā istiāshang.

30. Anung kitzada skunsalungas kiak halga $\bar{a}$ lth dāngu giouk sahaigāsēsi gwau waigen zing unga kōkopitāsēsi gwau.

31. Tlīstluan nung itlinga kit kin anyākwudunga dungalth unga il kātlāstlo, angels las wautliwan lā alth lā isisang, waigen itan aulthkaaungwē anyākwudunga inku unga il kouwāshang:

32. Waigen lā hangku gwaigangē wautliwan gwudā isisang, waigen lamatoēkētsitlē lamatoē isken kimptiē ishin gwudād tlāēdaḡuns kingān gwudād ltha il tlātisang: 
33. Soolgūst lamatoē il istāshang, stlangūst kimptiē gē il istāshang.

34. Itan anung King gas il soolgūst ga isgē hin il shūtāshang, halūto, dī Aung kitilung lās dalung īching: hētk tligē ēlthkīgang stāhā kingdomgē dalung an êlthkigang lth isto:

3j. Dì kwīdun tlo tou dì ga dalung gīdaḡun : dī kattūgun tlo dī dalung hutlthdaḡun : dī tliga kalat hāadāgun tlo kwulth kān dī dalung istagun.

36. Dì kalthōnāngun tlo dī addu dalung tlilthilthdaḡun: dì stigun tlo tuman dī dalung kinḡun: ketsitnē $\bar{a}$ lth iching tlo dì dalung kingatlāḡun.

37. Wadla, hinū ga lās gē hin hanḡang il shūtāshang, Shālānā, kīshinda dung kwōts talung kingstlo dung talung lthtanūdaiang: dung kattūstlo dung talung hutlthdaiang?

38. Kīshinda dung tliga kalat hāadas talung kingstlo kwulth kān dung talung istaiang: kīshinda dung kalthōnānstlo dung addu talung tlilthilthdaiang?

39. Kīshinda dung stis talung kingstlo, kētsitnē à dung isis talung kingstlo dung an talung istlāḡang?

40. Waigen anung King gas hangtlan hin ltha il shūtāshang, yenkien dalung ga lth shūḡung, $\bar{a}$ dì touilung isis swaun wauhangast edis an dalung istaḡini althlā, dì $\bar{u}$ dalung istaḡini. 
41. Wadla stlangūst ga isgē ishin hin il shūtāshang, waukwelth dī stāhā lth issu dalung dāungas, waigen zanoa swaunung hetgwaulana an isken lāgiē angelgas gē an ishin êlthkīgang ai lth isso.

42. Dī kwīdun tlo kum tou dī ga talung gìdāanḡun: dì kattūgun tlo kum dì dalung hutlthtānḡun.

43. Dì tliga kalat hāadāḡun tlo kum kwulth kān dī dalung ịstaanḡun : dī kalthōnānḡun tlo kum dī addu dalung tlilthilthdānḡun : dī stigun tlo: kētsitnē à lth ìching tlo kum tuman dī dalung kingānḡun.

44. Itan gē ishin hin hanḡang il shūtāshang, Shālānā, kīshinda dung kwots talung kāngang: dung kattūs ishin: dung tliga kalat hāadas ishin: dung kalthōnāns ishin: dung stis ishin: kētsit nē à dung isis ishin, waigen kum dung ga talung tlātāngang?

45. Waigen hin hangtlan ltha il shūtāshang, yenkien dalung ga lth shūḡung ashgē swaun wauhangast edis an kum dalung istaanḡini althlā, kum dī $\overline{\mathrm{u}}$ dalung istaanḡini.

46. A ga dāungas gè zanoa ed swaunung ai istiēdashang: waigen ga lās gē hēninga swaunung ai istiēdashang. . 
Chaptergē Lagwau Swaunshung wok Lthūunilth.

WAIGEN tlīstluan Jesus ashgē gūshouwē wautliwan kilth elthtaiang tlo, lagagahatijanḡe hin il shūtaiang:

2. Shantlan stungēlthstlo Passover lagunungē isēs an dalung ūnshītung, waigen nung ìtlinga kit alth ltha giadāshang il zitokliskidēanā

3. Wadlu ga laplēt îtlagidas gē isken takālunglēilung ishin, Ith hāada an ltha kiās ishin, laplēt an nung itlagida yūans giē ginkilislang roomgē $\bar{a}$ gwudā ltha idjang: Caiaphas hinu il kēyaiang.

4. Tliku Jesus ltha istakwolthtatlidzūasēs eddēà ltha kaoukgaiang lā ltha tīiēanā.

5. Waigen hin ltha shouan, lagunungè singē gud lā talung istiêu kum lānḡung, lth hāada gūshou saatsgasēs althlā.

6. Wadlu, Jesus Simon nung hēlōdas giē nē $\bar{a}$ idjang Bethany tligē gwau.

7. Waigen nung chada kalk à tou kwōyā yūan istaiang lā an kātlāḡang, waigen houān il lthtanugundang il kats ingwi il giastlaiang.

8. Tlīstluan lagagahatijanḡe kāngang tlo ltha kwudāelk il waugang: waigen hin ltha shouan; kashintlou tou kwōyāsiken an gūḡung?

9. Adshi tou kwōyāsi dālā $\mathrm{k}$ wan alth dāawau tlingāgung ltha kuniskidēga ga istāan. 
10. Waigen Jesus anūnshitālang tlo hin ltha il shūtaiang: kashintlou anung chadas kwutungē dalung kilth kwïidang? Lthāangwila là dì an il istas alth gwau.

11. Ltha kuniskidēgas dalung kwulthlu ishgīīgung, dī tlou kum dalung dāaḡīìanḡung.

12. Adshi tou dī tlu gwi il giastlasi althlā dī tlēēwaugēanu il istang.

13. Yenkien dalung ga lth shūḡung, tlīilan tligē askwan ai ashgē giatling las alth lhagūk ltha gūshūstlo, tliku anung chada waus ishin lā an ltha kil unshitgāsang.

14. Wadlu, ltha klāalth wok stung shu stāhā ga laplēt itlagidas gē à nung kaiitang, Judas Iscariot hinū il kēyaiang :

15. Waigen hinū il shouan, gūshū dī ga dalung istāshang, waigen Jesus dalung $\bar{a}$ lth istāshang? waigen dālā hudila klālē lth'ūnilth saoutka lā ga ltha kilth ēlthtaiang.

16. Waigen altsgēe timegē stāhā lā alth giadagē il istakwudangang.

17. Wadlu, shibıli tlikulthdē gu shantlanē tlāḡangu idjan: waigen lagagahatijanḡē Jesus an istlāgang ken hin lā ltha shūtaiang, kitlano itil dung tlaēlthtadāshang Passover lagunungē dung taḡēanā?

18. Waigen hinū il shouan, nung îtlinga ilnigē gu isis à lth istiēdo, waigen hin lth il shūdawang: kiagin timegē dūungelgung, dun$\bar{g} i \bar{e}$ nē $\bar{a}$ dì gagahatijanḡē alth Passover 
lagunungē lth tāsang hinū nung ìtlagidas shūḡung.

19. Tliku Jesus ltha shūtaiang kingānu ltha wauğang, waigen Passovergē ltha êlthkidaiang.

20. Waigen singyāstlo, lagagahatijanḡe klāalth wok stung alth il kouwaiang.

21. Waigen houān ltha lthtanūgundang, hinū il shouan: yenkien dalung ga lth shūgunng, dalung swaun dī alth giadāsang.

22. Waigen ltha kwutungē lthanga stiyūanan, waigen ltha wautliwan han hin il shüdiēdang, Shālānā, tlaou gwau?

23. Waigen hangtlan hinū il shouan, adshi kēlthka ai dī alth stlē unga nung istasu dī alth giadāshang.

24. Tliku nung itlinga kit edasēs ltha kālangang kingān il edasang: nung itlinga kit alth nung giadas an kin ga lthwōḡịgāsang! anung itlingas kum awolth lthkaiangasken il lādādunḡung.

25. Waigen Judas lā alth nung giadāgang hangtlan hinū il shouan, Nung îtlagidas, tlaougwau? Waigen hangtlan hin lā il shūtaiang, yen dung shūḡung.

26. Houān ltha lthtanūḡundang Jesus shibili istaiang: waigen $\overline{\mathrm{u}}$ il tlalāgālang tlo hē il ginanangang waigen lagagahatijange ga il istaiang, waigen hinū il shouan, istalthā, tālthā, adshi dì tlū u ìching.

27. Waigen skatlangwē il istaiang ken sing 
il killāgang: ltha ga il istaiang tlo hinū il shouan, dalung wautliwan lth adshi niltho.

28. Adshi dī ai giatling lāsu ìching, waigen ltha kwan kin dāungas dakiskitē an hagwodjināḡung.

29. Waigen hin dalung ga lth shūgung, adshi stāhā kum houshen vine hāna lth hutlāngshang, Aung unga giē kingdomgē gu vine hāna houtla dalung alth lth hutliē kū.

30. Shalang sas swaunshung ltha katzouang tlo, Olives lthdouwē à ltha issāganang.

31. Wadlu, Jesus hin ltha il shütaiang, aiat halgwau dalung wautliwan dì an kwutungē stiungkashang: kālungāsi althlā, lamatoē kētsitlē lth sahaskidashang, waigen lamatoē tligwanan istalgungashang.

32. Waigen houshen kwōtal stāhā lth kātlūs silīd, Galilee tligē à dalung kwunast lth kaiitshang.

33. Peter hangtlan hin lā il shūtaiang, dung an ltha wautliwan kwutungē stistlo, di tlou kum dung an kwutungēstī tlingānḡung.

34. Jesus hin lā il shūtaiang, yenkien dung lth shüdang, aiat halgwau, skou itlinga kingangē kwunast dì da dung kāda lth'ūnilthshang.

35. Peter hin lā il istaiang, dung alth dì kwōtalthsken kum dung da lth kādāngsang. Waikingān lagagahatijanḡē wautliwan ishin shouan. 
36. Wadlu Jesus Gethsemane tligē gu ltha alth kātlāḡang, waigen lagagahatijanḡè hin il shūtāiang: kwai lth adlun tlūadawang, wadshgwi singelthkang lth gūshūwas talthla.

37. Waigen Peter isken, Zebedee kitilung stung katdung il istaiang ken il kwutungē stiēdang, waigen il tlakwīdistlayūanan.

38. Wadlu, hin lā il shūtaouang, dī kwutungēe stīyūanḡung, dī kwōtaltalgung: ādlun lth isiwang, waigen di alth lthahadzuwang.

39. Waigen Jesus tliētlāst il kāgang waigen il tikwushtloaiang, waigen hinū singelthkang il gūshouang, O dī Aung, dung gwulāstlo agwan lth adshi skatlangwē dī ilā ista: tliku dung kwudungs kingān swaunan lth waushang : tliku lth kwudungs kingān kum lth wāngshang.

40. Waigen lagagahatijanḡe kaslaiang an il kātlāḡang, waigen hin Peter il shūtaiang kashintlou askaskit swaunshung gud kum dī alth dalung shanlthahadzāugūdja?

41. Shanlthahadzūltha, waigen singelthkang lth gūshū, waigen kum kin dāunga ai dalung isāngshang: hānts gwulāsiken kēā tlou hāaḡāḡung.

42. Houshen otgwau ltha stāhā il kaiitang, waigen singelthkang hin il gūshouang, $\mathrm{O}$ dī Aung kum adshi skatlangwē wadshgwau dī stāhā isānstlo kum lth hutlānsken : tliku dung kwuduns kingān lth wau.

43. Waigen houshen lagagahatijanḡē kasla- 
iang an il kātlāḡang il hangi langa kināgulthouāni althlā.

44. Lā il tastlaouang, waigen houshen wadshgwi il kaiitang, waigen kingān houshen singelthkang il gūshou lth'ūnilthēlang.

45. Wadlu, houshen lagagahatijanḡe an il kātlāḡang, waigen hin ltha il shütaiang, wēata th kasloo, waigen anshanszouta lth unga isto. Kwoking, askaskit dūungelgung, waigen ga dāungas gè stlē ai nung itlinga kit alth ltha giadāōung.

46. Kātlūultha, talung istiēdzing, kwoking dī alth nung giadas āanān īching.

47. Waigen houān il gūshūğundang, k woking Judas ltha klāalth wok stangang swaun kātlāgang, waigen lth hāada an ltha kiāsi isken, ga laplēt ìtlagidas gē ishin stāhā ltha skūla yūans sitzē isken skidangwē ishin dungalth lā alth istlāgang.

48. Waigen lā alth nung giadāgang kin kaountsida ltha ga il istaiang ken hinū il shouan: nung lth skwuntlas laou isisang, kwunan lth il gidsgildawang.

49. Waigen houitang Jesus an il kātlāḡang, waigen hinū il shouan, hai dī ìtlagīda, waigen kwunan lā il skwuntlaiang.

50. Waigen Jesus hin lā il shütaiang, toui, kashintlou ādlun dung kātlāğun? tliku kin gu dung istatlas kingän lth wau. Wadlu ltha istlāgang, waigen Jesus ltha gidsgildaiang, waigen stāhā lā ltha istaiang. 
51. Waigen kwoking, Jesus alth ltha idjan swaun stlē unga dunchistaiang: sitzē unga il gidsgilàasken, ga Laplēt gas gē an nung İtlagidas kitzad il sahaskidang, waigen il knu langa washt il skiatlaiang.

52. Wadlı, Jesus hin lā il shūtaiang, houshen sitzē kal ai sitzē unga lth gidsa : ltha wautliwan sitzē istas sitzē alth ltha gūasēsi althlā.

53. Aung unga à kum tliku wēata singelthkang lth gūshou tlingē kāng gaang gu dung kwudung us ? waigen ga angelgas gē klālē kwan dì ga il istäshang gu dì istatlastlo.

54. Kingān lth wausken, kasino Bible kālungē kingān istlidzūashang? Hin isisang Bible shouan:

55. Altsgē askaskitē gud Jesus ltha skūlas hin shūtaiang : kwolthtalē ltha istaḡuns kingān sitzē isken skidangwē ishin alth dī dalung istiēan gu dalung istlou üdjang? Shantlan wautliwan gud churchnē $\bar{a}$ dalung alth lth kouwaḡini kin dalung lth skadadiēanā waigen kum dī dalung gidsgildaānḡun.

56. Tliku prophetgas gē kālunḡangang kingān adshi wautliwan idjāni. Wadlu lagagahatijanḡè wautliwan lā stāhā istiēdang, waigen ltha knhūstaiang.

57. A Jesus ga istaianu Caiaphas ga Lapletgasgē an nung Itlagidas giē nē à la ltha istaiang, gaigu takālunglēilung isken, tha kiāsi ishin gwudā idjan. 
58. Waigen Peter lā tlā agwi kāgang ken ga Laplētgas gē an nung İtlagidas giē ginkilislang roomgè ai il katsaiang, waigen kētsitlēilung kwulth il kouwaiang tliku edgè il kāngèanā.

59. Ga laplēt îtlagidasgē isken, ltha kiāsi ishin, council hāada wautliwan ishin Jesus alth ga witness gē kilthkadungasēs da ltha kānḡang là ltha tìiēanā,

60. Waigen kum ltha kiāngāni. Yenkien ga witness gē kilthkadungas kwan istlāḡang, waigen kum ltha gūshouwē swaunshungāngang. Waigen otgwau, ga witness gē kilthkadungas stung istlāgang:

61. Waigen hin ltha shouan, anung itlingas hin shouan: Shānungetlagidas giē churchnē tlahunziē an dì tagwiāğung, waigen shantlan lth'ūnilth gud houshen lā tlaoulthtiouwē an dì tagwiāgung.

62. Waigen ga Laplētgas gē an nung İtlagidas giāgāng, waigen hin lā il shūtaiang, kum gu hanḡang lā dung shūtaāngwashou us? Gūshū adaltas stung dung an witness gādang?

63. Waigen Jesus kum klingān kilāngang. Waigen Laplēt an nung Itlagidas hin il shūtaiang, Shānungetlagidas hēninga hangku dung giāgung, altsīilth îtil ga lth shūda Shānungetlagidas kit Christ dung istoo?

64. Jesus hin il shūtaiang, yenkienu dung shūgung: waigen houshen dalung ga lth shū- 
ḡung, adshi stāhā nung ìtlinga kit Shānungetlagidas soolgūsta inku kouwas dalung kingasang, waigen shāshi yeni kātli ā il kātlātalthasang.

65. Wadlu“ ga Laplētgas gē an nung İtlagidas kin giandas unga il dungulthgwaiang ken hinū il shouan: il gūshūdāungang, gūshū anu houshen ga witness gē gu ìtil istatlang? kwoking wēata il gūshūdāungas dalung kwudunḡung, Shānungetlagidas kit il is hin il shūsi althlā.

66. Kasino dalung kwudunḡung? Hangtlan hin lā ltha shūtaiang agwan il kwôtalē lāgung.

67. Wadlu il hangā ltha tagwangang: lā ltha skodangang: waigen ltha tïtch stlē unga kāānung alth lā ltha tlagūgūuḡangang.

68. Waigen hin ltha shouan, itil ga lth shūda Christ, kistho dung skodang?

69. Wadlu, Peter ginkilislang roomgē kiakgust il kouwā̄undang, nung hāchada lā an kātlāgang ken hinū il shouan, dahā ishin Jesus Galilee hāadas alth stūnḡūn.

70. Waigen ltha wautliwan hangku lā da il kādaiang: waigen tliku dung shūs kum an dī ūnshitānḡung hinu il shūgangang.

71. Waigen tlīstluan kūwē ai kiak il kāgwālang tlo, nung hächada kalat il kāngang: waigen gaigu lth hāada isis hin il shūtaiang, anung itlinga ishin Jesus Nazareth hāadas alth stūnğūn. 
72. Waigen kwunan lā da il kādaiang ken hinū il shouan, anung itlinga isis kum an dì ūnshitānḡung.

73. Amzawan wadla, tlitzan Peter gians $k$ wulth ga tlazūgiangang gē lā an istlāgang ken hin ltha shouan, yenkien dahā ishin ltha swaun ìching dung kil ltha kil kingān edis althlā.

74. Itan Peter kātliyildas tista glīdistlaiang, waigen gūshou dāunga il shūdiēdang ken hinu il shouan, anung îtlingas kum an dī ūnshitānḡung.

75. Waigen houitang skou itlingas kingangang. Waigen tliku Jesus il shūtaiang è Peter kēidang: skou îtlinga kingangē kwunast dī da dung kādā lth'ūnilthasang hin lā il shūtaianā. Waigen il kāgwālang tlo il sahailth yūanan.

Chaptergē Lagwau Swaunshung wok Chigwau.

TLLISSTLUAN singaigastlo ga laplēt itlagidas 1 gè wautliwan isken lth hāada an ltha kiāsi wautliwan ishin Jesus an eddeā ltha kaoukgaiang lā ltha tỉiēanā :

2. Waigen tlīstluan lā ltha kētsgustlaiang tlo stāhā lā ltha halkaiitang, waigen Pontius Pilate nung Governorgas $\bar{a}$ là ltha istaiang.

3. Itan Judas lā alth nung giadāgang lā ltha tīiungkasas il kāngang tlo, kwutungē unga il stîlthtaiang, waigen dālā hudilas klālē lth'ūnilth 
ga laplēt îtlagidas gē isken ltha kiāsi ishin ga silthkang il istaiang.

4. Waigen hinū il shouan: kin dāunga th istağun ai skwunas alth lth giadāḡun althlā. Waigen hin ltha shouan, kasino oudshi itil an eddung, dahou an ittlagidāḡung.

5. Waigen churchnē yūans kātli à dālā hudila il hāūstazaiang ken stāhā il kaiitang, waigen agung il kūtliouang.

6. Waigen ga laplēt îtlagidas gē dālā hudilas istaiang tlo hin ltha shouan, churchnē dālā hōtē ai talung istiē $\bar{u}$ kum lānğung, ai saou isis althlā.

7. Ltha counsel gāgang ken skatlangu nung tlaoutlas giē kwulthkadazi wau alth ltha dakgang tliga kalat hāada gu ltha tlēēwaugēeanā.

8. Altsiilth ashgē shantlanē gud wadshi kwulthkadazi ai kwulthkadazi hin kēyāgang.

9. Wadlu tliku Jeremiah nung Prophetgas shouan kingānu edāni : waigen hinū il shouan, dālā klālē lth'ūnilth il saou ltha kilskudanā ltha istaiang, waigen Israel hāadē il kilskudang.

10. Waigen skatlangu nung tlaoutlas giē kwulthkadazi $\bar{a}$ ltha istaiang, waigen tliku Shālānā dī ga shūḡun kingān edāni.

11. Wadlu anung Governorgas hangku Jesus giāgāang; waigen hin lā alth il kiānangang Jew hāadē an gu dung King gā us ? Waigen Jesus hin il shūtaiang kwaulthangan dung shūḡung.

12. Waigen tlīstluan ga laplēt îtlagidas gē 
isken, ltha kiāsi ishin lā an witness gāgang tlo kum hanḡang il kilāngang.

13. Itan Pilate hin il shūtaiang, kin kwan dung an ltha witness gādas kum gu dung kwudungān us?

14. Waigen kum kil swaunshung alth hangtlan lā il shūtaangang, altsīilth anung Governorgas kaldungāyūanan.

15. Ashgē lagunungētlu anung Governorgas kētsit nē stāhā nung ga ltha istatlas kingān ltha ga il kāgwulthtaḡangang.

16. Wadlu, nung dāunga yūans ltha kētsguwādaiang Barabbas hinū il kēyaiang.

17. Altsiilth gwuda ltha idjang tlo Pilate hin ltha il shütaiang: Barabbas isken, Jesus ishin Christ hin ishin il kèyang: $\bar{a}$ ltha stung isis kinasu kiak dalung ga kētsit nē stāhā lth kāgwulthtāsang.

18. Lā an ltha kwutungē sahalthilas alth, a kētsit nē à lā ltha istas an il ūnshītang.

19. Waigen houān ginkilislang aulthkaaungwē inku il kouwaḡundang, il chā lā à da kil kaiitang, waigen hinū il shouan, wu nung ìtlinga lā is ā lth kum tlāḡāng, aiata shantlanē gud lā hagunan yenkien agung lth kung lthwaugaḡunḡung.

20. Wadlu ga laplēt îtlagidas gē isken, ltha kiāsi ishin ltha skūlas kilskudhanskitang Barabbas ltha ginungēanā, Jesus il zitokliskadēanā. 
21. Waigen anung Governorgas hin hangtlan ltha il shütaiang; $\overline{\mathrm{a}}$ ltha stung isis kinasu kētsitnē stāhā lth kāgwulthtāsang? Barabbas hin ltha shouan.

22. Pilate hin ltha il shūtaiang; Jesus, Christ hin ishin il kēyang, kasino lā lth edāsang. Ltha wautliwan hin il shütaiang, agwan lth il zitokliskadādi

23. Waigen hinū anung Governorgas shouan : kashintlou, gūsh dāungou il istouūdjang? Waigen kwunan houshen hin ltha shouan agwan lth il zitokliskadādi.

24. Altsīilth Pilate kum lāgwīkāēlthāns an il ūnshitālang tlo, waigen ltha kātliyildas il kāngang tlo, hānlth il istaiang ken ltha skūlas hangku il stlē unga glanang, waigen hinū il shouan, anung ìtlinga lās tīiē kum ga dī istatlānḡung: dalung $\bar{u}$ an ittlagidāḡung.

25. Waigen lth hāada wautliwan hin hangtlan shouan, agwan il ai itil inku ista, waigen itil kitilung inku ishin.

26. Itan Barabbas kētsit nē stāhā kiak ltha ga il kāgwulthtaiang ken Jesus il tīlthwangang lā ltha zitokliskadēanā.

27. Wadlu, anung Governorgas ga soldiers gē Jesus istaiang Governorgas giē nē $\bar{a}$, waigen ga soldiergas gē wautliwan lā ā ltha istaiang.

28. Kin il giandas hēst lā ltha tlaistlāgang, waigen kōdets s'het i lā ltha tlakatsaiang.

29. Waigen tlisstluan tatching kî l tha haiang 
tlo il kats ì ltha takutlaiang: taskga soolgūst il stlē ik ltha taskatlaiang ken lā hetgu kwollo unga kats ing alth ltha kaouslaiang, waigen isi ishin la alth ltha shounangangang ken hin ltha shouan, hai, Jew hāadē an nung King gas.

30. Waigen lā gwi ltha tagwangang: taskgē lā stāhā lth istaiang ken il kats ai ltha sahaskidang.

31. Waigen lā alth ltha shounanḡīis silīd kōdets s'hets hēst lā ltha tlakātlāgang ken kin il giandaiang lā gwi ltha istaiang, waigen stāhā lā ltha halkaiitang lā ltha zitokliskadēanā.

32. Itan stāhā ltha issāḡundang nung Cyrene hāada ltha kīaiang Simon hinū il kēyaiang: katdung lā ltha kaiidaiang skauma langa il skūlthgaiīdēanā.

33. Waigen tlisstluan Golgotha hin tliga kēyas gu ltha istlāgāni tlo, winegē shuīt kin hougut yūan lā ltha hutlthtaiang, waigen il kūkūdangāni tlo kum il hutlaangang. Golgotha tligē tlingits tligē hin ishin këyang.

34. Waigen lā ltha zitokliskadang, waigen kin il giandas langa ltha tlāādīgang ken gwudan langa ltha wasugangang.

35. Waigen tliku nung prophetgas shouan kingānu ltha wauḡang. Waigen hinū il shouan : kin lth giandas gwudē ltha tlāādīsang, waigen kiagin kōdetsē gwudan ltha wasuwāsang.

36. Gwu ltha tluadaiāni ken lā ltha lthahadzaiang. 
37. Il kats shāed lthken ltha istaiang ken inku hin ltha kālangang: anis Jesusu īching Jew hāadē an nung King gas.

38. Waigen kwolthtal lēilung stung gu lā $\mathrm{k}$ wulth zitohatajāgang: soolgūst nung idjan ken stlangüst ishin nung idjan.

39. Itan lā hetit ltha istalguns lā alth shounangang, waigen kats unga ltha kēkikidangang, waigen hin lā ltha shūdaḡangāni :

40. Dā tlou churchnē yūans tlahunzasingodjing waigen sin lth'ūnilth gud houshen dung tlaoutlasinḡuntliku: agung lth kaginda: Shānungetlagidas kit gu dung istōalth skaumē stāhā kāalth.

41. Waikingān ga laplet itlagidas gē isken, takālunglēilung ishin, ltha kiāsi ishin lā alth shounangang.

42. Waigen hin ltha shouan: ltha kalat il kagindaiang, waigen kum tliku Agung il kaginda tlingē kāng gaanḡung. Israel hāadē an il King gāstlo agwan lth skauma stāhā il kāalthta : wadla lā talung yetāshang.

43. Shānungetlagidas il yetang, agwan wēata lā il kagindada lā gu il statlasken : dīu Shānungetlagidas kit ìching hinū il shūḡinē althlā.

44. Kingān lth $\mathrm{k}$ wolthtal lēilung lā kwulth zitohatajas ishin lā alth shounangangang.

45. Wadlu, askaskit lthūunilth stāhā askaskit klāalthswansinḡūstlo tligē askwan gud halgā èlang. 
46. Waigen askaskit klāalthswansinḡu èlthstlo Jesus kwunan kil alth sahailthlaiang Eli Eli lama sabacthāni : dī İtlagīda, dī Ītlagīda, kashintlou dī dung dāngūdjung.

47. Ltha tītch waudlun tlazūgians tliku il shūs kwudāngānī tlo hin ltha shouan: Elijah an il aiyingungwau.

48. Waigen houitang ltha swaun addang ken spongegē il istaiang: skang kwun ik il kūgungjalang tlo vinegar ai il telthkwulthgaiang ken là ga il istaiang il hutliēanā.

49. Waigen ltha kalat hin shouan: agwan lth il eda, Elijah kātlāstlo lā il kagindiē talung kingzing.

50. Waigen Jesus houshen kwunan kil alth sahailthlaiang, waigen il kwōtalang.

51. Waigen kwoking churchnigē kwustahātītajāni, waigen tligē ildangang ken tīshē wautliwan àtlinḡangang.

52. Ga tlēēwas gē yesi washt asuḡangang, waigen lth hāada lā kwōtalthgias tlu kwan kàtlouang.

53. Waigen kwōtal stāha il kātlouang silīd shātlingnigē stāhā kiak unga ltha issāḡang, waigen ilnigè lasi ai ltha istālang ken ltha kwan agung ltha kingdaiang.

54. Wadlu, soldiergas gē lagwau klēlth an nung itlagidas isken, lā alth ga idjan gē ishin, tlisstluan tligē ildung isken kin an kaldungas ishin ltha kāngang tlo, Jesus a ltha lthahadzai- 
ang ken hin ltha shouan: yenkien Shānungetlagidas kit anis idjan. Waigen ltha lthwaugalth yüanan.

55. Waigen lth chāada kwan wadsbgust $\overline{\mathrm{u}}$ kāngang Jesus tlā ga istalanā Galilee tligē stāhā, waigen lā an ltha lthāangwilgangang.

56. Ltha shu Mary Magdalene idjāni : Mary James isken Joses ishin ou ishin: waigen Zebedee kitilung ou ishin.

57. Waigen singyāstlo, nung itlinga kintlinga Arimathea tligē stāhā kātlāḡang: Joseph hinū il kēyaiang; laou ishin Jesus kitzad idjāni.

58. Pilate $\bar{a}$ il kaiitang ken Jesus kwōt il ginangang: itan Pilate il tlu lā ga istahālang.

59. Waigen Joseph il kwōt istaiang ken gioung skwuna lā addu il istaiang.

60. Waigen giang shātlingnigē houtlas ai lā il istaiang: itan tīshē shātlingnē an il tlaoutlaiang: waigen kwau yūan shātlingnigē kūwē $\bar{a}$ il skōkīskutang ken stāhā il kaiitāni.

61. Waigen Mary Magdalene isken, Mary kalat ishin, shātlingnigē hantlā il tlūadouang.

62. Waddalēku Preparation shantlanaiu idjang, altsīilth ga laplèt îtlagidas gē isken Pharisee hāadē ishin Pilate à gwudā idjang:

63. Waigen hin ltha shouan: nung Itlagidas, anung kilthkadungas shūgung ai itil këidung: houān il hēningāgundang hinū il shouan, shantlan lth'ūnilth silīd houshen lth kātlūshang.

64. Altsīilth wadshi shātlingnigè $\bar{a}$ shantlan 
lth'ūnilē ku ltha lthahadzālth : kum waikingān edānsken, lagagahatijanḡe halgwau il kwōt kwolthtātlāshang, waigen kwōtal stāhā il katlouang lth hāada ga ltha shūasang: waigen kwunāgē hadlouāḡun telgu otgwaugē ishin hadlouāshang.

65. Pilate hin ltha il shūtaiang, ga soldiergas gè dalung dāang: kūwē gud lth unga istiēdo, waigen shātlingnigē $\bar{a}$ ltha lthahadzādou.

66. Altsiilth $\bar{a}$ ltha istiēdang, waigen shātlingnige $\bar{a}$ ltha lthahadzaiang: kwau kūwē inku kēyi unga ltha kālangang, waigen ga soldiergas gè ltha kwulth idjāni.

Chaptergē Lagwau Swaunshung wok Stanshungā.

SUNDIGAS halyākwulēlē $\bar{a}$, Mondiga shantlanē istalstlo, Mary Magdalene kātlāḡang, waigen Mary kalat ishin shātlingnigē il kingouēanā.

2. Waigen kwoking, tlige ildayüanan, Shālānā giē angelgē shā stāhā kātlātālāni althlā: il kātlāḡang tlo kūwē stāhā kwauĩ il skōkistlaiang waigen inku il kouwaiang.

3. Il hangi sēoulthta kingānu edang, waigen kin il giandaiang taou kingānu addaiang:

4. Là ga ltha lthwaugas tista Jesus $\bar{a}$ ga lthahadzaiang gè glīdistlaiang, waigen ltha kwōtalthkaḡuns kingān Itha idjāni. 
5. Waigen anung angelgas hin lth chāadas shūtaiang: kum lth lthwauḡāngu: Jesus da dalung kingsa an dī ūnshitung nung ltha zitokliskidunā.

6. Kum ādlun il isānḡung, il kātlūḡun althlā tliku il shouan kingānu. Halūto, tlìtzan Shālānā tlēēwauḡun silī lth kingo.

7. Waigen houitang lth istiēdo, kwōtal stāhā il kātlūs lagagahatijanḡē ga lth shūdo: waigen kwoking Galilee tligē $\bar{a}$ dalung kwunast il kāiitung: gaigu lā dalung kingasang: kwoking dalung ga lth shūdang.

8. Waigen shātlingnigē stāhā houitang il istiēdouang: il lthwaugawāsken isi ishin tlika il gūlouang, waigen lagagahatijanḡè $\bar{a}$ giatlingē il gihal knhūstaouang.

9. Lagagahatijanḡē ga $\overline{\mathrm{a}}$ il shūtāouānītlo, kwoking Jesus lā an kātlaouang ken hinū il shouan, hai : Waigen houitang lā $\bar{a}$ il istalouang ken il stai langa il gidsgildaouang waigen lā $\bar{a}$ singelthkang il gūshūouang.

10. Wadlu, Jesus hin il shūtaouang, kum lth Ithwauḡāngu, Galilee tligē $\bar{a}$ dì touilung istiēdalth wāla, waigen gai gu dī ltha kingasang.

11. Houān il istalouḡundang, kwoking ga soldiergas gē tītch ilnigē gu istlāḡang ken tliku kin edang wautliwan ga laplēt itlagidas gē ga ltha shütaiang.

12. Waigen ltha kiasi alth gwudā ltha idjan 
tlo ltha counsel gāgang, waigen dālā kwan ga soldiergas gē ga ltha istaiang:

13. Hin ltha shouan, lagagahatijanḡè halgwau il tlu kwolthtātlāḡun talung kāstalthā hin lth shūwang.

14. Waigen anung Governorgas k $k \bar{u} \bar{i}$ adshi attawāsitlo il kwutungē wau talung kil saaskitashang, waigen dalung talung kagindāshang.

15. Altsīilth dālā ltha istaiang, waigen tliku ltha ltha skadadaiang kingān ltha waugang: waigen ashgē giatlingē ashgē shantlanē gud Jew hāada shu kokgustlowaiang.

16. Waigen lagagahatijanḡe klāalth wok swaunshung Galilee tligē à istiēdang, lthdou gu isi $\bar{a}$ Jesus ltha istiēdhālang $\bar{a}$.

17. Waigen lā ltha kāngāni tlo lā à singelthkang ltha gūshūḡangang, waigen ltha tìtch lā kwudūkīkitang.

18. Waigen Jesus ltha an kātlāgang tlo hin ltha il shūtaiang, kin tagwia wautliwan shā tligē gu isis isken hētk tligē gu isis ishin dì ga istiāḡun.

19. Altsiilth istiēdūlthā, waigen gwaigangē wautliwan kin lth skadadou, nung Aung kēyi à ìsken, nung kit kēyi à ishin, nung Hānts Lās kēyi $\bar{a}$ ishin ltha lth baptizdo:

20. Waigen kin wautliwan alth dalung lth kingwoguns tumankāngē ltha lth skadadowang, waigen kwoking dalung alth lth ishgīisang, waikingān ed swaunungshang. 




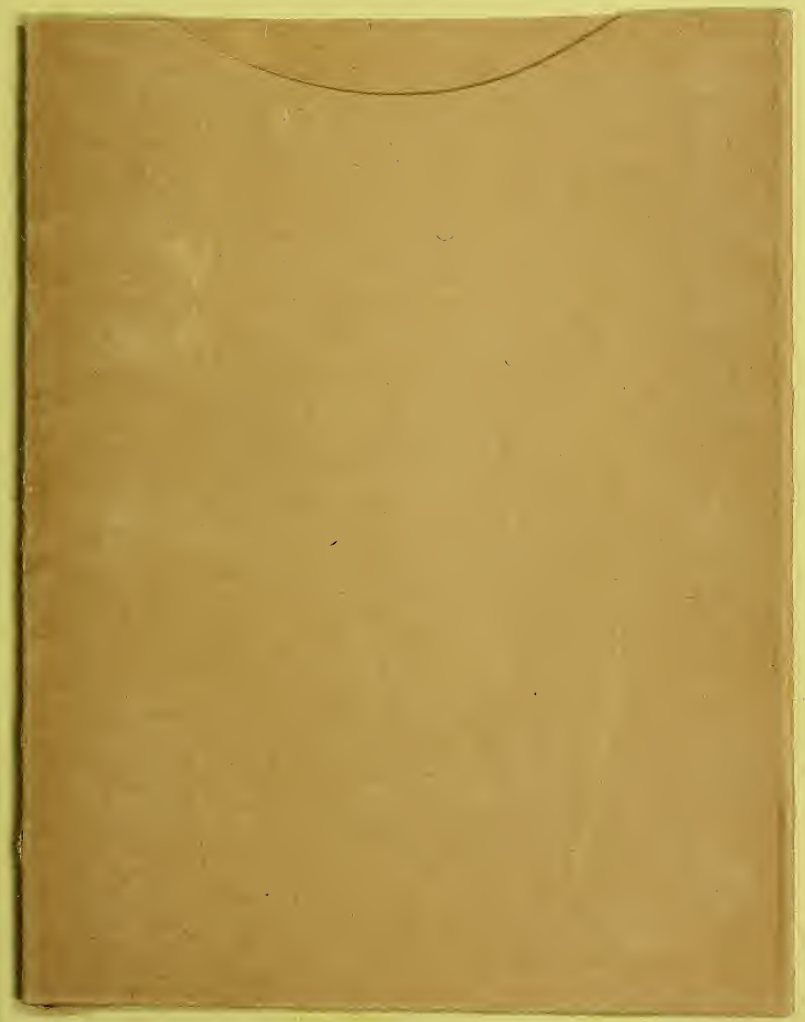




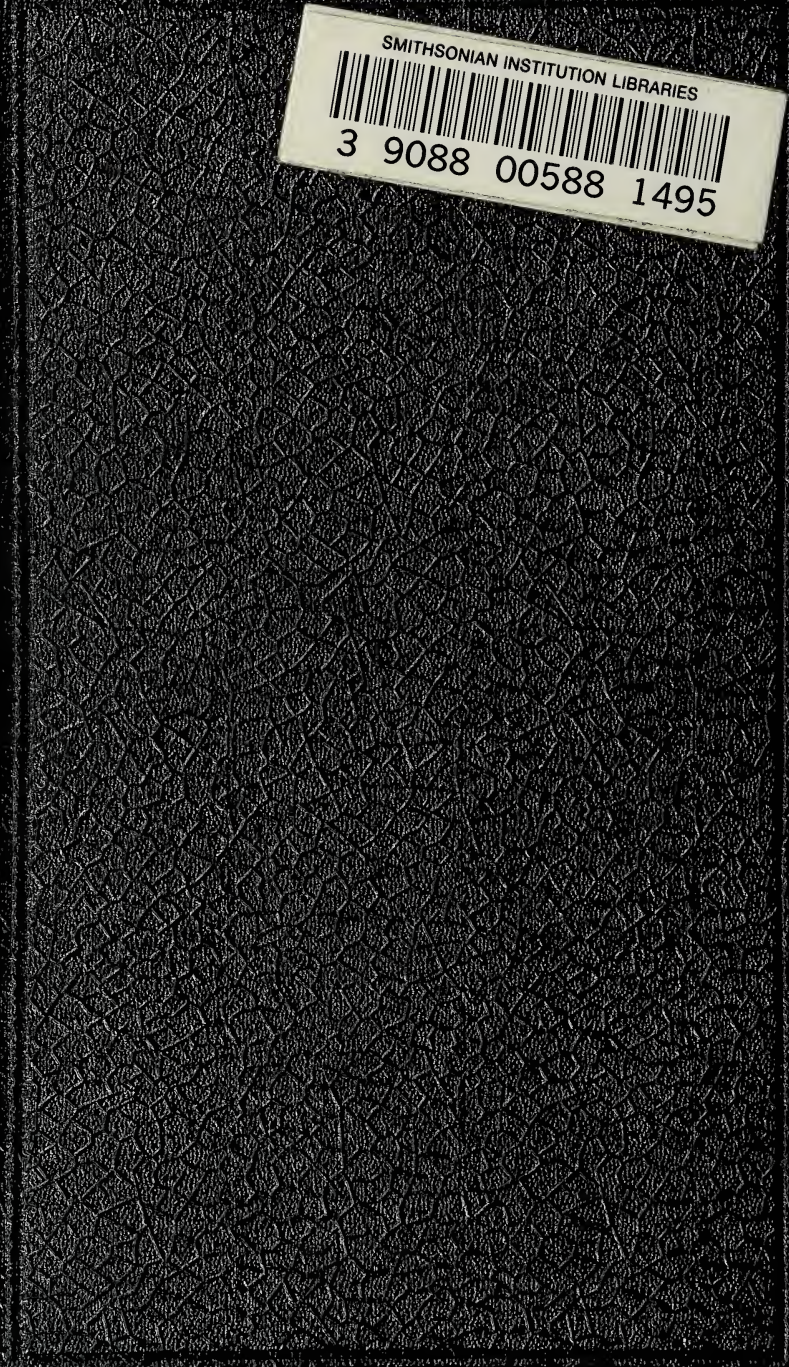

